\title{
Carbon Dioxide Removal via Macroalgae Open-ocean Mariculture and Sinking: An Earth System Modeling Study
}

\author{
Jiajun $\mathrm{Wu}^{1}$, David P. Keller ${ }^{1}$, and Andreas Oschlies ${ }^{1,2}$ \\ ${ }^{1}$ GEOMAR Helmholtz Centre for Ocean Research Kiel, Kiel, Germany \\ ${ }^{2}$ Kiel University, Germany
}

Correspondence: Jiajun Wu (jwu@geomar.de)

\begin{abstract}
In this study we investigate macroalgae open-ocean mariculture and sinking (MOS) as ocean-based carbon dioxide removal (CDR) method. Embedding a macroalgae model into an Earth system model, we simulate macroalgae mariculture in the open-ocean surface layer followed by fast sinking of the carbon-rich macroalgal biomass to the deep seafloor (depth $>3,000 \mathrm{~m})$. We also test the combination of MOS with artificial upwelling (AU), which fertilizes the macroalgae by pumping nutrient-rich deeper water to the surface. The simulations are done under RCP4.5, a moderate emission pathway. When deployed globally between years 2020 and 2100, the simulated CDR potential of MOS is 270 PgC, which is further boosted by $\mathrm{AU}$ to $447 \mathrm{PgC}$. More than half of MOS-sequestered carbon retains in the ocean after cessation at year 2100 until year 3000.

The major side effect of MOS on pelagic ecosystems is the reduction of phytoplankton net primary production (PNPP) due to canopy shading and the competition for nutrients by macroalgae. MOS shrinks the mid layer oxygen minimum zones (OMZs) by reducing the organic matter export to, and remineralization in, subsurface and intermediate waters, while it creates new OMZs on the seafloor by oxygen consumption from remineralization of sunk biomass. MOS also impacts the global carbon cycle, reduces the atmospheric and terrestrial carbon reservoir when enhancing the ocean carbon reservoir. MOS also enriches the dissolved inorganic carbon in the deep ocean. Effects are mostly reversible after cessation of MOS, though recovery is not complete by year 3000. In a sensitivity experiment without remineralization of sunk MOS biomass, the entire MOS-captured carbon is permanently stored in the ocean, but the lack of remineralized nutrients causes a long-term nutrient decline in the surface layers and thus reduces PNPP.

Our results suggest that MOS has a considerable potential as an ocean-based CDR method. However, MOS has inherent side effects on marine ecosystems and biogeochemistry, which will require a careful evaluation beyond this first idealised modeling study.
\end{abstract}

\section{Introduction}

Anthropogenic emissions are rapidly increasing the global atmospheric $\mathrm{CO}_{2}$ concentration. In the last decade (2011 to 2020 ),

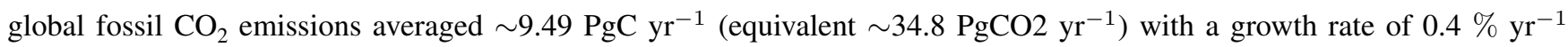
(Friedlingstein et al., 2021). In 2019, $\mathrm{CO}_{2}$ emissions reached a record high of $9.71 \pm 0.49 \mathrm{PgC} \mathrm{yr}^{-1}$ (equivalent $35.6 \pm 1.8 \mathrm{Pg}$ $\mathrm{CO}_{2} \mathrm{yr}^{-1}$ ), and there is no sign of a peak (Edo et al., 2019; Friedlingstein et al., 2021). The slow speed of emission reductions 
until now makes it difficult to reach the promised climate goals to keep global warming within the guardrail of $2^{\circ} \mathrm{C}$ (Peters et al., 2013), much less the recent agreement to seriously consider an even more ambitious $1.5^{\circ} \mathrm{C}$ goal (UNFCCC, 2015 ).

In addition to mitigation efforts to reduce greenhouse gas (GHG) emissions, it is increasingly realized that Carbon Dioxide Removal (CDR), sometimes also called Negative Emissions Technologies (NETs), are likely to be a necessary step to achieve the targets of the Paris Agreement (Minx et al., 2017; Rogelj et al., 2018). CDR aim to remove GHGs, mainly $\mathrm{CO}_{2}$, from the atmosphere and store them, ideally permanently, in either the terrestrial, marine or geological carbon reservoirs, thereby mitigating global warming (Glaser, 2010). Due to the limited remaining emission budget $\left(650 \pm 130 \mathrm{Pg} \mathrm{CO}_{2}\right.$ to $1.5{ }^{\circ} \mathrm{C}$ and $1300 \pm 130 \mathrm{Pg} \mathrm{CO}_{2}$ to $2{ }^{\circ} \mathrm{C}$ ), deployment of $\mathrm{CDR}$ is required in most pathways studied in the scientific literature to achieve these ambitious targets (Lawrence et al., 2018; IPCC, 2018).

As the second-largest inorganic carbon reservoir on the planet, the ocean plays a pivotal role in naturally regulating the atmospheric $\mathrm{CO}_{2}$ concentration. Since the beginning of the industrial era, the ocean has taken up more than $560 \mathrm{PgCO}_{2}$, about $25 \%$ of the anthropogenic $\mathrm{CO}_{2}$ emissions ( $2030 \mathrm{PgCO}_{2}$, Gruber et al. (2019); Ciais et al. (2013); Heinze et al. (2015)). Its high carbon storage capacity could theoretically match or exceed fossil fuel resources (Scott et al., 2015). Thus, a variety of ocean-based CDR methods have been proposed to take advantage of this potential storage capacity. The proposed ocean-based $\mathrm{CDR}$ approaches aim at increasing the rate of oceanic $\mathrm{CO}_{2}$ uptake and storage by either enhancing abiotic processes (i.e., chemical or physical, e.g. ocean alkalinization (Keller et al., 2014; Taylor et al., 2016; Köhler et al., 2013; Albright et al., 2016)) or biotic processes (e.g. ocean fertilization (Keller et al., 2014; Smetacek et al., 2012; Oschlies et al., 2010; Matear and Elliott, 2004; Robinson et al., 2014)). Some technologies also seek to remove $\mathrm{CO}_{2}$ directly from seawater and store it in some other reservoir, e.g., a geological one (Eisaman et al., 2012).

Macroalgae species (also known as 'seaweed' or 'kelp') are highly efficient primary producers with a general net primary production (NPP) rate of 91-522 $\mathrm{gC}^{2} \mathrm{yr}^{-1}$ and a high C:N ratio (Atkinson and Smith, 1983; Fernand et al., 2017). Utilizing macroalgae for biological ocean-based CDR has recently received a renewed interest (Duarte et al., 2017; Chung et al., 2011; Gao et al., 2020; Fernand et al., 2017; Raven, 2018). The macroalgae aquaculture industry is well established globally with an annual harvest of over 30 million tonnes wet weight (WW, FAO (2018)). Thus, some proposals have focused on using harvested macroalgae for producing biochar (Roberts et al., 2015; Bird et al., 2011) or bio-energy combined with carbon capture and 50 storage (BECCS, Chung et al. (2011); Buschmann et al. (2017); Gao and McKinley (1994); Chen et al. (2015); Fernand et al. (2017)). However, as current macroalgae aquaculture facilities are mainly located in coastal regions, the scope to expand macroalgae aquaculture is limited by the shortage of suitable coastal areas due to nutrient availability and shifting temperature regimes (Duarte et al., 2017; Oyinlola et al., 2020). To address these issues, several offshore macroalgae aquaculture facilities have been designed and evaluated (e.g. the SeaweedPaddock by Sherman et al. (2019), the offshore ring by Buck and Buchholz (2004), or the depth-cycling strategy by Navarrete et al. (2021) in which macroalgae are physically towed into the deep nutrientrich water at night). Moreover, the Advanced Research Projects Agency-Energy (ARPA-E) of the U.S. Department of Energy has committed more than 60 million dollars on the Macroalgae Research Inspiring Novel Energy Resources (MARINER) program to develop the technologies for macroalgal biomass production, including integrated ocean cultivation and harvesting 


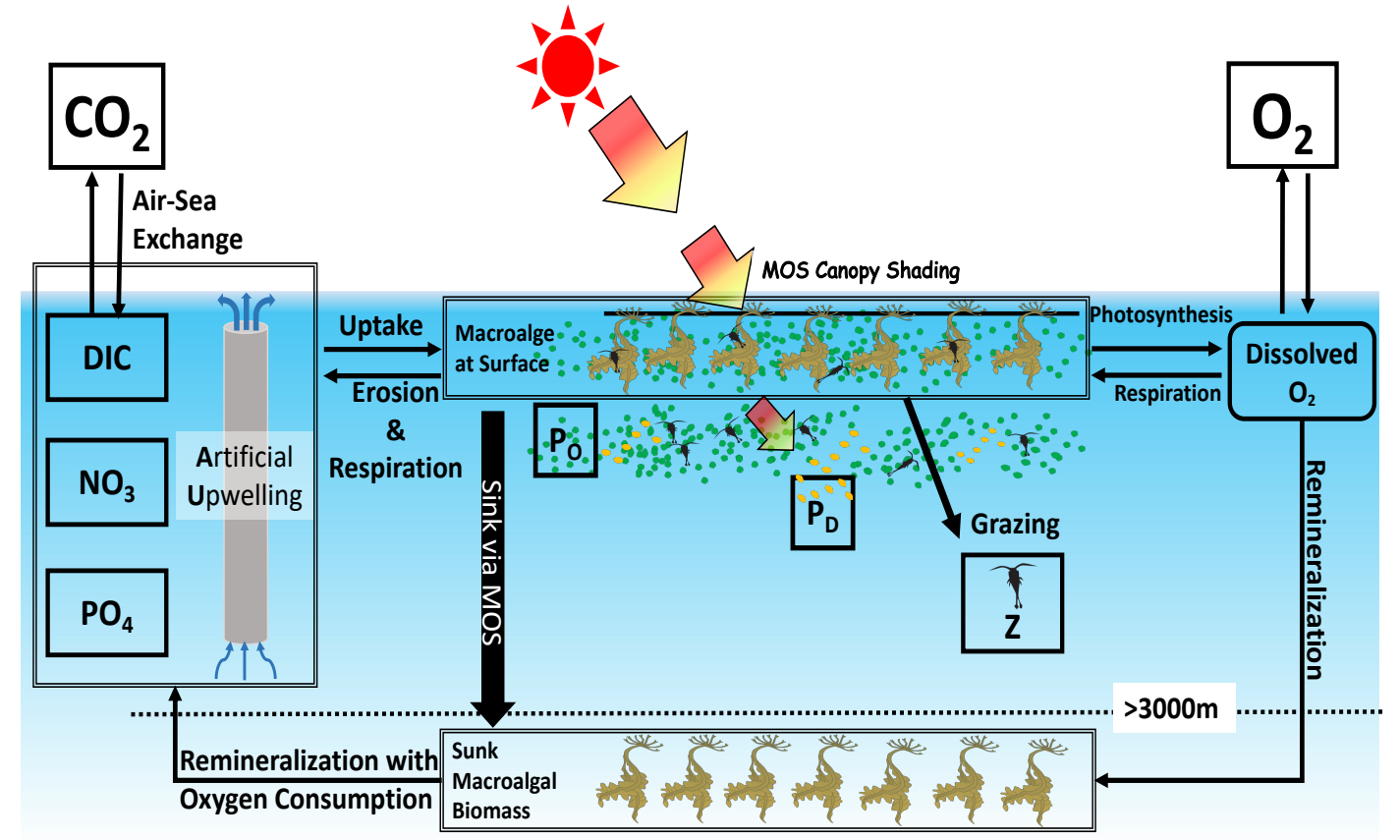

Figure 1. Schematic illustrating the biogeochemical fluxes and physical impacts of MOS on nutrients $\left(\mathrm{NO}_{3} \& \mathrm{PO}_{4}\right)$, oxygen, dissolved inorganic carbon (DIC), oridnary phytoplankton ( $\mathrm{P}_{O}$ in green), diazotrophs $\left(\mathrm{P}_{D}\right.$ in pale brown) \& zooplankton $(\mathrm{Z})$.

systems (APAR-e, 2021). Thus, the ideas of expanding macroalgae cultivation to the open oceans (mariculture) are ambitious but no longer fictional, and they provide a theoretical possibility to expand macroalgae aquaculture to the open-ocean for CDR.

In this study we evaluate 'Macroalgae Open-ocean mariculture and Sinking (MOS)' as ocean-based CDR method that is designed to artificially enhance the macroalgae-based carbon dioxide removal. Simulated macroalgae are seeded and cultivated on offshore floating platforms that are moored to the seabed (e.g., see platform designs in Buck and Buchholz (2004)). The platforms are also assumed to float below the open ocean surface (at $5 \mathrm{~m}$ depth) to avoid storm damages. At the end of an annual cycle, platforms with matured macroalgae are rapidly sunk to the seafloor and unload the biomass there. This can be thought of as a short circuiting of the biological pump by bringing marine biomass directly to the seafloor without having it remineralized along the way. Afterwards, the sunk biomass is assumed to continue remineralization at the seafloor, consuming oxygen and releasing dissolved inorganic carbon $(\mathrm{C})$, nitrogen $(\mathrm{N})$ and phosphate $(\mathrm{P})$ into the deep ocean where it ideally remains for centuries to millennia (Fig.1). In practice, some of the biomass may also be permanently buried in sediments (Luo et al., 2019; Sichert et al., 2020), and we will explore the extreme case of zero remineralization in the water column in a sensitivity experiment. In another sensitivity experiment we investigate combining MOS with artificial upwelling (AU) to alleviate nutrient limitation in the open ocean surface (Duarte et al., 2017; Kim et al., 2019; Laurens et al., 2020).

To investigate the biogeochemical and climatic implications of MOS we use an Earth system model of intermediate complexity. Though the idea of massive macroalgae cultivation and biomass offsetting for CDR has been assessed in some earlier 
publications (Orr and Sarmiento, 1992; Gao and McKinley, 1994; Froehlich et al., 2019; Lehahn et al., 2016), as far as we are aware it has not been evaluated using an Earth system model (ESM). ESM-based assessments are required for studying the response of the global carbon cycle to such perturbations and for comprehensively estimating the efficacy (with regards to atmospheric $\mathrm{CO}_{2}$ removal) of such methods. Furthermore, such models can dynamically simulate macroalgae growth, the permanence of carbon storage (i.e., the fate of sunk biomass on the seafloor), as well as their interactions with global marine biogeochemistry. It is essential to clarify these issues before any decisions about eventual implementation of MOS can be made.

\section{Methods}

\subsection{Model description}

In this study we employ the University of Victoria Earth System Climate Model (UVic ESCM) version 2.9 (Weaver et al. (2001); Eby et al. (2009); Keller et al. (2012)), which consists of three dynamically coupled components: a three-dimensional ocean circulation model (Pacanowski, 1996) including a dynamic-thermodynamic sea-ice model (Bitz and Lipscomb, 1999), a terrestrial model (Meissner et al., 2003; Weaver et al., 2001) and a simple one-layer atmospheric energy-moisture balance model (Fanning and Weaver, 1996). The model has a fully coupled carbon cycle including dynamic terrestrial, atmospheric and oceanic carbon inventories. The horizontal resolution of all components is $3.6^{\circ}$ longitude $\times 1.8^{\circ}$ latitude, and the ocean component has 19 vertical layers. The descriptions of air-sea gas exchange and seawater carbonate chemistry are based on the Ocean Carbon Cycle Model Intercomparison Project (OCMIP) abiotic protocol (Orr et al., 1999). The ocean biogeochemistry is presented with a nutrients-phytoplankton-zooplankton-detritus (NPZD) model that includes one general phytoplankton, diazotrophs, and one zooplankton type (Keller et al., 2012; Eby et al., 2013). The UVic ESCM has been evaluated in several recent studies (e.g. Keller et al. (2014); Mengis et al. (2016); Reith et al. (2016); Kvale et al. (2021)).

\subsection{Modelling MOS in the UVic ESCM}

\subsubsection{Macroalgae model}

The macroalgae model is an idealized generic model of genus Laminaria and Saccharina, mainly based on Martins and Marques (2002) and Zhang et al. (2016). For simplicity and to limit the number of state variables, we did not include a dynamic C:N:P ratio or a representation of luxury nutrient uptake and storage (Broch and Slagstad, 2012; Hadley et al., 2015).

The assumed constant C:N:P ratio (Tab.1) is based on seasonally averaged measurements of the biomass composition of these genus (Zhang et al., 2016; Martins and Marques, 2002). Frond and macroalgae life cycle processes (e.g. alternations of generations) are also not considered in our model (Brush and Nixon, 2010; Trancoso et al., 2005; Duarte and Ferreira, 1997). We thus assume that the plantlet (e.g. sporophytes for Saccharina) will be reseeded annually on the MOS infrastructure. The assumed deployment strategy, i.e., timing of seeding and sinking, of MOS is latitude-dependent according to the seasonality 
of solar irradiance (see Sect.3.1). Whenever conditions are unfavorable for macroalgae and no growth occurs during an annual cycle, no re-seeding of macroalgae will occur in these regions.

The growth of macroalgae is regulated by water temperature (T), solar irradiance (I) and dissolved nutrient concentrations. The rate of biomass change is governed by Eq. 1 as the imbalance of $\boldsymbol{N} \boldsymbol{G R}$ (net growth rate, $\mathrm{d}^{-1}$ ) and $\boldsymbol{L R}$ (loss rate, fraction of daily biomass loss due to mortality, erosion and grazing by zooplankton, $\mathrm{d}^{-1}$ ).

$110 \frac{d \text { Biomass }}{d t}=(\mathrm{NGR}-\mathrm{LR}) \times$ Biomass

The NGR is regulated by:

$N G R=R_{\text {growth }}-R_{\text {resp }}$

where $\mathbf{R}_{\text {growth }}$ is the gross growth rate $\left(\mathrm{d}^{-1}\right)$ and $\mathbf{R}_{\text {resp }}$ is the respiration rate $\left(\mathbf{d}^{-1}\right)$. $\mathbf{R}_{\text {growth }}$ is a function with limiting factors of sea water temperature $\left(\mathbf{T}_{w}\right)$, irradiance $\left(I_{m a}\right)$ and external nutrient concentrations $\left(\mathrm{NO}_{3}\right.$ and $\left.\mathrm{PO}_{4}, \mathbf{N P}\right)$.

In the current model the macroalgal growth rates are controlled by external concentrations of available nutrients via assumed Michaelis-Menten kinetics with half-saturation constants $K_{N}$ and $K_{P}$ for $\mathrm{NO}_{3}$ and $\mathrm{PO}_{4}$, respectively:

$$
\begin{aligned}
& f(N)=\frac{\mathrm{NO}_{3}}{K_{N}+\mathrm{NO}_{3}} \\
& f(P)=\frac{\mathrm{PO}_{4}}{K_{P}+\mathrm{PO}_{4}}
\end{aligned}
$$

$f(N P)=\operatorname{Min}\{f(N), f(P)\}$

The temperature limiting factor used here is an optimum curve following Bowie et al. (1985). $\mathbf{T}_{\text {opt }}$ is the species-specific optimum temperature at which the growth rate is maximized.

$$
\begin{aligned}
f\left(T_{w}\right) & =e^{-2.3 \times X_{T}^{2}} \\
X_{T} & =\frac{T_{w}-T_{o p t}}{T_{x}-T_{o p t}} \\
125 T_{x} & =\left\{\begin{array}{ccc}
T_{\min } & \text { if } & T_{w} \leq T_{o p t} \\
T_{\max } \quad \text { if } & T_{w}>T_{o p t}
\end{array}\right.
\end{aligned}
$$


Respiration is described by an Arrhenius function considering water temperature $\mathbf{T}_{w}$ in degrees Celsius (Duarte and Ferreira, 1997; Martins and Marques, 2002):

$R_{\text {resp }}=R_{\max 20} \times r^{\left(T_{w}-20\right)}$

where $\mathbf{R} \_\mathbf{m a x} 20$ is the maximum respiration rate at $20^{\circ} \mathrm{C}$ of the simulated macroalgae species, $\mathbf{r}$ stands for the empirical coefficient for macroalgae respiration (Tab. 1).

Solar irradiance density is another limiting factor for macroalgae photosynthesis. Similar to Schmittner et al. (2005) and Keller et al. (2012), here we employ Steele's photo-inhibition relationship (Kirk, 1994) to describe the limiting factor of shortwave radiation $\left(f\left(I_{m a}\right)\right)$ at depth $Z$, which describes the distance between the ocean surface and the top of the macroalgae meadow (Eq.11). In the UVic ESCM, the shortwave radiation ( $\mathbf{I}_{m a}$ ) reaching the depth $Z$ is calculated with Eq.12 modified from Keller et al. (2012) and Schmittner et al. (2005). $\mathbf{I}_{s}$ stands for the shortwave radiation density at the top of the layer. $\mathrm{P}_{O}$ and $\mathrm{P}_{D}$ are biomass of ordinary phytoplankton and diazotrophs, respectively, in the layers above the macroalgae meadow. $\boldsymbol{k}_{w}$ is the light attenuation coefficient for water. $\boldsymbol{I}_{o p t}$ is the optimum light intensity for macroalgae growth. $k_{c}$ is the light attenuation coefficient of phytoplankton and also accounts for co-varying particulate and dissolved inorganic and organic materials (Kvale and Meissner, 2017). As described in Sect.2.2.1, the morphology of the frond will not be considered, therefore the self-shading effects by fronds are not considered here (Duarte and Ferreira, 1997; Brush and Nixon, 2010).

$f\left(I_{m a}\right)=\frac{I_{m a}}{I_{o p t}} \times e^{\left(1-\frac{I_{m a}}{I_{o p t}}\right)}$
$I_{m a}=I_{s} \times e^{\left(-k_{w} Z_{m}-\int_{0}^{Z_{m}}\left(P_{o}+P_{D}\right) k_{c} \times d Z_{m}\right)} \times d f$

with $\mathbf{Z}_{m}$ denoting the depth of MOS macroalgae platforms beneath the water surface. $\mathbf{Z}_{m}$ is assumed as 5 meters, compromising the empirical depth with sufficient light for macroalgae photosynthesis (1m to $2 \mathrm{~m}$ for cultivation (Buck and Buchholz, 2004), 0m to $10 \mathrm{~m}$ for wild communities (Eriksson and Bergström, 2005)) and the depth to reduce the risks of damaging by stressful turbulence or severe weather events (e.g. hurricanes). $\boldsymbol{d} \boldsymbol{f}$ denotes the day length as a fraction of $24 \mathrm{~h}$.

The loss rate LR is regulated by:

$L R=E R+$ Graze $_{m a}$

$E R=$ Biomass $\times R_{\text {erosion }}$

Graze $_{m a}=\mu_{Z}^{\max } Z \times \psi_{m a} \times$ Biomass

where the erosion of biomass (ER) is controlled by the individual erosion rate $\mathrm{R}_{\text {erosion }}$ which is a constant independent of physical impacts according to Trancoso et al. (2005) due to the absence of a dynamic frond morphology function. The eroded macroalgal biomass will be directly converted back to nutrients and DIC (dissolved inorganic carbon) according to the macroalgae stoichiometry ratios without remineralization or further degradation by zooplankton. Graze ${ }_{m a}$ is the biomass loss 
due to grazing by zooplankton. $\mathrm{Z}$ is the zooplankton biomass which is calculated by the NPZD model. $\mu^{\max } Z$ stands for the maximum potential growth rate of zooplankton defined in Keller et al. (2012, Eq.28). The zooplankton grazing preference on macroalgae $\left(\psi_{m a}\right)$ is defined in Sect.2.2.3.

\subsubsection{Remineralization of sunk macroalgal biomass}

Biomass sinking is simulated by instantly transferring the macroalgal biomass from the surface grid cell to the deepest grid cell

at the respective location at the end of each cultivating period. Afterwards the next macroalgae generation will start to grow in the surface layer. Eq.(16) calculates the temperature dependent remineralization rate of sunk macroalgal biomass $\left(\mu_{m a}\right)$ following the function of remineralization of detritus in the UVic ESCM (described in Schmittner et al. (2008, Eq.A16)). Remineralization consumes oxygen and returns $\mathrm{DIC}, \mathrm{PO}_{4}$ and $\mathrm{NO}_{3}$ from the sunk macroalgal biomass to the sea water, and is described as

$\mu_{m a}=\mu_{m a_{0}} \exp \left(T_{w} / T_{b}\right)\left[0.65+0.35 \tanh \left(\mathrm{O}_{2}-6\right)\right]$

where $\mu_{m a 0}$ is the remineralization rate of sunk macroalgal biomass at $0^{\circ} \mathrm{C} . \mathbf{T}_{w}$ and $\mathbf{T}_{b}$ represent the sea water temperature and e-folding temperature of biological rates, $\mathrm{O}_{2}$ is the dissolved oxygen concentration in mmol $\mathrm{m}=3$. When the dissolved oxygen is insufficient ( $<5 \mathrm{mmol} \mathrm{m} \_3$ ), aerobic remineralization will be replaced by oxygen-equivalent, but slower, denitrification via reduction of $\mathrm{NO}_{3}$ (Keller et al., 2012). Note that remineralization will cease when $\mathrm{NO}_{3}$ is completely consumed.

There are considerable uncertainties concerning the fate of sunk macroalgae (Sichert et al., 2020; Krause-Jensen and Duarte, 2016; Luo et al., 2019). A sensitivity simulation explores the situation where $\mu_{m a_{0}}$ is set to zero, which would assume permanent deposition of the sunk biomass on the seafloor without decaying.(Sect.3.2).

\subsubsection{Interactions with pelagic microbial ecosystems}

Besides the competition for nutrient resources, the macroalgae canopies may also reduce downward solar irradiance ('canopy shading') and thus limit phytoplankton photosynthesis beneath the macroalgae (Jiang et al., 2020)). Furthermore, zooplankton can graze on macroalgae (Baird et al., 2003). Eq.(17, modified from Eq.14, (Keller et al., 2012)) describes the shortwave radiation attenuation $\left(\mathrm{I}_{\text {phyt }}\right)$ through the macroalgae layer as well as phytoplankton and water (MOS is not deployed in areas covered by sea ice):

$I_{\text {phyt }}=I_{s} \times e^{-k_{w} Z-\int_{0}^{Z}\left(P_{o}+P_{D}\right) k_{c} \times d Z-k_{m a} \times h_{m a} \times \text { Biomass }}$

where $\mathbf{k}_{m a}$, the macroalgae light extinction coefficient $\left(\mathbf{m}^{-1}\right)$, is calculated based on the biomass of macroalgae in carbon as:

$k_{m a}=a_{m a} \times$ Biomass $\times M R_{C: N}$

Here $\mathrm{a}_{m a}$ is the macroalgae carbon specific shading area $\left(\mathrm{m}^{2} \mathrm{kgC}^{-1}\right.$, Trancoso et al. (2005)), $\mathbf{h}_{m a}$ is the thickness of macroalgae layer, $\mathrm{MR}_{C: N}$ stands for the molar $\mathrm{C}: \mathrm{N}$ ratio of macroalgal biomass. 
The original NPZD model in Keller et al. (2012) is extended by allowing zooplankton to graze on macroalgae. The grazing thus provide a grazing option for zooplankton in addition to the traditional NPZD-type model food sources (phytoplankton, diazotrophs, detritus and zooplankton via self-grazing). Therefore, the four original grazing preferences ( 0.3 on phytoplankton, 0.1 on diazotrophs, 0.3 on detritus and 0.3 on zooplankton (Keller et al., 2012, Tab.1)) are reduced by $\frac{1}{4} \psi_{m a}$ each. In the areas where MOS are absent (i.e, in the ice-covered ocean surface), the zooplankton grazing will follow the original description in Keller et al. (2012, Tab. 1) without the preference for macroalgae. No $\mathrm{CaCO}_{3}$ formation by macroalgae is simulated here (Bach et al., 2021; Macreadie et al., 2017, 2019), as calcareous macroalgae species and epibiont calcifiers are not considered. Therefore, the only alkalinity impact of growing and remineralizing macroalgae comes via changes in nitrate and phosphate.

\subsubsection{Mass conversions}

In order to parameterize and validate the model, it is necessary to convert from commonly measured macroalgae variables (often in wet and dry weight units) to the model units. These conversions include: the calculation of carbon and $\mathrm{CO}_{2}$ sequestered in macroalgal biomass $\left(\mathrm{C}_{m a}\right.$, gram carbon), as well as the conversions of dry weight (DW, gram) and wet weight (WW, gram)):

$C_{m a}=$ Biomass $\times M R_{C: N} \times 12.011$

$\mathrm{CO}_{2 \mathrm{ma}}=C_{m a} \times 3.67$

$D W=C_{m a} \div M R_{C: D W}$

$W W=D W \times M R_{D W: W W}$

where 3.67 is the ratio between the atomic mass of $\mathrm{CO}_{2}(44 \mathrm{~g} / \mathrm{mol})$ to carbon $(12 \mathrm{~g} / \mathrm{mol})$, Biomass is in moles of nitrogen, 12.011 is the relative molecular weight of carbon $(\mathrm{g} / \mathrm{mol})$.

\subsubsection{MOS carbon retained in the ocean and outgassing}

The DIC from remineralization of sunk biomass will eventually be conveyed back to the ocean surface and may leak back to the atmosphere. Eq.23 calculates the ocean-retained fraction (FR, \%) of MOS-captured carbon (MOS-C).

$F R=\frac{C_{\text {retained }}}{C_{\text {captured }}}=\frac{\left(\text { DIC }_{\text {remineralized }}+C_{\text {SunkBiomass }}\right)}{C_{\text {captured }}}$

where the $\mathrm{C}_{\text {captured }}$ is carbon in cumulative sunk biomass, $\mathrm{C}_{\text {SunkBiomass }}$ is the sunk macroalgal biomass that still remains on the sea floor.

In order to track the leakage of MOS-C after remineralization, a tracer of remineralized MOS-C (MOS_DIC) is added to 210 the UVic ESCM aside of the original DIC tracer. MOS_DIC participates in the inorganic ocean carbon cycle Weaver et al. (2001, Section 3e). When reaching the surface, the outgassing of MOS_DIC will follow the air-sea gas exchange process in UVic ESCM, which is given in Weaver et al. (2001, Section 3e). To assess its outgassing, we calculate the partial pressures of 
$\mathrm{CO}_{2}\left(\mathrm{pCO}_{2}\right)$ in the ocean for MOS_DIC separately. The air-sea exchange flux of MOS-C is also calculated for analysing the location and quantity of outgassing. The results of MOS-C outgassing is shown in Sect. 4.6.

Table 1. Model parameters

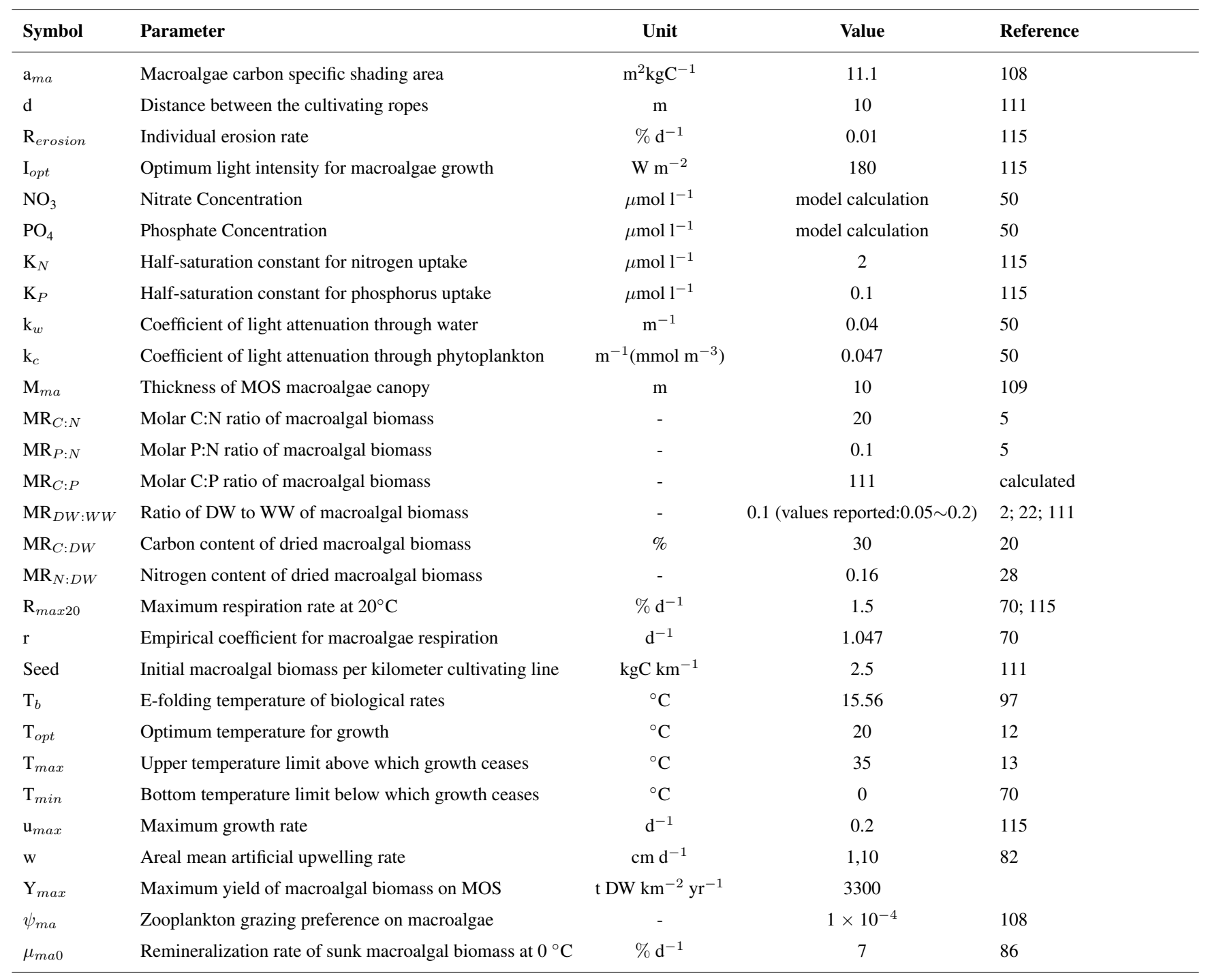

\section{Experiment design}

The UVic ESCM is spun up for $>10,000$ years to an equilibrium state under pre-industrial (year 1765) atmospheric and astronomical boundary conditions, and is then integrated for another 250 years without prescribing atmospheric $\mathrm{CO}_{2}$ concentrations to allow the carbon cycle to equilibrate. Afterwards, the model is run from 1765 until 2005 and forced with historical fossil-fuel emissions and land-use changes (crop and pastureland) (Keller et al., 2014). From year 2005 to 2100, simulations are forced 
with $\mathrm{CO}_{2}$ emissions and other non- $\mathrm{CO}_{2} \mathrm{GHGs}$, land use change by agriculture, volcanic radiative forcing and sulphate aerosols which are prescribed according to the Representative Concentration Pathway 4.5 (RCP4.5, Meinshausen et al. (2011); Thomas (2014); Keller et al. (2014); Partanen et al. (2016). Solar insolation at the top of the atmosphere, wind stress, and wind fields are varied seasonally. After the year $2300, \mathrm{CO}_{2}$ are assumed to decrease linearly until the end of year 3000 with the other forcing held constant.

The full list of simulations is given in Table 3. To test the maximum potential as well as the global carbon cycle and biogeochemical responses, we simulate MOS for 1,000 years beginning in year 2020 (MOS_Conti). Additionally, termination experiments (MOS_Stop) are performed to analyse the response of the ocean and climate to an abrupt termination of MOS.

\subsection{Deployment strategies of MOS}

The current study focuses on estimating the maximum carbon sequestration potential of MOS, and assumes instantaneous seeding on floating infrastructure in the open ocean. The macroalgae is represented as a biogeochemical tracer (Eq 1) that is not subject to physical transports and remains fixed in the top (1st) ocean layer of the UVic ESCM, which is assumed to be well mixed. MOS deployment must fulfill the following requirements:

- the water depth must be $\geq 3,000 \mathrm{~m}$ : according to the assessment by Reith et al. (2016), leakage of dissolved inorganic carbon added to deep waters (in this case from remineralization of sunk macroalgal biomass) is small at such depths compared to shallower ones;

- the ambient surface $\mathrm{NO}_{3}$ concentration is greater than Seed plus $\mathrm{K}_{N}$ (Tab. 1); this ensures sufficient nutrients for initial growth as Seed is directly transferred from dissolved $\mathrm{NO}_{3}$ and $\mathrm{K}_{N}$ is the half saturation constant for $\mathrm{NO}_{3}$ uptake;

- spatially located between $57^{\circ} \mathrm{N}$ and $72^{\circ} \mathrm{S}$ to remain in sea ice free waters.

Note that the DIC, N and P components of the initial Seed are directly removed from the inorganic matter pool of the respective grid box in order to maintain model mass balance and avoid adding extra nutrients/carbon to the ocean at the time of seeding.

During the MOS simulations, seasonality of temperature as well as solar radiation are essential limiting factors of the primary productivity of MOS in various latitudinal regions. In order to avoid the unnecessary loss of macroalgal biomass during winter periods when solar radiation is insufficient and the ambient water temperature is low, we partitioned the global ocean surface into three belts (N, M and S) and pragmatically applied farming strategies according to Tab. 2. 
Table 2. Latitudinal division of MOS deployment regions

\begin{tabular}{clll}
\hline \multirow{2}{*}{ Belt } & \multirow{2}{*}{ Latitudinal range } & \multicolumn{2}{c}{ Date for } \\
\cline { 3 - 4 } & & Seeding & Sinking \\
\hline $\mathrm{N}$ & $51.3^{\circ} \mathrm{N}$ to $17.1^{\circ} \mathrm{N}$ & 01.May & 31. Oct \\
$\mathrm{M}$ & $17.1^{\circ} \mathrm{N}$ to $18.9^{\circ} \mathrm{S}$ & 01.Jan & 31.Dec \\
$\mathrm{S}$ & $18.9^{\circ} \mathrm{S}$ to $56.7^{\circ} \mathrm{S}$ & 01.Nov & 30.Apr* \\
\hline
\end{tabular}

*In the following year macroalgae will stop growing and wait for sinking. After an annual cultivation cycle, the macroalgal biomass is instantaneously delivered to the seafloor apart from a small fraction (equivalent to Seed) that remains at the surface for re-seeding. In some regions where conditions are unfavorable and no net macroalgae growth had occurred during the last cultivation period, the total Biomass will be sunk once without any further re-seeding. In order to prevent MOS from removing too much atmospheric $\mathrm{CO}_{2}$ in long-term simulations where emissions eventually reach zero, MOS deployment will be terminated once atmospheric $\mathrm{CO}_{2}$ concentration hit 280ppm, assuming that there is no need for more CDR once pre-industrial $\mathrm{CO}_{2}$ values have been reached.

\subsection{Sensitivity Studies}

As test simulations indicated that the CDR potential of MOS is in many ocean regions limited by the availability of nutrients in the surface layer, sensitivity simulations were performed with MOS combined with artificial upwelling (AU) that pumps up nutrient-rich deeper waters to the surface and thereby relaxes nutrient stress and enhances the macroalgae growth.

The simulated MOS-AU system is based on Oschlies et al. (2010) and Keller et al. (2014). However, because these earlier studies revealed a dominant effect associated with low temperatures of the upwelled colder waters, we here concentrate on the nutrient aspect and simulate a hypothetical MOS-AU system that keeps temperatures at ambient levels (e.g. via heat exchangers).

In the simulated AU system, water together with dissolved tracers is transferred from the grid box at the lower end of the pipes to the surface grid box resulting in a model grid box-average upwelling rate (w, set to $1 \mathrm{~cm} / \mathrm{day}$ ). The lower end of the pipes is fixed at a depth of $1000 \mathrm{~m}$. Similar to the normal MOS simulations without AU, the MOS_AU simulations are deployed from year 2020 and then terminated at either year 2100 in discontinuous run or year 3000 in continuous one (Tab. 3).

The MOS-AU joint system is deployed using the following strategies: AU pipes will be deployed everywhere with depth $\geq$ $3000 \mathrm{~m}$ and start upwelling immediately. If surface nutrient concentrations are raised to the initial seeding condition (Sect. 3.1) in any grid box, MOS will be deployed, thereby expanding the range where MOS can grow.

Another model parameter selected for sensitivity studies is the remineralization rate of sunk macroalgal biomass $\left(\mu_{m a}\right.$, Eq. 16). $\mu_{m a}$ is a critical factor impacting the residence time of MOS-captured carbon in the ocean and associated benthic oxygen 
consumption by remineralization. Macroalgal biomass has been reported to be recalcitrant to microbial degradation, however, the fate of macroalgal biomass in the deep sea is uncertain (Krause-Jensen and Duarte, 2016; Luo et al., 2019; Sichert et al., 2020). Thus, an extreme and idealized situation with $\mu_{m a}$ set to zero is tested in sensitivity simulations (MOS_NoRe). This can be thought of as a case where all biomass is permanently buried upon reaching the seafloor.

Table 3. Description of the Model Experiments. "Stop" represents the termination of the simulation in year 2100; "Conti" represents the continuous MOS deployment till year 3000; "AU" represents artificial upwelling; NoRe represents zero-remineralization of sunk macroalgal biomass.

\begin{tabular}{|c|c|c|}
\hline Category & Experiment & Description \\
\hline Normal MOS & Control_RCP4.5 & Control simulation under RCP4.5 \\
\hline \multirow[t]{2}{*}{ simulations } & MOS_Conti & As Control_RCP4.5, but MOS deployed from year 2020 to year 3000 \\
\hline & MOS_Stop & As Control_RCP4.5, but MOS implemented from year 2020 to year 2100 \\
\hline Sensitivity & MOS_Conti_NoRe & As MOS_Conti, but with zero remineralization rate \\
\hline \multirow[t]{3}{*}{ simulations } & MOS_Stop_NoRe & As MOS_Stop, but with zero remineralization rate \\
\hline & MOS_AU_Conti & MOS synergy with $\mathrm{AU}$, area-averaged upwelling velocity $(\mathrm{w})$ is $1 \mathrm{~cm} /$ day. \\
\hline & MOS_AU_Stop & As MOS_AU_Conti, but MOS implemented until year 2100 \\
\hline
\end{tabular}

\section{Results}

\subsection{Evaluation of MOS}

To evaluate if the simulated MOS systems have plausible macroalgae growth characteristics, we evaluate the seasonal dynamics of the simulated MOS system for a 30 days averaged time slice from 2020 to 2024 under the RCP4.5 emission scenario and without artificial upwelling.

\subsubsection{Distribution of MOS}

The red contours in Fig.2a delineate the occupied area that basically follows the pattern of the simulated $\mathrm{NO}_{3}$-rich ocean surface (Keller et al. (2012, Fig 9), Garcia et al. (2010, WOA2009 Dataset)) in the Northern and the equatorial Eastern Pacific, as well the Southern Ocean. Except for the coastal regions and Arctic areas which are not considered for MOS here, the distribution pattern of MOS agrees with the other estimation of potential open-ocean macroalgae farming locations (e.g. Lehahn et al. (2016, Fig.2.A),Froehlich et al. (2019, Figure 1.)). Another powerful limiting factor is the ocean surface temperature (Garcia et al., 2010, WOA2009 Dataset) which is too warm in many places for our idealized species, i.e., temperatures are above the $\mathrm{T}_{\text {opt }}\left(20^{\circ} \mathrm{C}\right)$ and nearly reaches the $\mathrm{T}_{\max }\left(35^{\circ} \mathrm{C}\right)$. 


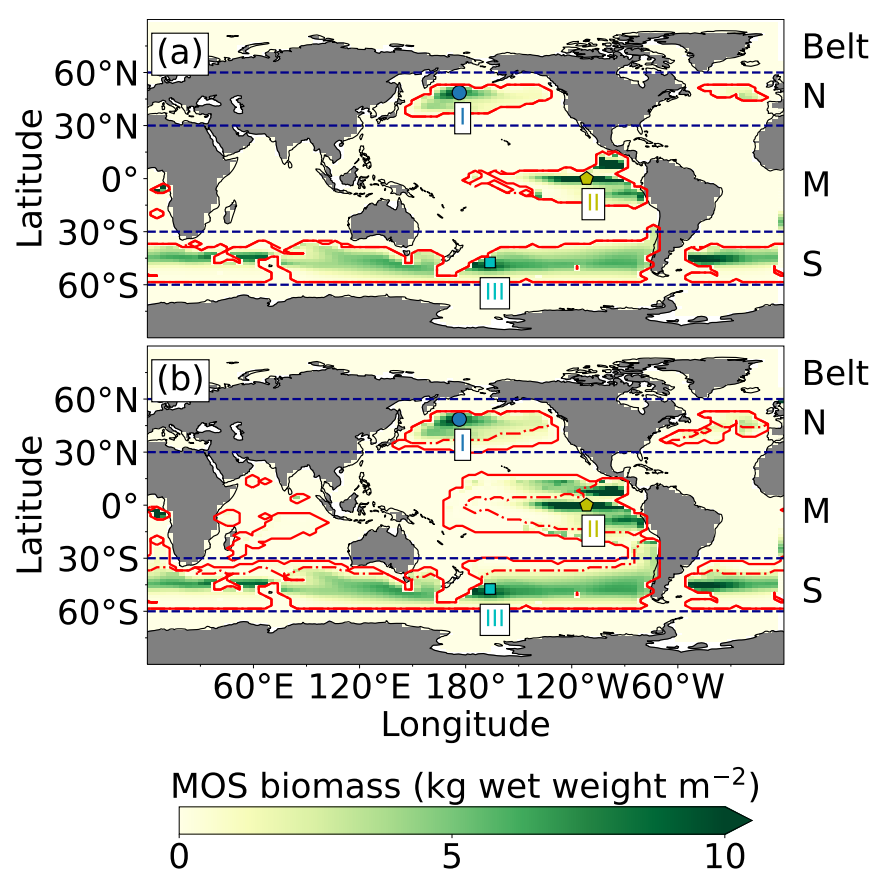

Figure 2. Annual vertically integrated NPP of MOS (a) and MOS_AU (b) in year 2024. Red solid lines outlines the MOS occupied area at year 2024 in both, while red dashed lines outline the initial MOS seeding area at year 2020 in (a). The simulated MOS area generally covers the $\mathrm{NO}_{3}$-rich ocean surface (a) and can be expanded with nutrients supplement by AU (b), larger than the estimated adequate area for macroalgae in previous studies (Lehahn et al., 2016; Froehlich et al., 2019)). Results for areas I (blued circle), II (yellowish pentagon) and III (cyan rectangle) are discussed in the text and displayed in Fig 3.

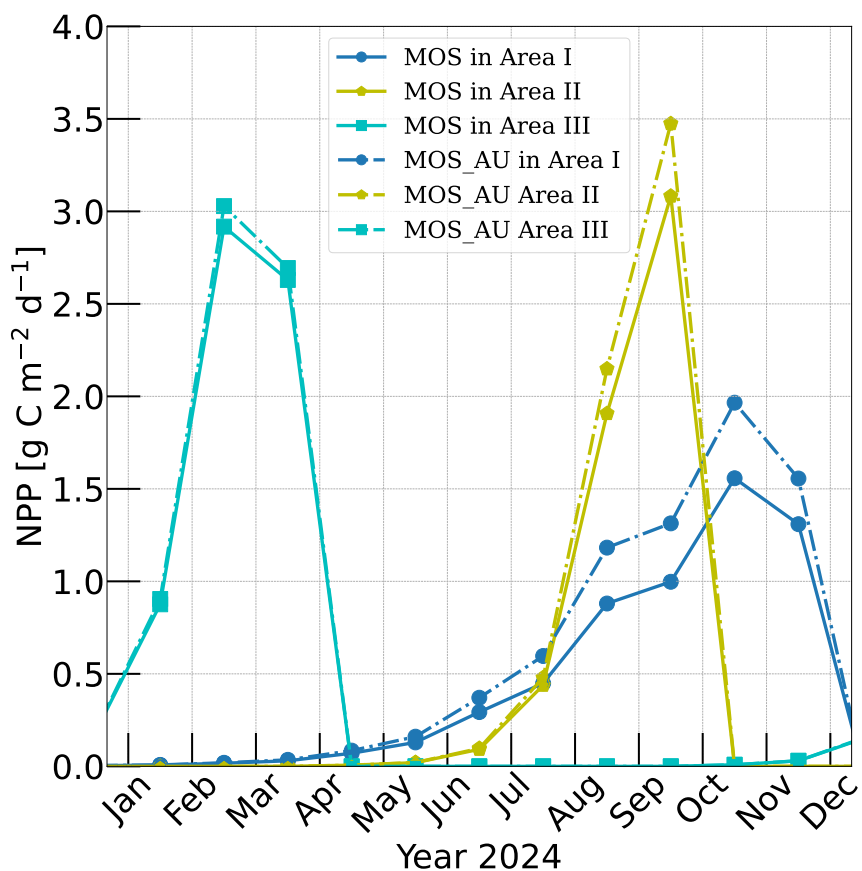

Figure 3. Vertically integrated MOS NPP rates simulated for year 2024 and representative Areas I (dark blue circle), II (yellow pentagon) and III (cyan rectangle) highlighted by rectangles with corresponding colours in Fig.2. The NPP of MOS (solid) from the selected area I, II and III are reasonable compared to reported macroalgae NPP, and MOS_AU (dashed) shows an enhancement of NPP as expected.

At the beginning of year 2020, a surface area $\mathrm{S}_{M O S}$ of 72 million $\mathrm{km}^{2}$ was selected by the MOS algorithm according to the requirements described in Sect.3. This is equivalent to a total cultivated rope length $\left(\mathrm{L}_{M O S}\right)$ of $7.2 \times 10^{9} \mathrm{~km}$ (Eq.A1, Sect.A1). When the macroalgae start to grow and to consume nutrients, regions with nutrient levels insufficient for further growth are gradually abandoned. By the end of year 2024, the MOS coverage has declined by about $3 \%$ to $69.6 \times 10^{9} \mathrm{~km}^{2}$ (Tab.4).

Despite the similar distribution patterns, MOS occupied area $\left(69.6 \times 10^{9} \mathrm{~km}^{2}, \sim 19.7 \%\right.$ of the world ocean $)$ is larger than the assessments of $\sim 10 \%$ of the world ocean by Lehahn et al. (2016) and $\sim 48$ million $\mathrm{km}^{2}$ by Froehlich et al. (2019). Compared to the static estimation based on historical nutrient levels and temperature suitability (Lehahn et al. (2016, Fig.2.A)), the dynamic processes redistributing nutrients as well as the explicit macroalgae growth module in our simulations contribute to the simulated larger potential area for MOS, especially in equatorial Eastern Pacific and the Southern Ocean. Besides, the 
adequate area for macroalgae cultivation was limited to the Economic Zones (EEZs) by Froehlich et al. (2019) due to limitations of cost and political feasibility. This constraint has been ignored in the current study. Thus, our simulated MOS-adequate area is $45 \%$ larger than the estimation by Froehlich et al. (2019).

\subsubsection{Macroalgae model validation}

Validation of the macroalgae model is crucial, as the productivity and macroalgal biomass yield is vital for $\mathrm{CO}_{2}$ sequestration.

Here we examine the simulated seasonality, NPP rate, and biomass yield of MOS in comparison with available observations and assessments. Simulated NPP is high in the first year of deployment in many regions because nutrients are abundant, and then sharply declines in the following years as a new local biogeochemical state is reached. Thereafter, NPP gradually reaches a relatively steady state by 2024 (Fig.A2). To provide some validation of the macroalgae model we select three areas named Area I, II and III from Belt N, M and S (Fig.3) and analyse their performance in year 2024. Each area covers 4 grid boxes in the uppermost ocean layer of the UVic ESCM.

In our simulations, simulated macroalgae NPP rates are comparable to the observed ranges in the productive areas that we selected here. Observed wild macroalgae NPP varies widely, ranging from 91 to $750 \mathrm{gC} \mathrm{m}^{-2} \mathrm{yr}^{-1}$ (Krause-Jensen and Duarte, 2016). Our model reproduces the macroalgae NPP of 159.2-199.3 $\mathrm{gC} \mathrm{m}^{-2} \mathrm{yr}^{-1}$ in the selected areas (Tab.4). Simulated biomass yields in these areas are in the previously reported range as well. Reports of the biomass yield of aquacultured

310 Laminaria saccharina (now regarded as a synonym of Saccharina latissima) range from $40 \mathrm{t} \mathrm{DW} \mathrm{km}^{-2} \mathrm{yr}^{-1}$ in an off-shore cultivation experiment by Buck and Buchholz (2004) to $456 \mathrm{t} \mathrm{DW} \mathrm{km}{ }^{-2}$ in a coastal cultivation experiment by Peteiro et al. (2014). In our simulations, the yield of selected areas ranges from 492.4 to $648.2 \mathrm{t} \mathrm{DW} \mathrm{km}^{-2} \mathrm{yr}^{-1}$. The selected Area I yields 648.2 DW $\mathrm{km}^{-2} \mathrm{yr}^{-1}$. In regions with similar latitudes as Area I, the biomass yield of aquacultured Saccharina japonica

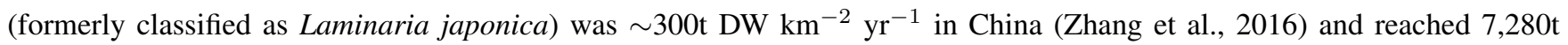
DW $\mathrm{km}^{-2} \mathrm{yr}^{-1}$ in Japan (Yokoyama et al., 2007). Nevertheless, some simulated low values from the globally averaged and latitudinal belt-averaged results are not surprising considering that the open ocean tends to be more nutrient limited than coastal or near-shore regions where the aforesaid observed macroalgae NPP was measured. Our results provide some confidence that our idealized model can simulate macroalgae well enough with respect to typical biomass yield, seasonality and geographical distribution. 
Table 4. Properties of globally implemented MOS. Selected areas are from data of year 2024, whereas Belt areas are values averaged from 2020 to 2024. Areal NPP rates and Biomass Yield refer to the respective MOS area.

\begin{tabular}{|c|c|c|c|c|c|c|c|c|c|}
\hline \multirow[b]{2}{*}{ Property } & \multirow[b]{2}{*}{ Unit } & \multirow[b]{2}{*}{ Exp. } & \multicolumn{4}{|c|}{ Selected area $\left(10^{3} \mathbf{k m}^{2}\right)$} & \multicolumn{3}{|c|}{$\operatorname{Belt}\left(\mathbf{1 0}^{9} \mathbf{k m}^{2}\right)$} \\
\hline & & & I & II & III & $\mathrm{N}$ & M & $S$ & Global \\
\hline \multirow{2}{*}{ MOS occupied area $\left(\mathbf{S}_{M O S}\right)$} & \multirow{2}{*}{$\mathrm{km}^{2}$} & MOS & \multirow{2}{*}{-218.8} & \multirow{2}{*}{320.3} & \multirow{2}{*}{204.2} & 9.1 & 15.7 & 44.8 & 69.6 \\
\hline & & MOS_AU & & & & 17.4 & 44.3 & 64.6 & 126.3 \\
\hline \multirow{2}{*}{ NPP } & \multirow{2}{*}{$\mathrm{gC} \mathrm{m}^{-2} \mathrm{yr}^{-1}$} & MOS & 159.2 & 176.9 & 199.3 & 50.8 & 52.0 & 67.5 & 61.8 \\
\hline & & MOS_AU & 202.2 & 231.1 & 217.7 & 45.5 & 32.2 & 56.9 & 46.7 \\
\hline \multirow{2}{*}{ Biomass Yield } & \multirow{2}{*}{$\mathrm{t} D W \mathrm{~m}^{-2} \mathrm{yr}^{-1}$} & MOS & 648.2 & 492.4 & 579.7 & 173.2 & 160.3 & 206 & 191.4 \\
\hline & & MOS_AU & 715.3 & 615.4 & 597.0 & 142.2 & 85.4 & 169 & 136 \\
\hline \multirow{2}{*}{ Total $\mathrm{CO}_{2}$ captured in biomass } & \multirow{2}{*}{$\mathrm{PgCO}_{2} \mathrm{yr}^{-1}$} & MOS & 0.14 & 0.16 & 0.12 & 1.6 & 2.5 & 9.2 & 13.3 \\
\hline & & MOS_AU & 0.15 & 0.20 & 0.12 & 2.5 & 3.8 & 10.9 & 17.2 \\
\hline
\end{tabular}

\subsection{Evaluation of MOS with Artificial Upwelling (AU)}

As expected, AU increases the area occupied by MOS from $69.6 \times 10^{9} \mathrm{~km}^{2}$ in the run without AU to $129.6 \times 10^{9} \mathrm{~km}^{2}$ in the run with AU (Fig.2.2). Obvious expansions of areas with suitable growing conditions are found in the Eastern Tropical Pacific and the North Atlantic. AU also expands S_MOS to the Indian Ocean, which was almost abandoned in regular MOS simulations. In Area I, II and III, both NPP rate and biomass yield are enhanced due to the upwelled nutrients (column Belt, Tab.4, Fig.3). A closer look into the Belt N, M and S areas shows that both the NPP rate and biomass yield per square-meter of the deployment area decrease in simulation MOS_AU when compared to the standard MOS simulation (column Belt, Tab.4). This is related to a 'dilution effect': in the new MOS-adequate areas increased by AU, the available nutrients are limited, thus the MOS NPP is relatively low compared to the original nutrient-rich NPP areas. Despite of this, the expanded MOS area in MOS_AU increases the total $\mathrm{CO}_{2}$ captured by about 30\% (Tab.4).

\subsection{MOS deployment until year 2100}

This section showcases the CDR and climate change mitigation capacities of MOS within the 21st century. Impacts of MOS on marine biogeochemistry (nutrients, dissolved oxygen and pelagic ecosystem) and global carbon cycles will also be examined.

\subsubsection{CDR \& climate change mitigation capacities}

Over the 80 years between year 2020 and year 2100, MOS is mainly deployed in nutrient-rich regions such as the Southern Ocean and the northern and eastern equatorial Pacific (Fig.B1(a)), despite some contraction of initially occupied areas occurred due to the removal of nutrients. 
By the year 2100, MOS (MOS_Stop and MOS_Conti) has sequestered $270 \mathrm{PgC}\left(990 \mathrm{PgCO}_{2}\right.$, Tab.5), representing 37\% of the cumulative $\mathrm{CO}_{2}$ emissions in the RCP4.5 pathway. Essentially all of MOS-captured carbon is retained in the ocean over this period as either remineralized dissolved inorganic carbon, or organic carbon in the sunk biomass.

Table 5. Model Simulations under the RCP4.5 emission scenario. MOS-C represents the carbon sequestered via MOS. $\mathrm{C}_{a t m}, \mathrm{C}_{o c}, \mathrm{C}_{t e r}$ stand for atmospheric, oceanic and terrestrial carbon reservoir respectively. $\Delta \mathrm{SAT}$ stands for surface averaged temperature relative to $13.18^{\circ} \mathrm{C}$, the pre-industrial.

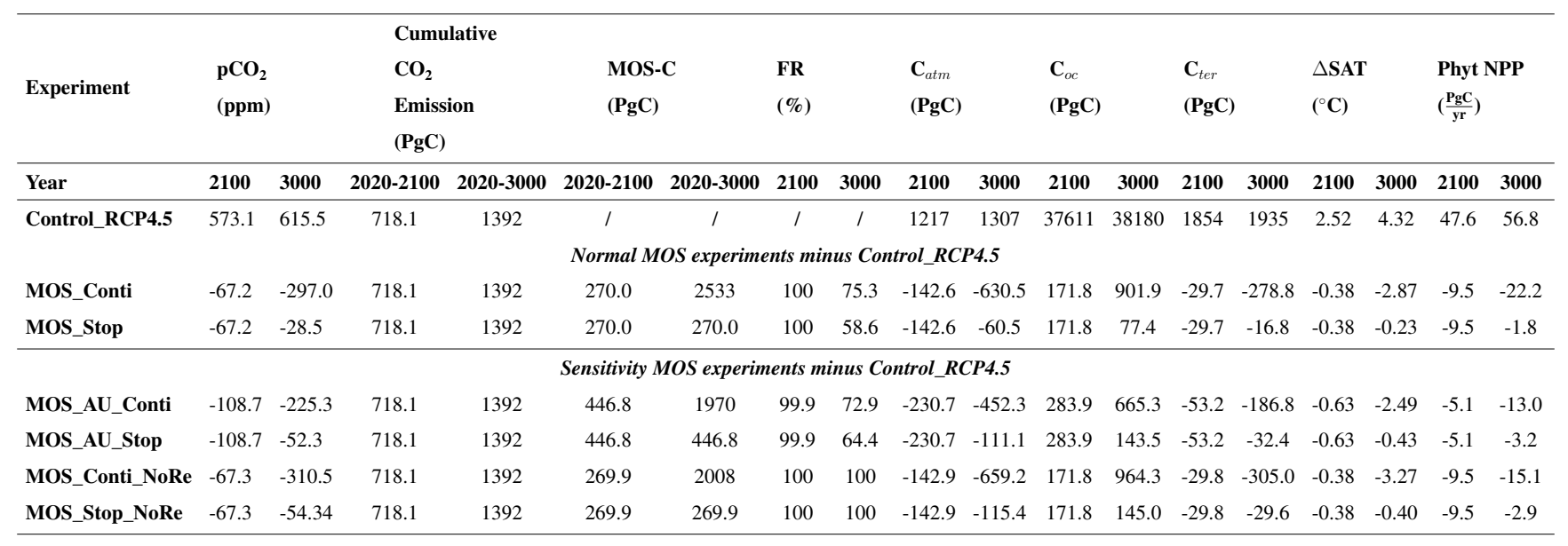

In the model MOS thus gradually reduces atmospheric $\mathrm{CO}_{2}$, and thereby also limits global warming with respect to preindustrial period ( $\triangle \mathrm{SAT}$, Fig.4); i.e., the temperature increase of $2.14^{\circ} \mathrm{C}$ by the year 2100 is $0.38{ }^{\circ} \mathrm{C}$ lower than $\Delta \mathrm{SAT}$ of Control_RCP4.5, but still missing the $2{ }^{\circ} \mathrm{C}$ target.

When AU is deployed in conjunction with MOS the CDR capacity and mitigation effects of MOS are enhanced (Figs.4a\&c, Fig.5). By the end of year 2100, 446.8 Pg carbon is sequestered by MOS_AU, an increase of 39.5\% relative to normal MOS. Correspondingly, MOS_AU successfully achieves the $2^{\circ} \mathrm{C}$ target of the Paris Agreement by maintaining a $\Delta \mathrm{SAT}$ at $1.89^{\circ} \mathrm{C}$ relative to pre-industrial (Fig.4c \& Tab. 5). As in the run without AU, essentially all of the carbon captured via MOS is stored in the ocean until the end of the 21 st century (FR, Tab. 5). 


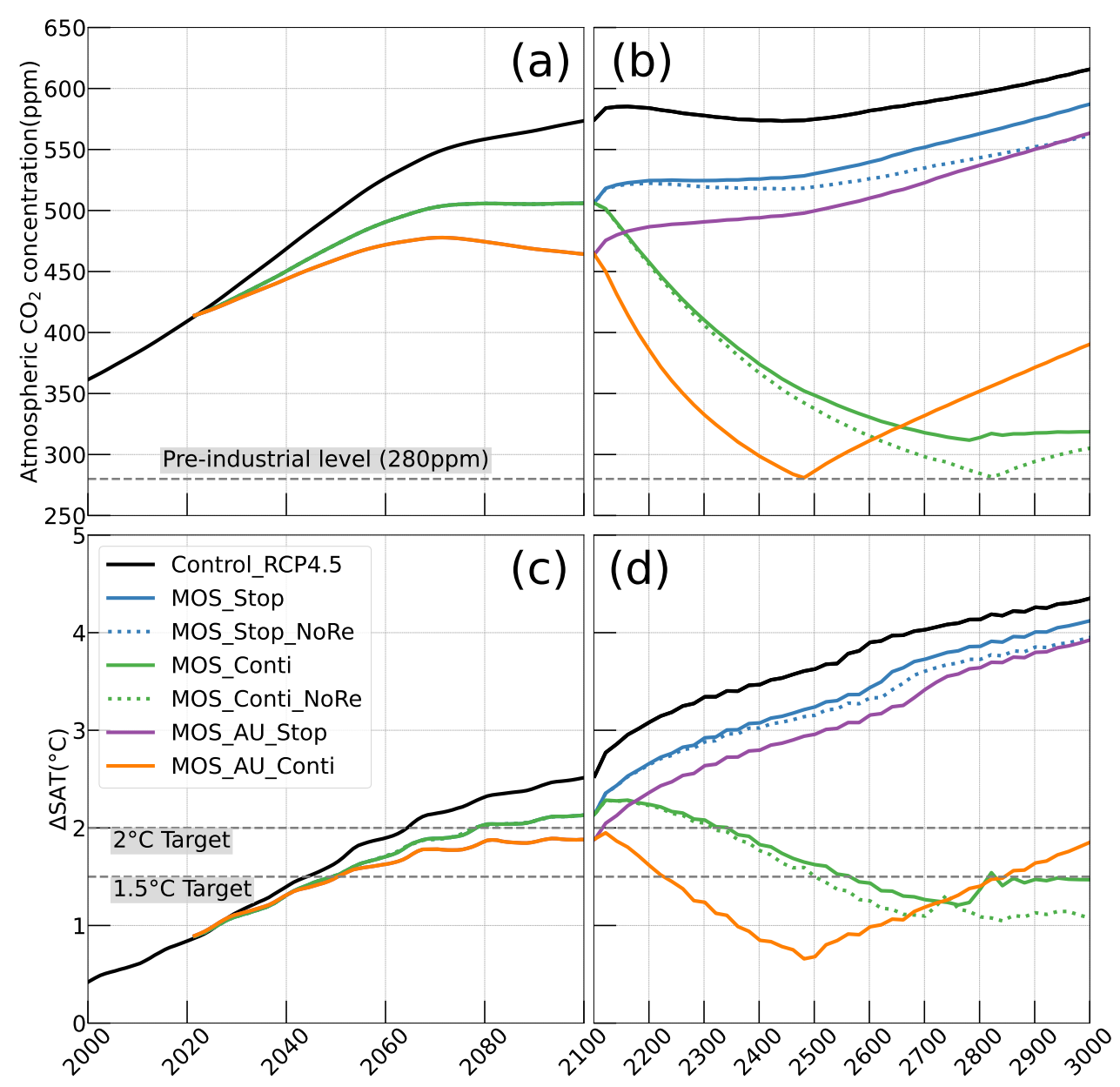

Figure 4. Simulations of: $\mathbf{a}, \mathbf{b}$ :annual global mean atmospheric $\mathrm{CO}_{2}$ concentration; $\mathbf{c}, \mathbf{d}$ : surface averaged temperature relative to the preindustrial (averaged of year 1850 to year 1900) level of $13.18^{\circ} \mathrm{C}(\Delta \mathrm{SAT})$. Under RCP4.5 scenario, MOS reaches the $2^{\circ} \mathrm{C}$ target in conjunction with $\mathrm{AU}$, while the $1.5^{\circ} \mathrm{C}$ cannot be met in all MOS simulations. Note that MOS is terminated whenever pre-industrial concentrations of atmospheric $\mathrm{CO}_{2}$ are reached, as seen for MOS_AU_Conti (orange solid) and MOS_Conti_NoRe (blue dotted) in (b\&d). Both atmospheric $\mathrm{CO}_{2}$ and $\triangle \mathrm{SAT}$ remain lower than control after MOS termination. 


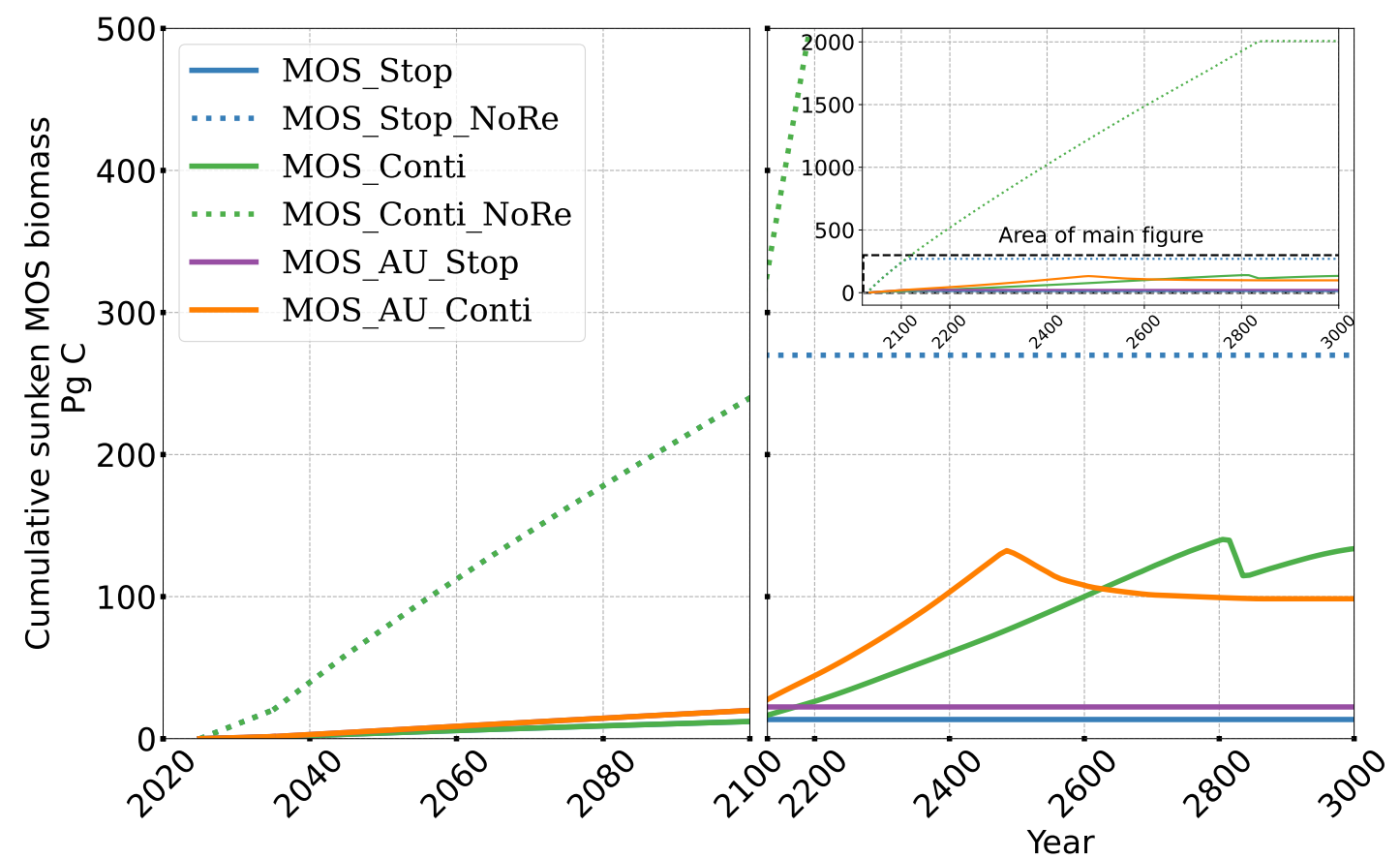

Figure 5. Temporal evolution of globally integrated sunk macroalgal biomass on the sea floor. Biomass generally increases with fertilization by AU. In the idealized zero-remineralization simulations, all sunk macroalgal biomass remains on the seafloor, and globally integrated sunk macroalgal biomass shows a monotonous increase.

\subsubsection{Global carbon cycle impacts}

The net effect of the MOS-induced climate-carbon cycle perturbation is an increase of the oceanic carbon reservoir $\left(\mathrm{C}_{o c}\right)$ and a decrease of the atmospheric and terrestrial carbon reservoirs $\left(\mathrm{C}_{a t m}, \mathrm{C}_{t e r}\right)$. MOS enhances oceanic carbon uptake by increasing the atmosphere to ocean carbon flux (Fig.B10), which is driven by the DIC removal by MOS in the oceans' surface layer. However, the terrestrial carbon reservoir declines (relative to Control_RCP4.5) in all MOS simulations (Tab.5). The atmosphere to land carbon flux is reduced in MOS simulations (Fig.B9). One cause is the photosynthesis reduced by lower $\mathrm{CO}_{2}$ fertilization of land biota (Keller et al., 2018). This result is in line with other studies showing that CDR can lead to a weakening and even reversal of natural carbon sinks Keller et al. (2018). Besides, it is also worth noting that the increment of $\mathrm{C}_{o c}$ in MOS/MOS_AU is $98.2 \mathrm{PgC} / 163.9 \mathrm{PgC}$ less than the cumulative amount of carbon sunk out of the surface layer via MOS by year 2100 (Tab.5). One reason is that the reduced oceanic carbon uptake by declined PNPP (Sect. 4.3.4) offsets 37\% of the MOS-induced carbon sequestration.

MOS also impacts the distribution of DIC in the ocean. The DIC profiles in Fig.6 illustrate that the general effect of MOS is to move more DIC to greater depth $(\mathrm{z} \geq 3000 \mathrm{~m})$. By the end of year 2100, MOS simulations show an increased total DIC concentration in the deeper oceans when compared to Control_RCP4.5 (except for the zero-remineralization sensitivity runs discussed below). For instance, in the deep Southern Ocean, the DIC concentration is on average nearly $80 \mu$ mol $/ \mathrm{kg}$ higher 
https://doi.org/10.5194/esd-2021-104

Preprint. Discussion started: 14 January 2022

(c) Author(s) 2022. CC BY 4.0 License.
Earth System

Dynamics

Discussions

than the Control_RCP4.5 in year 2100 (Fig.6). The conjunction of MOS with AU increases average deep ocean DIC even more. An example is the simulated increase of DIC in the deep Pacific Ocean and Atlantic Ocean basins by MOS_AU in year 2100 (orange line in Fig.6 DIC panel). In contrast, DIC concentrations are reduced in shallower waters (depth $<1000 \mathrm{~m}$ ) as the air-sea carbon flux is unable to fully compensate the carbon removal by MOS.

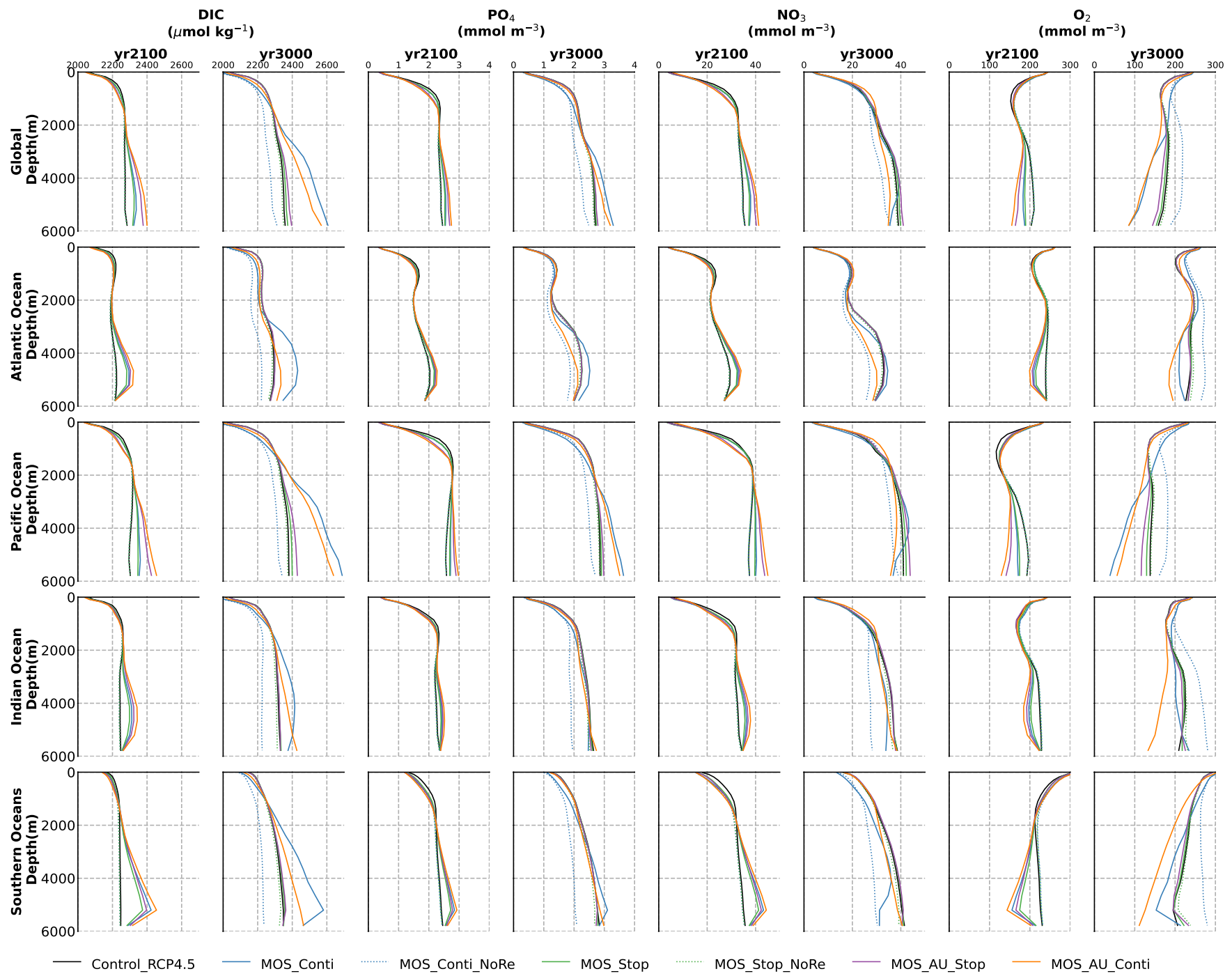

Figure 6. Global and basin-wide averaged vertical profiles of various model tracers in year 2100 and year 3000 under the RCP4.5 emission scenario. In general, MOS (except for the zero remineralization ones) transports DIC and nutrients in the surface layer to the deep ocean. The oxygen levels are increased in the mid layers due to the declined downward organic particle flux (Sect.4.3.4) but decreased in the deep ocean caused by the remineralization of sunk biomass. These impacts are strengthened when MOS is deployed continuously and/or in conjunction with AU. 


\subsubsection{Impacts on global nutrients distributions}

By the year 2100, the deployment of MOS has changed the global patterns of $\mathrm{NO}_{3}$ and $\mathrm{PO}_{4}$. At the surface $\mathrm{NO}_{3}$ and $\mathrm{PO}_{4}$ concentrations decrease due to MOS nutrient consumption. In the deep ocean (depth $\geq 3000 \mathrm{~m}$ ), $\mathrm{PO}_{4}$ and $\mathrm{NO}_{3}$ increase due to the remineralization of sunk macroalgal biomass (except for the MOS_NoRe simulations). The largest increase in deep ocean $\mathrm{PO}_{4}$ appears in the Southern Ocean, while the smallest increase is found in the Indian Ocean ( $\mathrm{PO}_{4}$ yr2100 groups in Fig.6). This is caused by the distribution of MOS in the surface layer, which in our simulations occupies large areas in the Southern Ocean but only a relatively small region in the Indian Ocean (Fig.2.1).

The remineralization of sunk biomass consumes dissolved oxygen and releases $\mathrm{NO}_{3}$ and $\mathrm{PO}_{4}$. As can be seen from the $\mathrm{NO}_{3}$ yr2100 and $\mathrm{O}_{2}$-yr2100 panels of Fig.6, deep ocean nutrients generally increased when $\mathrm{O}_{2}$ is diminished (Sect.4.3.5), as expected from aerobic respiration of sunk biomass. Low-oxygen environments and the associated switch from aerobic remineralization to denitrification, however, occupy relatively small areas, so that this impact is not easily detectable in global nutrient profiles.

\subsubsection{Impacts on simulated pelagic ecosystems and the organic particle export}

In our simulations, large scale deployment of MOS has an impact on pelagic ecosystems, mainly on phytoplankton NPP (PNPP) and on biomass.

In the MOS simulation, the globally integrated annual PNPP decreases by $20 \%$ (9.5 PgC/yr) by year 2100 (Tab. 5). One reason is the canopy shading effect of the floating macroalgae farms, which reduces downward solar radiation available for the phytoplankton community below. In addition, there is nutrient competition between macroalgae and phytoplankton. As shown in Fig.7a, by the end of the 21st century, PNPP declines in MOS areas, e.g. northern and eastern equatorial Pacific and the Southern Ocean. Intriguingly, in a few regions outside the MOS deployment region, PNPP increases instead. For instance, a 'halo' of enhanced PNPP can be observed surrounding the eastern equatorial Pacific MOS region (Fig.7.a). Similar circumstances are simulated in the North Pacific, the Southern Ocean $\left(60^{\circ} \mathrm{E}: 120^{\circ} \mathrm{E}, 30^{\circ} \mathrm{S}\right)$ and off the equatorial west coast of Africa. This PNPP-enhancement is sustained by the outflow of residual $\mathrm{NO}_{3}$ from MOS deployment regions (see Fig.B8). One reason is that the P:N ratio in macroalgae model (1:10) is higher than the Redfield ratio (1:16) in the UVic ESCM, leading to a relatively smaller $\mathrm{NO}_{3}$ demand by macroalgae growth and some relaxation of nitrogen limitation in phytoplankton. Besides, as described in Sect.2.2.1, the macroalgae growth is constrained by the maximum biomass yield. Thus, macroalgae nutrient uptake cannot compensate the loss of nutrient consumption by light-limited PNPP, especially when AU supplies additional nutrients to the surface. 

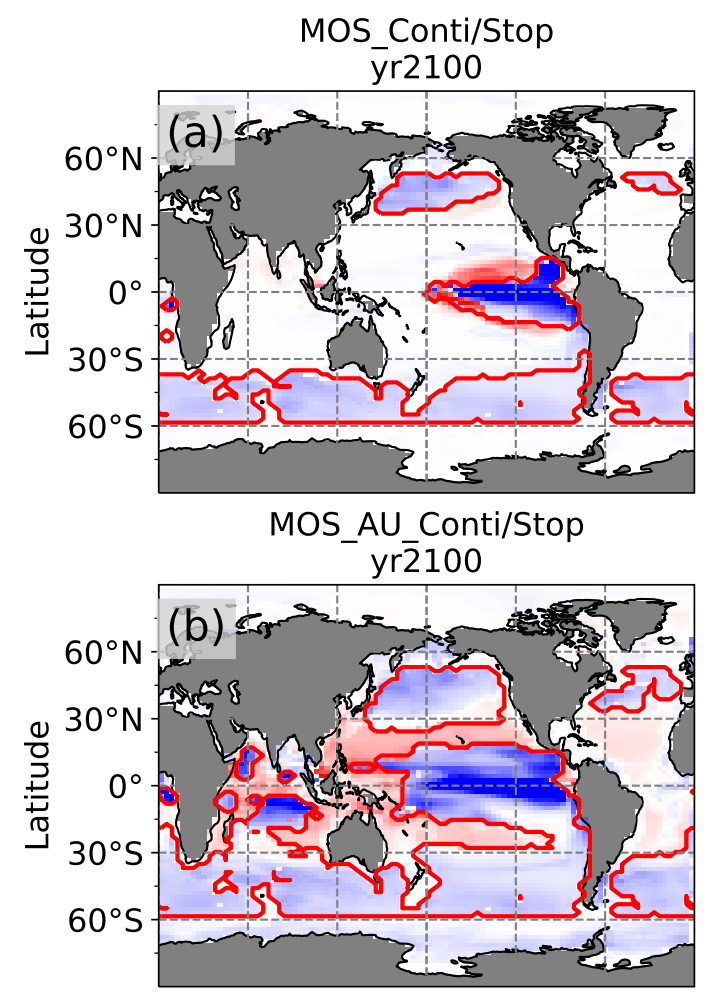

Control RCP4.5

yr $\overline{1} \overline{1} 00$

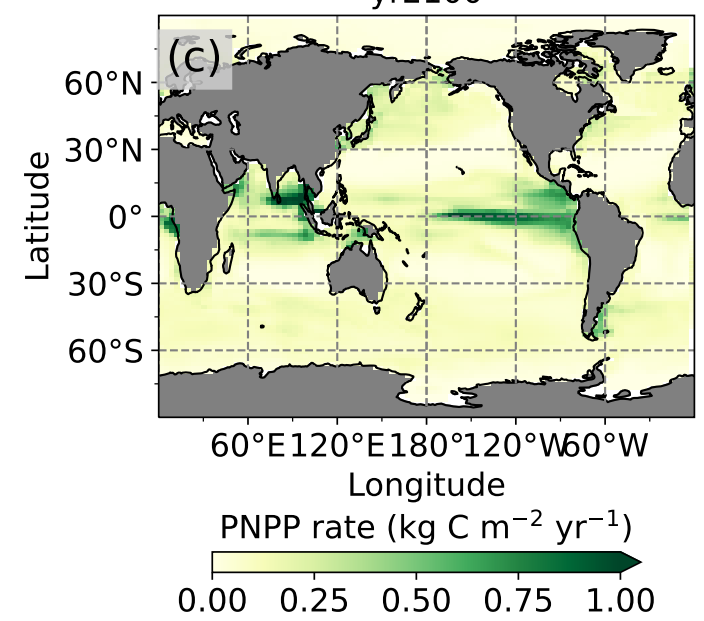

Figure 7. Vertically integrated annual PNPP in year 2100. a\&b: MOS minus Control_RCP4.5 with red boundaries contouring the MOS occupied area; c: Control_RCP4.5. a illustrates a decline in PNPP in MOS occupied areas accompanied by a 'halo' of enhanced PNPP surrounding MOS areas, particularly in the ETP caused by the leakage of residual nutrients (Sect.4.3.4). These impacts on PNPP are amplified in MOS-AU (b). 
In the MOS_AU simulations, the PNPP 'halo' can be seen in almost the whole MOS-free ocean surface (Fig.7.b). The AU fertilization effect enhances the nutrient leakage from the MOS area. This leads to a higher PNPP in MOS_AU than in the normal MOS simulations (Fig.7.c), but still lower than in the Control_RCP4.5 run (Fig.8.a1).

Changes in the global particle organic carbon (POC) export flux generally follow the pattern of PNPP changes (Fig.8.b1). Thus, when MOS is present, the PNPP reduction results in a weakened POC flux.

As the zooplankton grazing preference for macroalgae is lower than for phytoplankton the zooplankton community is still mainly fed by phytoplankton. Therefore, the declines in zooplankton biomass (Fig.B3) agree with the declining phytoplankton biomass trend (Fig.B5).
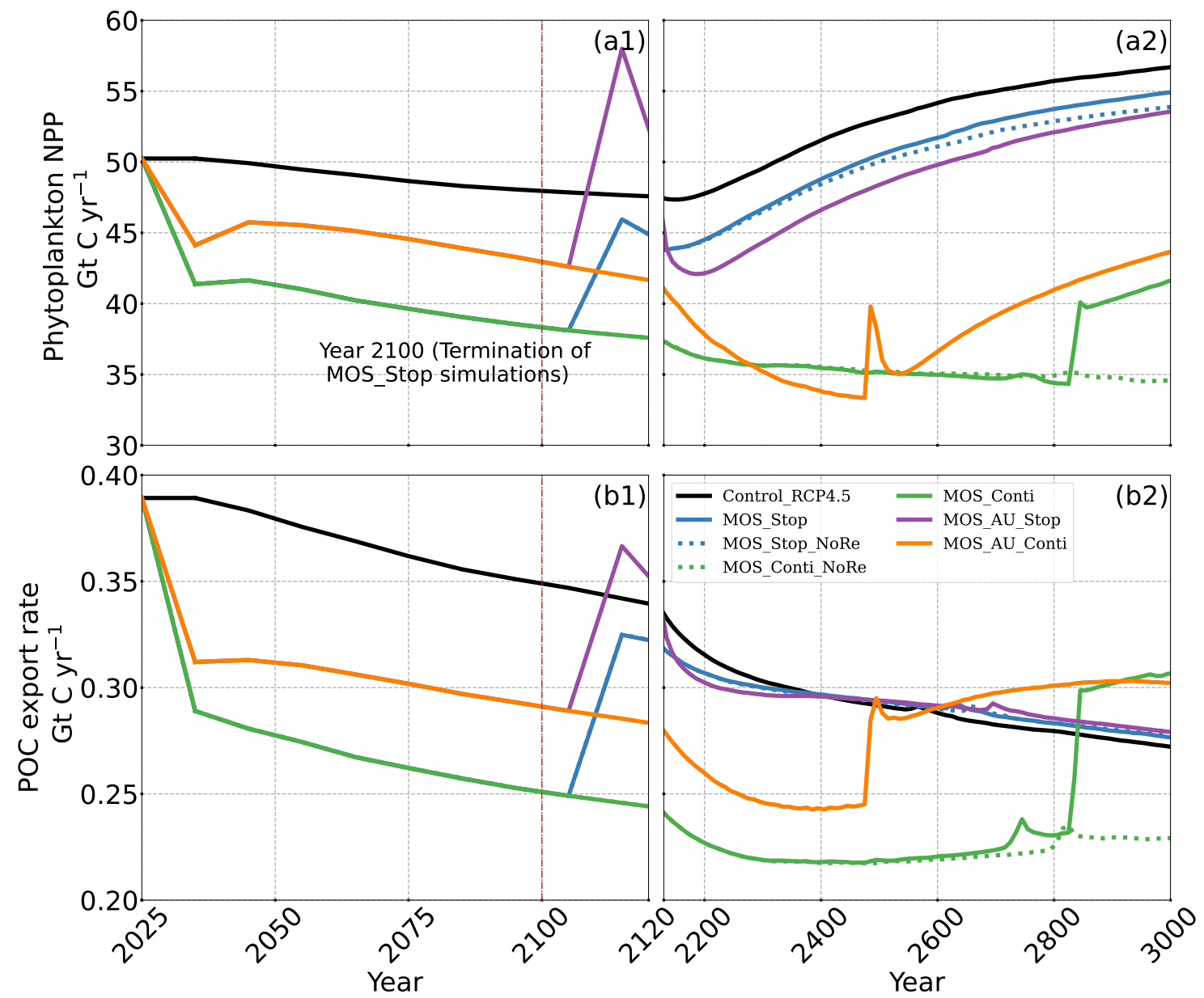

Figure 8. Temporal evolution of globally integrated PNPP (a1, a2); downward POC flux at 2km depth (b1, b2). The termination runs branch off of the continuous ones in year 2100 and are identical up to that point. Through the 21st century, MOS reduces PNPP and POC export due to canopy shading and competition for nutrients. Obvious rebounds followed by quick decline can be observed right after terminations of MOS. 


\subsubsection{Impacts on dissolved oxygen}

The two major impacts of MOS on oceanic dissolved oxygen are: 1) increased deoxygenation at the sea floor by the remineralization of sunk macroalgal biomass (except for MOS_NoRe) and 2) increased dissolved oxygen at mid depths (e.g. $300 \mathrm{~m}$ depth) caused by the reduction of the downward POC flux and the associated decline in oxygen consumption by POC remineralization.

In Control_RCP4.5, the global oceanic dissolved oxygen inventory decreases throughout the simulation. The two main driving mechanisms are the reduced solubility in the warming ocean and the decelerating overturning circulation. The longterm decline of oxygen is especially obvious at depth $(1200 \mathrm{~m})$, which is induced by increasing deep water residence times and the accumulation of respiratory oxygen deficit under global warming (Oschlies et al., 2019; Oschlies, 2021).

As a result of reduced respiration in the upper water column, the size of the oxygen minimum zone (OMZ) in Eastern Tropical Pacific (ETP) shrinks substantially, and the volume of waters with $\mathrm{O}_{2}<80 \mathrm{mmol} / \mathrm{m}^{3}$ in the North Pacific even disappears. In the Southern Ocean dissolved oxygen increases as well (Fig.9.c). This is more pronounced when AU is applied (Fig.9.e). The increase in dissolved oxygen is caused by decreased microbial remineralization of POC, a consequence of the reduced downward POC flux resulting from the inhibition of PNPP in the surface layer (Sect. 4.3.4). Some decrease in oxygen concentrations occurs in the western Pacific and the Indian Ocean (Fig.9.g), where the surface PNPP is enhanced by the surplus nutrients leaked out from MOS occupied area (see Sect.4.3.4 and Fig.7.c).

Fig.9.d\&f and the $\mathrm{O}_{2}$ yr2100 panel of Fig.6 illustrate how MOS changes the dissolved oxygen in the deeper ocean. Within the normal MOS simulations, the decline of benthic dissolved oxygen mainly happens in the Southern Ocean by year 2100 with the appearance of a few new areas with oxygen concentrations less than $80 \mathrm{mmol} \mathrm{m}^{-3}$ (Fig.9.d). However, when AU is also deployed, the increased macroalgal biomass sinking and remineralization creates even more benthic OMZs (Fig.9.f) in the benthic ETP and North Pacific Ocean. These new benthic OMZ locations correspond to MOS-occupied surface areas. 


\begin{tabular}{|c|c|c|c|c|c|c|}
\hline \multicolumn{7}{|c|}{ Dissolved $\mathrm{O}_{2} \mathrm{mmol} \mathrm{m}^{-3}$} \\
\hline . & 50 & 100 & 150 & 200 & 250 & 300 \\
\hline
\end{tabular}

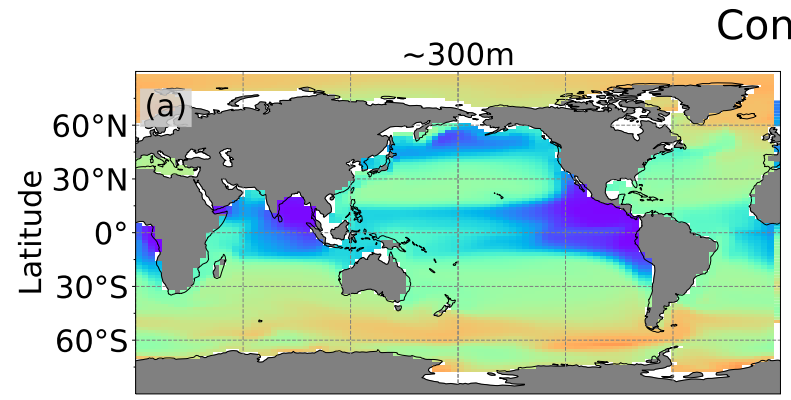

Control_RCP4.5
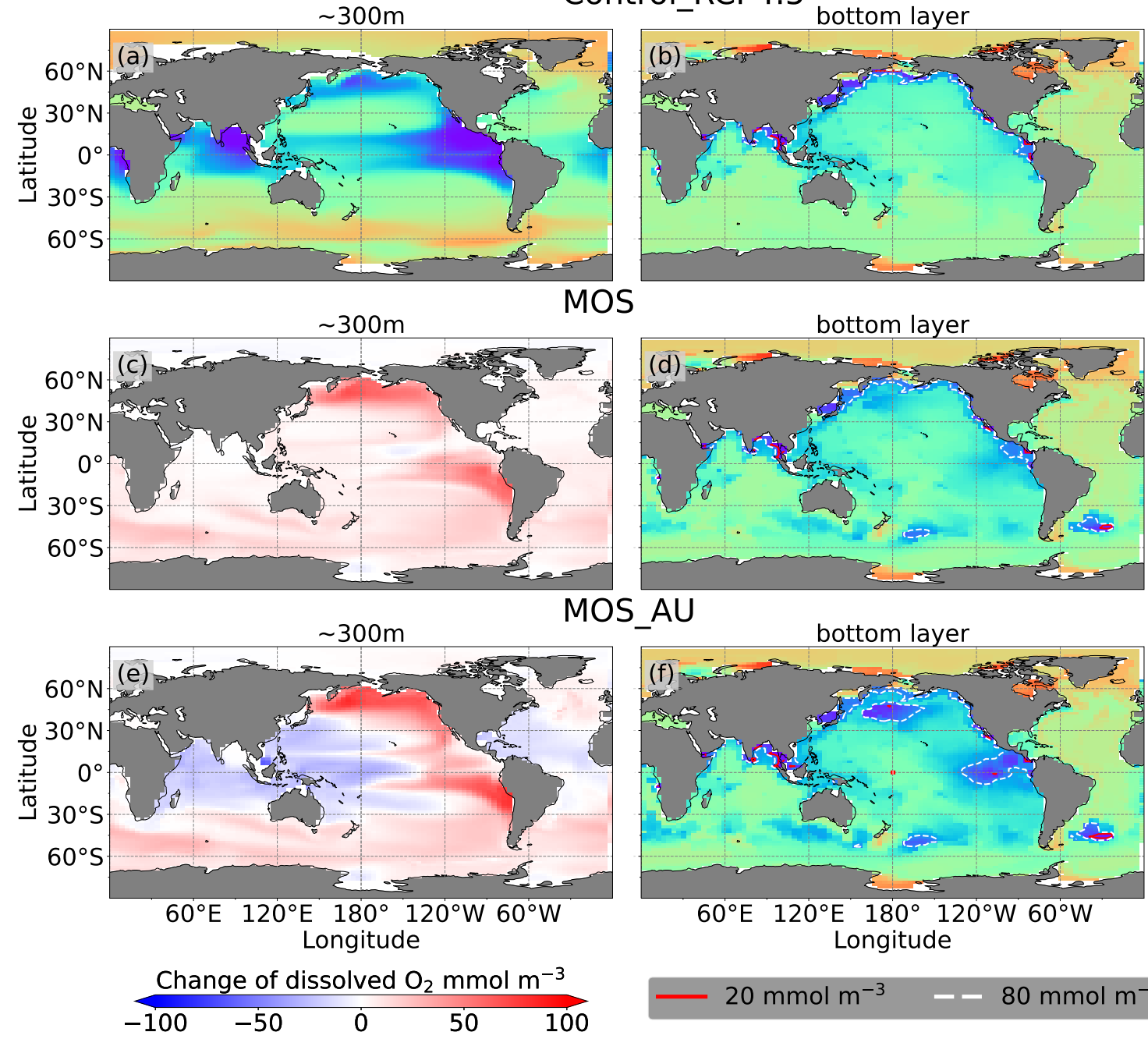

$20 \mathrm{mmol} \mathrm{m}^{-3}$

- $80 \mathrm{mmol} \mathrm{m}^{-3}$

Figure 9. Dissolved $\mathrm{O}_{2}$ concentration distribution in year 2100 at $300 \mathrm{~m}$ depth $(\mathbf{a}, \mathbf{c}, \mathbf{e})$ and the seafloor $(\mathbf{b}, \mathbf{d}, \mathbf{f})$; lines delineate boundaries of OMZs anywhere within the water column with less than $80 \mathrm{mmol} \mathrm{m}^{-3}$ oxygen (white dashed) and less than $20 \mathrm{mmol} \mathrm{m}^{-3}$ (red solid)). At 300m depth, dissolved oxygen levels are raised in MOS simulations caused by the decline in POC export (c), exception are the reduced oxygen concentrations in regions outside the MOS-AU deployment (e). On the seafloor, remineralization of sunk biomass and creates several new low-oxygen areas $(\mathbf{d}, \mathbf{f})$. 


\subsection{Long-term effects of MOS}

Here we will analyse the long-term effects of hypothetical massive MOS deployment beyond the Paris Agreement time frame on a millennial timescale.

Even after a simulated continuous millennial-scale deployment, the distribution of MOS in year 3000 is nearly identical to the one in year 2100 with only a minimal decrease in biomass (Fig.B1.b). When deployed beyond the year 2100 (MOS_Conti), MOS will continue to sequester carbon and reduce atmospheric $\mathrm{CO}_{2}$ on millennial timescales or, in our set-up, until atmospheric $\mathrm{CO}_{2}$ falls back to the pre-industrial level of 280ppm. The MOS_Conti simulation ultimately sequesters 2533 PgC and decreases atmospheric $\mathrm{CO}_{2}$ to $318.5 \mathrm{ppm} \mathrm{CO}_{2}$ by the year 3000, but never achieves the pre-industrial $\mathrm{CO}_{2}$ level. Notably, atmospheric $\mathrm{CO}_{2}$ stops decreasing by year 2780 and rebounds afterwards even though MOS continues to sequester carbon. This can be explained by a recurrent deep convection in the Southern Ocean around year 2800 that accelerates oceanic carbon leakage back to the atmosphere (Martin et al., 2013; Reith et al., 2016; Oschlies, 2021). Meanwhile, the leakage of MOS-captured carbon eventually offsets the MOS carbon sequestration (Sect.4.6).

In the sensitivity simulations MOS_Conti_NoRe and MOS_AU_Conti, atmospheric $\mathrm{CO}_{2}$ reaches $280 \mathrm{ppm}$ by the year 2820 and 2475, respectively. After reaching 280ppm, MOS is stopped and atmospheric $\mathrm{CO}_{2}$ increases again as remineralized carbon leaks out of the ocean and the surface ocean adjusts to the no MOS situation. The largest increase in $\mathrm{CO}_{2}$ is found in MOS_AU_Conti. Meanwhile, when MOS is deployed (uninterruptedly or till the $\mathrm{CO}_{2} 280$ ppm trigger), the land carbon uptake is constantly lower than the control level owing to the reduced $\mathrm{CO}_{2}$ fertilization effect. Due to the permanent storage of MOS-C in sunk biomass, rebounds of atmospheric $\mathrm{CO}_{2}$ are relatively gentle in MOS_Conti_NoRe (Fig.B10). Nevertheless, the atmospheric $\mathrm{CO}_{2}$ levels in continuous MOS simulations are significantly lower (35\% to 50\% of Control_RCP4.5) by the end of year 3000 .

The side effects of MOS also persist and often grow in magnitude with continuous deployment. Though PNPP is enhanced around MOS areas by nutrient leakage (PNPP 'halo', see Sect.4.3.4), the global reduction of surface nutrients and local canopy shading by MOS leads to continuous but gentle lowering of global PNPP after the sharp decreases in the initial 20 years (Fig.8.a2). For instance, in MOS_Conti, PNPP drops by $\sim 60 \%$ by the end of year 3000 (Tab. 5). Correspondingly, in MOS_Conti POC export eventually declines by 50\% relative to Control_RCP4.5 (Fig.8b2). In sensitivity run MOS_AU_Conti, the nutrient supply by AU, which initially maintains a higher phytoplankton biomass and NPP than in MOS without AU (Sect.4.3), declines with time as source waters of the upwelling become reduced in nutrients. Therefore, PNPP as well as the POC export levels drop after year 2200 (Fig.8.a2\&b2).

The redistribution of DIC and nutrients is intensified in the continuous simulations. As shown in Fig.6, when remineralization of MOS sunk biomass is turned on, the Pacific deep ocean and the Southern deep ocean show the highest DIC and PO enrichment by year 3000. The accumulations depend on ocean circulation (e.g., thermohaline circulation) and the distribution of MOS at the surface. In MOS_Conti_NoRe, the ocean DIC decreases globally relative to Control_RCP4.5. This results from the continuous DIC removal into biomass via MOS with no remineralization. Another cause of the declined global DIC is the 
https://doi.org/10.5194/esd-2021-104

Preprint. Discussion started: 14 January 2022

(c) Author(s) 2022. CC BY 4.0 License.

(c) (1)

\section{Earth System \\ Dynamics}

Discussions

declining downward POC flux owing to the PNPP reduction caused by the declining nutrient levels in the surface layer (see Sect.4.3.4).

$\mathrm{NO}_{3}$ enrichment in the deep ocean is considerably smaller than that of DIC and $\mathrm{PO}_{4}$, because of enhanced denitrification in the developing benthic OMZs (Sect.4.3.5, Fig.B2). In the zero remineralization situations, deep ocean $\mathrm{PO}_{4}$ and $\mathrm{NO}_{3}$ concentrations decrease compared to the control levels, due to the reduced remineralization of POM resulting from the weakened downward flux of POM.

As shown in Fig.10 and the $\mathrm{O}_{2}$ yr3000 panel of Fig.6, dissolved oxygen concentrations at mid depth (e.g. 300m) increased during millennial MOS deployment due to reduced PNPP and associated downward flux and remineralization of POM in the water column. In benthic waters, regions with very low dissolved oxygen are shown in Fig.10.f\&j in the Pacific and Southern Ocean. In contrast, increased oxygen concentrations are found in MOS_Conti_NoRe (Fig.10.h), especially in the Atlantic, the Indian and the Southern Ocean. Besides the absence of oxygen consumption by macroalgal biomass remineralization, another reason for these observable oxygen increases lies in the reduction of POC downward flux described in Sect. 4.3.4. 

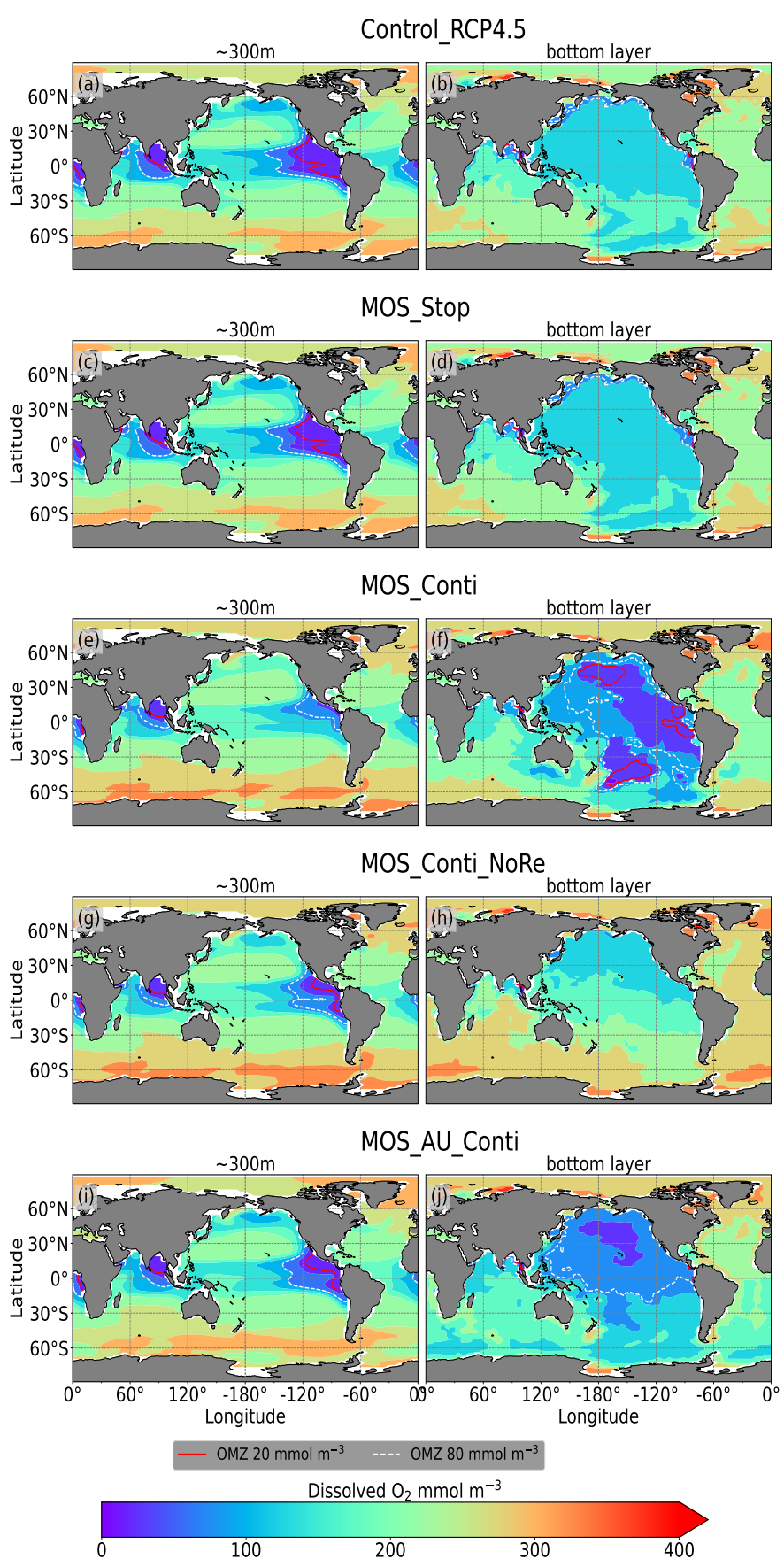

Figure 10. Dissolved $\mathrm{O}_{2}$ concentrations at depth $\sim 300 \mathrm{~m}$ (left panel) and the ocean bottom (right panel) in year 3000: contour lines indicate boundaries of OMZs with less than $80 \mathrm{mmol} \mathrm{m}^{-3}$ oxygen (white dashed) and less than $20 \mathrm{mmol} \mathrm{m}^{-3}$ (red solid). Continuous MOS deployment further shrinks the OMZ at 300m depth (e,g,i) but expands them at bottom (f,j) except for the zero remineralization one in $(\mathrm{h})$. 


\subsection{Termination effects}

After termination of MOS_Stop in year 2100, the atmospheric $\mathrm{CO}_{2}$ concentrations and SAT both rise, but generally remain lower than those of the Control_RCP4.5 simulation (Fig.4.b,d). More than half (FR ranges from 58.6\% to 64.4\%, Tab.5, calculated by Eq. 23) of MOS-captured carbon is still stored in the ocean by the end of year 3000. As shown in Fig.4.b,d, in the termination simulations MOS_Stop and MOS_AU_Stop $\mathrm{CO}_{2}$ concentration and SAT gradually converge against the Control_RCP4.5 run as a result of DIC from remineralized macroalgal biomass being transported to the ocean surface and into the atmosphere (see subsequent Sect.4.6). By year 3000, the atmospheric $\mathrm{CO}_{2}$ in $\mathrm{MOS}_{-}$Stop is only $28.5 \mathrm{PgC}$ less than in Control_RCP4.5, while $\triangle \mathrm{SAT}$ slightly rebounds from $-0.38^{\circ} \mathrm{C}$ to $-0.23^{\circ} \mathrm{C}$. In MOS_AU_Stop, the differences of $\mathrm{pCO}_{2}$ and $\triangle \mathrm{SAT}$ are smaller than the normal MOS, as AU has augmented MOS carbon sequestration and $64.4 \%$ of it is retain in the ocean. As expected, the idealized non-remineralization condition (MOS_Stop_NoRe) is able to permanently store the sequestered carbon, thus the rebounds of $\mathrm{CO}_{2}$ and $\triangle \mathrm{SAT}$ are less than the normal MOS_Stop.

In all MOS termination simulations, PNPP and POC export rebound abruptly following the cessation of MOS, but sharply drop over the subsequent decades (Fig.7.a1). The sharp increase in PNPP and POC export results from the sudden absence of macroalgae as a main competitor for nutrients and light. The subsequent decline in PNPP and POC export results from consumption of the surface nutrients and the lack of subsurface nutrients that has previously been exported directly to the seafloor with sinking of macroalgae biomass (Fig.B6). Afterwards, PNPP recovers gradually due to the slow returning of remineralized nutrients to the upper ocean. By the year 3000, PNPP in MOS_Stop recovers to 97\% of the control level (Tab. 5), with the only differences attributable to the slightly different climate state. In the MOS_NoRe simulation, the PNPP recovery is slower due to the permanent nutrient removal from the upper water column. In the MOS_AU_Stop simulation PNPP rebounds to higher levels than the normal MOS, but drops to lower levels afterwards. The amplified oscillation of PNPP results from the simultaneous termination of AU and MOS: When MOS_AU_Stop is suddenly terminated, the canopy shading and nutrient competition by MOS are removed. Meanwhile, the surplus of nutrients from AU still remains. This boosts PNPP rapidly. However, once these nutrients are consumed, the natural nutrient supply to surface waters is insufficient to maintain the high PNPP.

After the termination of MOS, the rate of oceanic carbon uptake falls abruptly (Fig. B10). After a short peak caused by the abrupt rebound of PNPP, it remains slightly lower than the control level due to the declined PNPP rates and lower atmospheric $\mathrm{CO}_{2}$ levels. Oppositely, the MOS-induced reduction in terrestrial carbon uptake starts to rebound after MOS cessation (Fig.B9) due to the rise of atmospheric $\mathrm{CO}_{2}$, which tend to enhance the terrestrial photosynthesis.

When MOS deployment is stopped, the elevated (compared to Control_RCP4.5) dissolved oxygen concentrations at mid depth generally decline as the downward POC flux recovers $\left(\mathrm{O}_{2}\right.$ yr3000 panel in Fig.6). The lowered oxygen concentrations in the deep ocean are also reversible after cessation of MOS. For instance, by year 3000, the benthic dissolved oxygen of MOS_Stop (Fig.9.d) is similar to Control_RCP4.5 (Fig.9.b). 


\subsection{Leakage of MOS Sequestered Carbon}

The leakage of MOS sequestered carbon (MOS-C) occurs mostly in the Southern Ocean (Fig.11, Fig.B4). The explanation lies in the dynamics of Southern Ocean upwelling, where Pacific Deep Water (PDW), Indian Deep Water (IDW) and Antarctic Deep Water (AADW), laden with DIC of remineralized MOS biomass, reach the subantarctic ocean surface (Talley, 2013; Weber and Bianchi, 2020; Anderson and Peters, 2016). Moreover, the recurrent deep convection (see Sect.4.4) in the Southern Ocean around year 2600 accelerates the carbon leakage, which can be observed in Fig.11 as an enhanced outgassing around year 2600 .

The outgassing of MOS-C in discontinuous simulations (e.g. MOS_Stop) starts since year 2100, while the continuous ones starts since year 2300 (Fig.11). Thus, by the end of the 21st century, nearly the entire MOS-C in all MOS simulations is retained in the ocean. However, by the year 3000, even in the continuous MOS simulation, only about $75 \%$ of MOS-C remains in the ocean, while the accelerated vertical water transport by AU slightly reduces this portion to 73\%. In run MOS_Stop 59\% of MOS-C remains in the the ocean by year 3000, whereas the additional sunk macroalgal biomass in MOS_AU_Stop results in more MOS-C (64\%) being retained (Tab.5). When sunk biomass is free from remineralization (NoRE runs), the contained carbon is permanently isolated from the atmosphere and stored in the ocean.

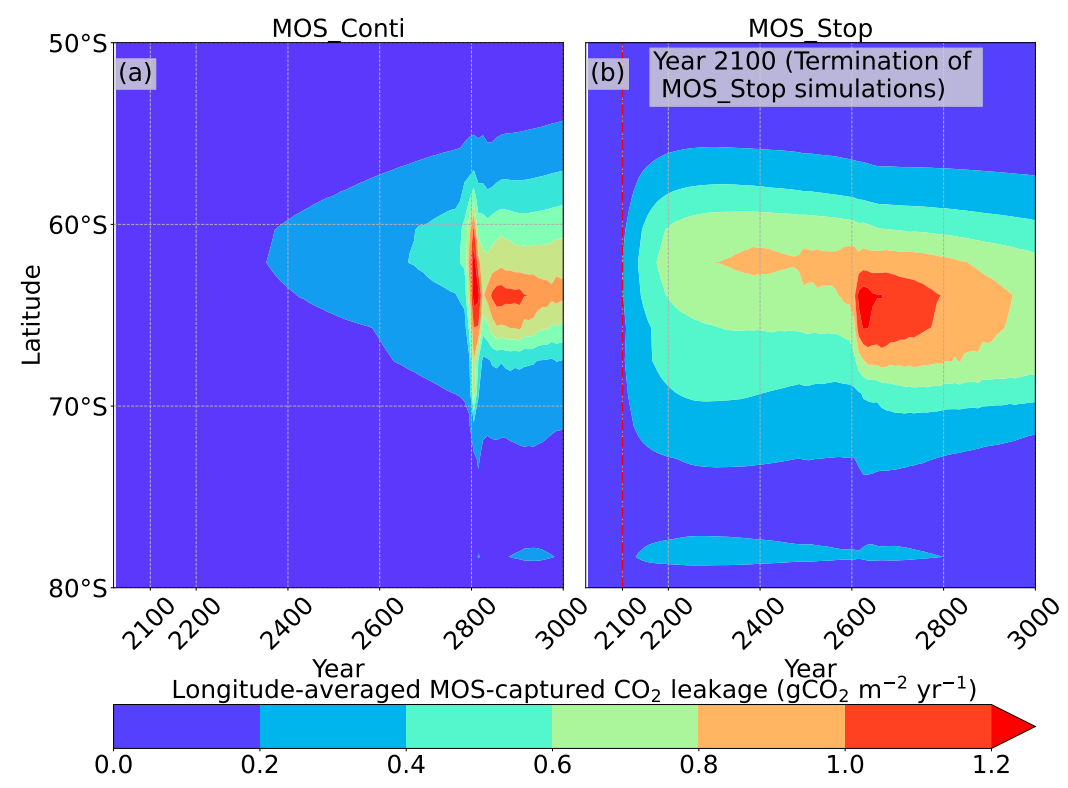

Figure 11. Longitude averaged MOS-captured carbon outgassing in the simulation (a) MOS_Conti and (b) MOS_Stop. When conveyed back to the surface, the DIC from MOS remineralization participates the air-sea exchange (Sect. 2.2.5). MOS-C outgassing starts in year 2100 when MOS is terminated (a), or after year 2300 when continuously deployed. The outgassing mainly happens in the Southern Ocean. The outgassing is strengthened around year 2800 when a Southern Ocean deep convection event accelerates the upwelling of deep waters with high concentrations of remineralized DIC (Sect. 4.4. 


\section{Concluding discussions}

515 In this study we have tested the potential of the 'macroalgae open-ocean mariculture and sinking (MOS)' as a carbon dioxide removal method. Although environmental conditions (e.g. nutrients, temperature, etc.) in the open oceans differ considerably from the coastal/near-shore regions where macroalgae aquaculture is currently applied in reality, our simulations suggest that in certain open ocean regions macroalgae may successfully grow and sequester carbon (if engineering constraints can be overcome). Even for continuous deployment at a maximum scale currently deemed possible, MOS alone is not able to reduce the warming to the $2{ }^{\circ} \mathrm{C}$ target by the end of the 21 st Century under the RCP4.5 moderate mitigation scenario. This finding is consistent with conclusions from previous studies that no single carbon dioxide removal method alone can ensure reaching the current climate goals (Keller et al., 2014; Anderson and Peters, 2016; Fuss et al., 2020; IPCC, 2018).

In order to estimate the maximum $\mathrm{CO}_{2}$ removal potential, the possible synergy of MOS with artificial upwelling (AU) has been investigated. The employed AU concept aims at piping nutrient-rich deep water to the surface to enhance the growth of macroalgae in MOS. As expected, AU is found to have the potential to successfully enlarge the growing area of MOS and enhance the CDR capacity of MOS.

In the first 80 years of deployment, the maximum MOS carbon sequestration potential is $3.38 \mathrm{PgC} / \mathrm{yr}$ for regular MOS, but can be boosted up to $5.56 \mathrm{PgC} / \mathrm{yr}$ with assistance from $\mathrm{AU}$. If deployment is discontinued from year 2100 , about $58.6 \%$ to $70.2 \%$ (normal MOS and MOS_AU, respectively) of MOS sequestered carbon would be retained in the ocean by year 3000.

Several potential side effects have also been revealed and analysed. One side effect is the reduction in phytoplankton NPP due to canopy shading and nutrient removal from the sea surface to the bottom by MOS. The declined PNPP in turn offsets $\sim 37 \%$ of the MOS CDR. Intriguingly, some areas with enhanced PNPP (PNPP 'halo', Sect.4.3.4) are found surrounding the major areas occupied by MOS, fueled by the residual $\mathrm{NO}_{3}$ that leaks from MOS areas.

Another strong side effect of large-scaled MOS is the impact on oxygen distributions. Dissolved oxygen concentrations increase in near-surface and intermediate waters, as MOS reduces the downward flux of plankton-derived organic matter by restraining the surface PNPP. On the other hand, the massive amount of sunk biomass from MOS at the ocean bottom and its subsequent remineralization consumes oxygen and can create large benthic OMZs.

An uncertain factor is the fate of the sunk biomass. It will affect the benthic fauna by depositing large amounts of organic matter as well as expanding low oxygen regions on the sea floor upon oxygen consumption by remineralization. Therefore, we performed additional sensitivity simulations focusing on the macroalgal biomass remineralization rate. When macroalgal biomass does not undergo microbial remineralization, the captured $\mathrm{CO}_{2}$ can be permanently stored without leakage. This increases the CDR potential of MOS. The benthic OMZs created by remineralization of sunk biomass would also be avoided, while the shrinking of intermediate water OMZs persists. However, other side effects can not be neglected: in zero remineralization simulations, the constant removal of nutrients in the surface will impede the recovery of PNPP. This may eventually affect the marine surface ecology and ocean services such as food provision.

The impacts of MOS on oxygen distributions may also influence the oceanic sources of $\mathrm{N}_{2} \mathrm{O}$, an atmospheric GHG gas and a major ozone-depleting compound (Ravishankara et al., 2009). The increased/decreased oxygen levels in the mid/bottom layers 
impacts denitrification, and may weaken the $\mathrm{N}_{2} \mathrm{O}$ sources in the subsurface but increases those in the deep waters (Bange et al., 2019).

Moreover, attention should also be paid to the calcification by calcareous macroalgae (if cultivated) and/or associated epibionts that grow on macroalgae. Bach et al. (2021) have suggested that epibionts living on Sargassum offsets $16.5 \%$ of the POC fixed by Sargassum and therefore decrease its natural carbon sequestration potential if the biomass was intentionally sunk for CDR purposes. These calcification rates and the response to ocean acidification of macroalgae are also speciesspecific Koch et al. (2013). These factors need to be investigated with further research if macroalgae are to be considered for ocean-based CDR, e.g. ocean afforestation (N'Yeurt et al., 2012; Bach et al., 2021).

A side effect not investigated here is the production and emission of halocarbons from macroalgae farms. Macroalgae species have been reported to generate halocarbons in polar, temperate and tropical coastal regions with a highest producing rate of 6000 pmol $\mathrm{CHBr}_{3} \mathrm{gFW}^{-1} \mathrm{~h}^{-1}$ (Leedham et al., 2013; Baker et al., 2001; Carpenter and Liss, 2000; Latumus, 1995). These volatile low molecular-weight halocarbon compounds (e.g. $\mathrm{CH}_{3} \mathrm{I}, \mathrm{CHBr}_{3}$ and $\mathrm{CHCl}_{3}$ ) are potent greenhouse gases (Meinshausen et al., 2011). They also influence stratospheric ozone destruction when transported by deep atmospheric convection into the stratosphere (Ziska et al., 2013; Tegtmeier et al., 2012, 2013), therefore enhancing radiative forcing (Ramaswamy et al., 1992; Daniel et al., 1995). Large-scale MOS cultivation might release a significant quantity of halocarbons. Further studies are needed to investigate possible effects of halocarbon emissions from large-scaled macroalgae cultivation.

Besides the CDR effect of MOS, in case of large scale deployment, the macroalgae farms are likely to increase the albedo of the oceans's surface, especially when they occur near the sea surface (Fogarty et al., 2018; Bach et al., 2021). Meanwhile, we have not considered possible hydrodynamic impacts on ocean circulation, as the thick macroalgae layers and the farming infrastructures may influence the momentum and mixing of the ambient flow fields (Liu and Huguenard, 2020; Nepf, 2012; Thomas and McLelland, 2015).

The MOS model analysis presented here clearly has some limitations, that future studies might improve on. One of the most critical issues is to improve the realism of the model design by including more representative macroalgae species for various regions. Another aspect is the consideration of dynamic cellular stoichiometry of macroalgae. With a better simulation of the cellular quota, we could improve our understanding of the relation of nutrient and carbon fluxes between MOS and the environment. Explicit consideration of the variable morphology of the macroalgae, as well as of the impacts of currents on frond erosion (Broch and Slagstad, 2012) would also improve the representation of macroalgae loss rates in the model. Further optimization of deployment timing and location for MOS are achievable by evaluating data from field tests or implementations of macroalgae mariculture in the open oceans. Another aspect that needs improvement is the modeling of benthic macroalgal biomass remineralization. Here we treated macroalgal biomass homogeneously as particulate organic matter. Though the degradation of macroalgal fragments under deep sea conditions (e.g. low temperature and unique microbial colonies) remains unclear, it might be different from POC in terms of remineralization rate and oxygen consumption. Tracking of macroalgae sequestered carbon will be required to record its fate and possible carbon leakage after sinking (e.g. by an eDNA method to trace macroalgae carbon in marine sediments by D'Auriac et al. (2021)). The economic perspectives of developing and deploying MOS also needs to be investigated. Furthermore, more research on how large-scale macroalgae mariculture will impact human 
https://doi.org/10.5194/esd-2021-104

Preprint. Discussion started: 14 January 2022

(c) Author(s) 2022. CC BY 4.0 License.

(c) (1)

Earth System

Dynamics

Discussions

activities (e.g., ocean shipping, fisheries) needs to be undertaken. Associated legal and political issues regarding the usage of international waters for MOS deployment should be considered as well.

585 Overall, this study adds to the rapidly expanding field of considering macroalgae cultivation for $\mathrm{CO}_{2}$ removal. The evidence from this study suggests that macroalgae mariculture\&sinking has a considerable CDR potential but brings about substantial side effects on marine ecosystems, and marine biogeochemistry. Given this, the concept requires further research with less idealized experimental settings to determine if its CDR benefits outweigh the side effects (Dean et al., 2021).

\section{Model codes and data availability}

590 The model codes and simulation data are available upon request and will be available online with final publication.

\section{Author contribution}

J.W., D.P.K. and A.O. conceived and designed the experiments. J.W. implemented and performed the experiments and analyzed the data. J.W. wrote the manuscript with contributions from D.P.K. and A.O.

\section{Competing interests}

595 The authors declare that they have no conflict of interests.

\section{Acknowledgements}

D.P.K. and A.O. have been supported by the European Union's Horizon 2020 research and innovation program under grant agreement numbers 869357 (OceanNETs) and 820989 (COMFORT). J.W. has been supported by the China Scholarship Council. We thank Wolfgang Koeve, Nadine Mengis, Karin Kvale and Fabian Reith for helpful discussions. 
https://doi.org/10.5194/esd-2021-104

Preprint. Discussion started: 14 January 2022

(C) Author(s) 2022. CC BY 4.0 License.

(c) (i)
Earth System

Dynamics

Discussions

\section{Appendix A: MOS validations}

\section{A1 MOS yield calculation}

For the convenience of calculation, we assume that when MOS occupies a surface grid cell the area is covered by parallel cultivation ropes (lines) with an interval distance of $d$ (see table $1 \&$ Fig.A 1$)$. The total length of cultivation lines $\left(\mathrm{L}_{M O S}\right.$, in meters) of MOS in the grid cell is then:

$L_{M O S}=S_{M O S} \div d$

where $\mathrm{S}_{M O S}\left(\mathrm{~m}^{-2}\right)$ is the area of ocean surface occupied by MOS. Accordingly, the conversion between macroalgal biomass

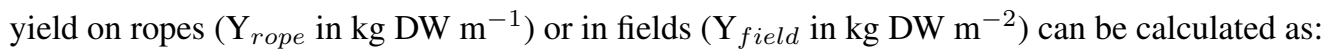

$Y_{\text {rope }}=Y_{\text {field }} \times d$

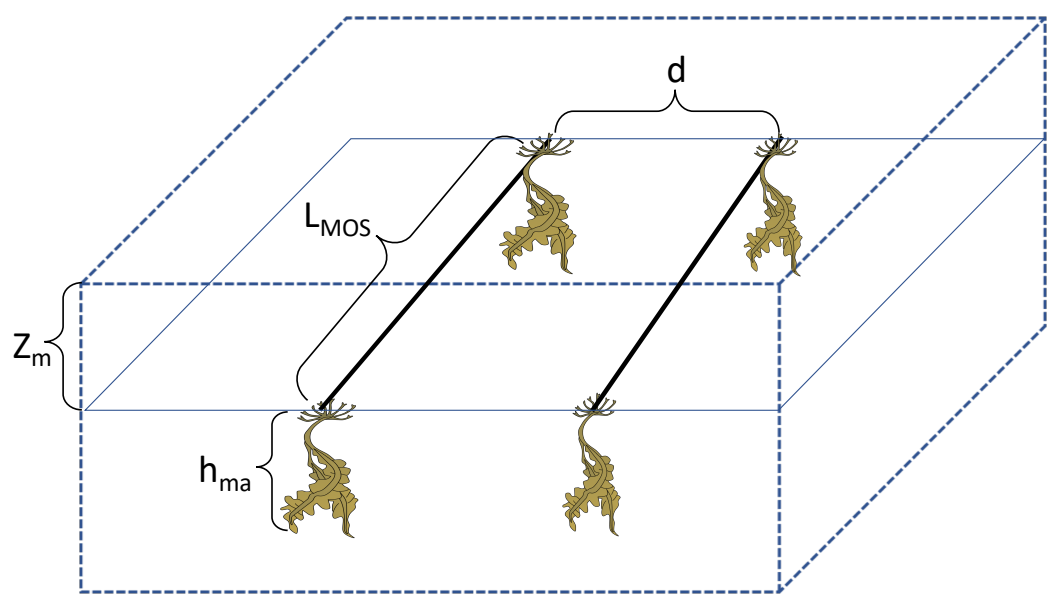

Figure A1. Sketch of key features of MOS. 


\section{A2 MOS NPP}

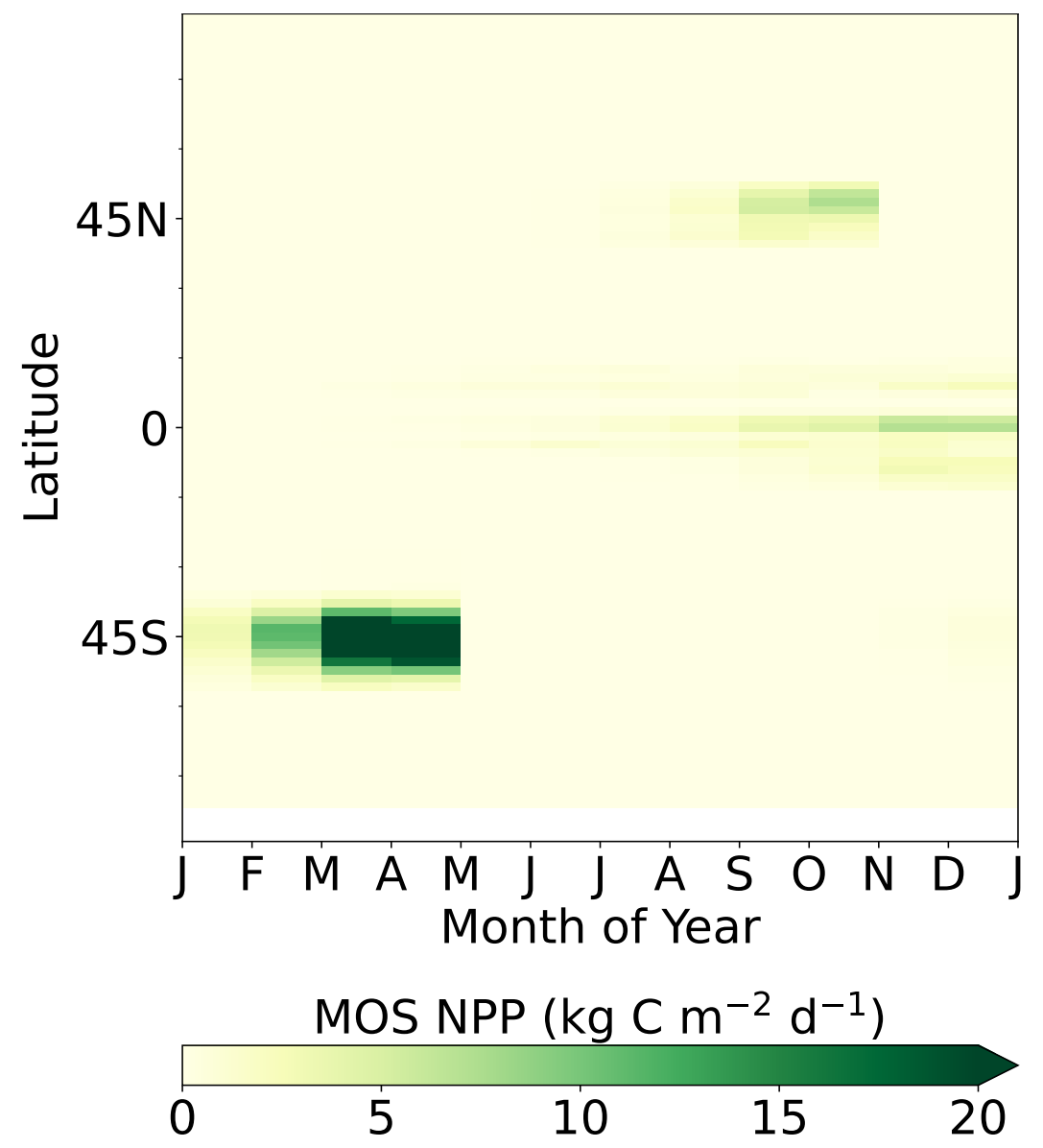

Figure A2. Hovemoeller plot of latitudally and vertically integrated MOS NPP. High NPP are found in the Southern Ocean. The change of MOS NPP follows the seasonal solar radiation in UVic ESCM. 

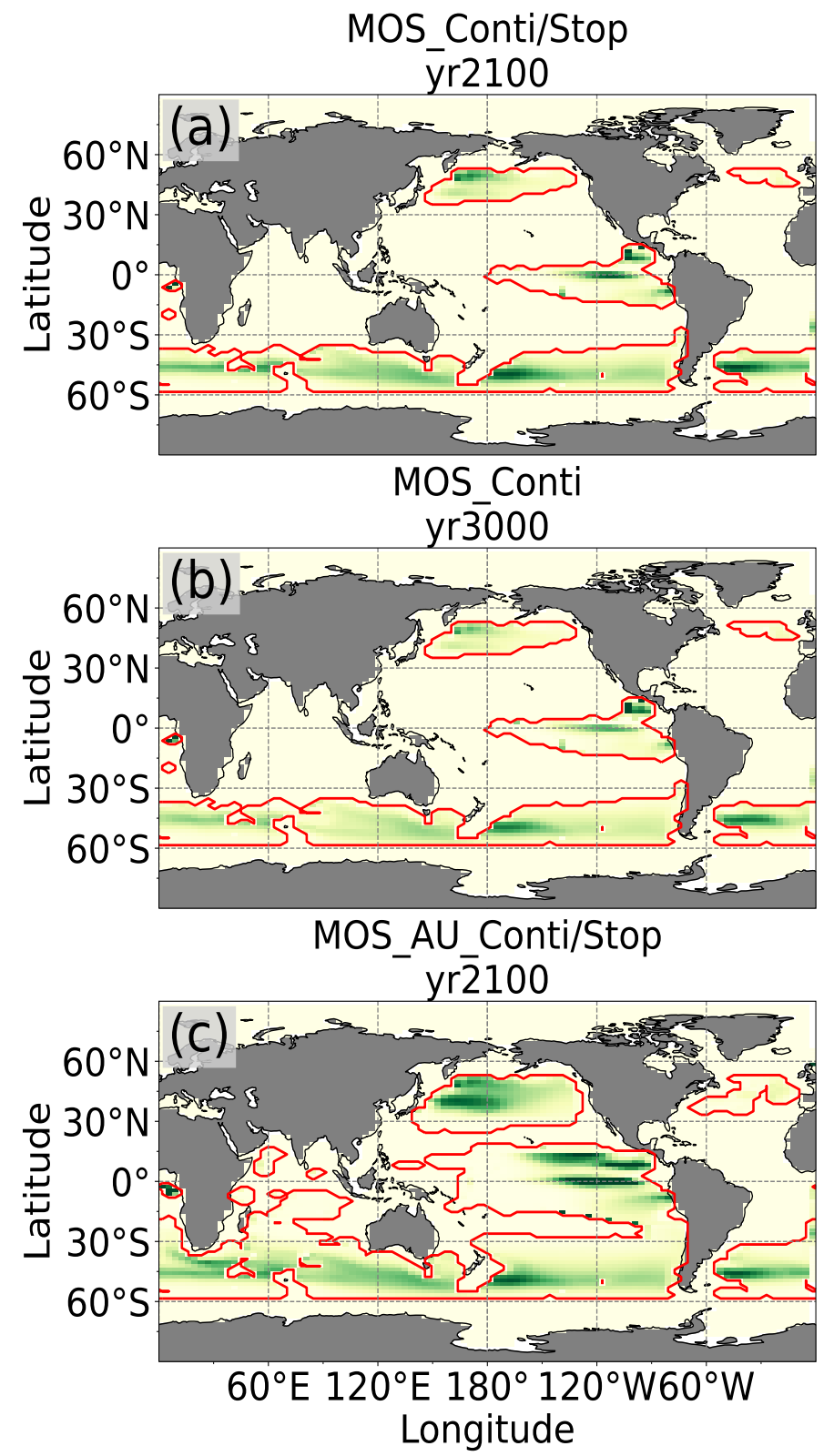

MOS biomass (kg wet weight $\mathrm{m}^{-2}$ )
\begin{tabular}{|llllll}
\hline & & & & & 10 \\
0 & 2 & 4 & 6 & 8 & 10
\end{tabular}

Figure B1. MOS biomass distributions. Red lines contour the maximum MOS occupied area during the previous years. 


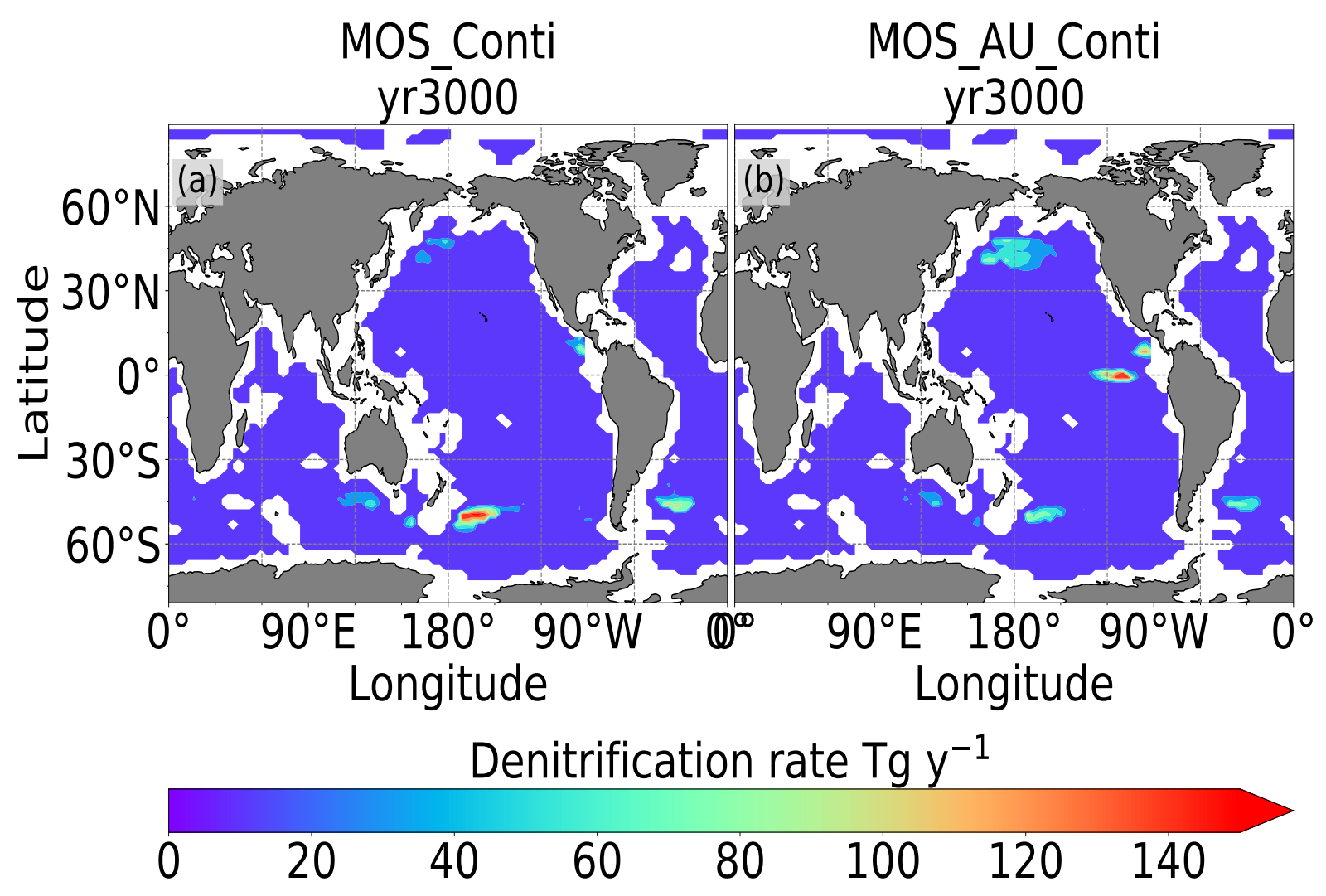

Figure B2. Denitrification rate at depth 3000-6000m in year 3000, where the oxygen level is lower than $5 \mu$ mol m=3 caused by the remineralization of continuously sunk MOS biomass. 


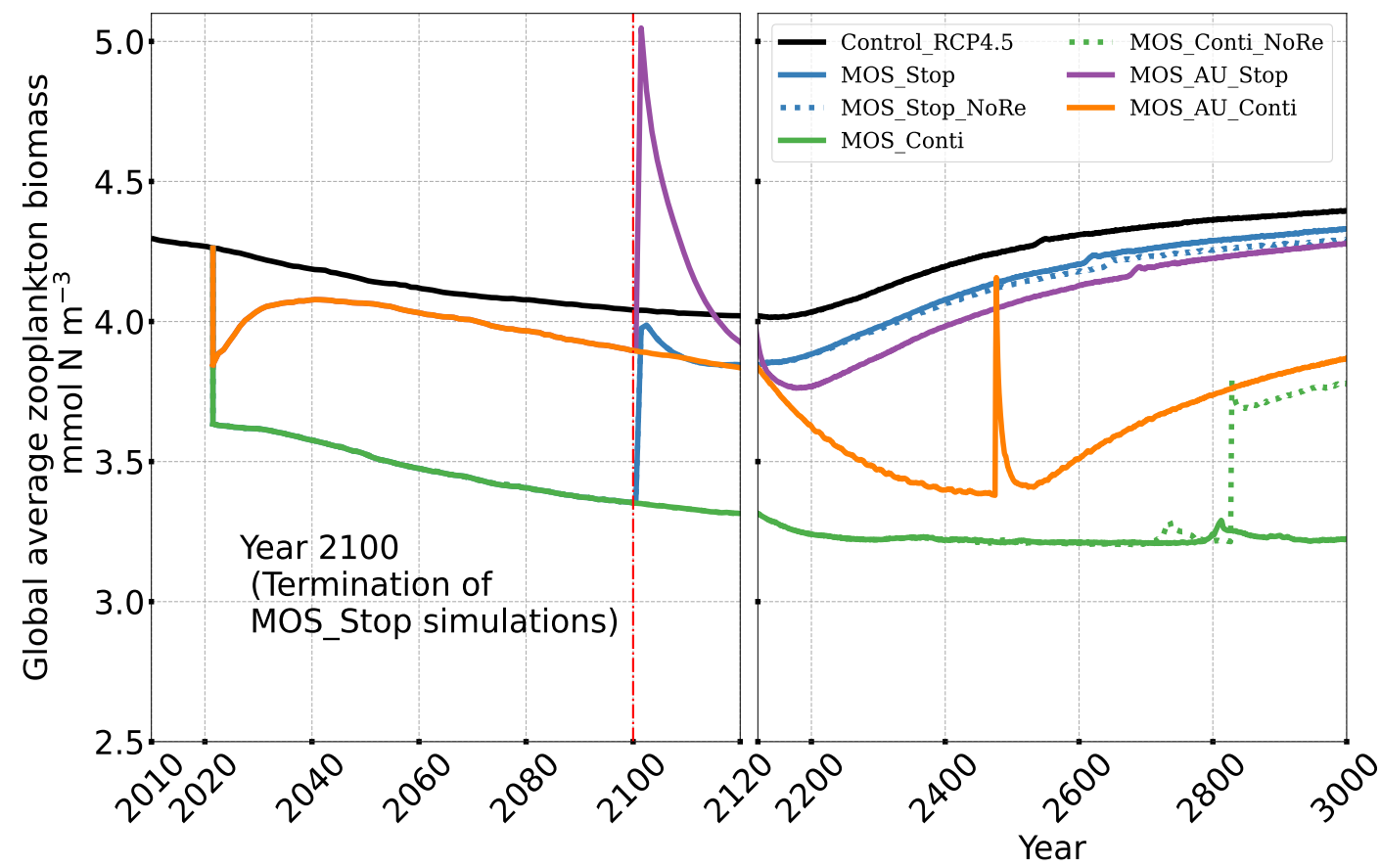

Figure B3. Plot of global averaged biomass of zooplankton 


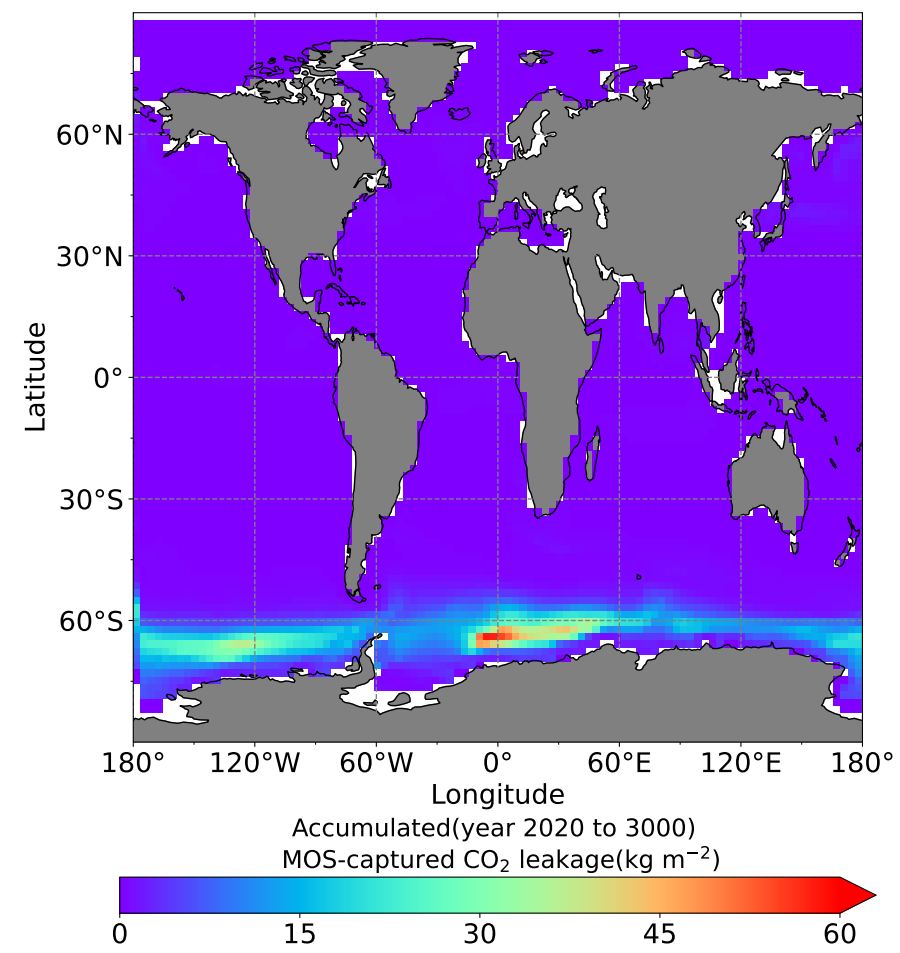

Figure B4. Cumulative (year 2020 to 3000) leakage of MOS-captured carbon in the simulation MOS_Stop. 


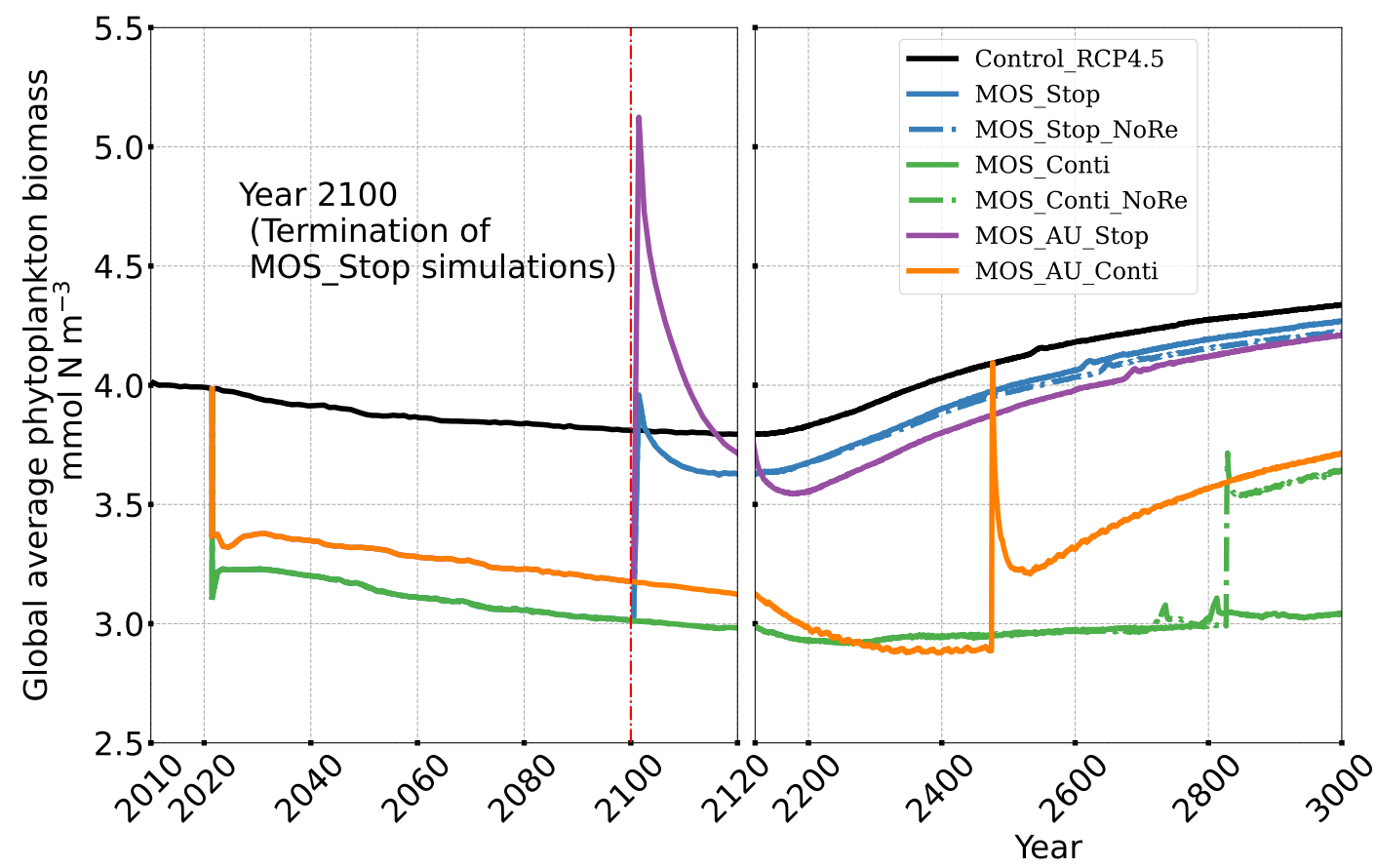

Figure B5. Plot of global averaged phytoplankton biomass

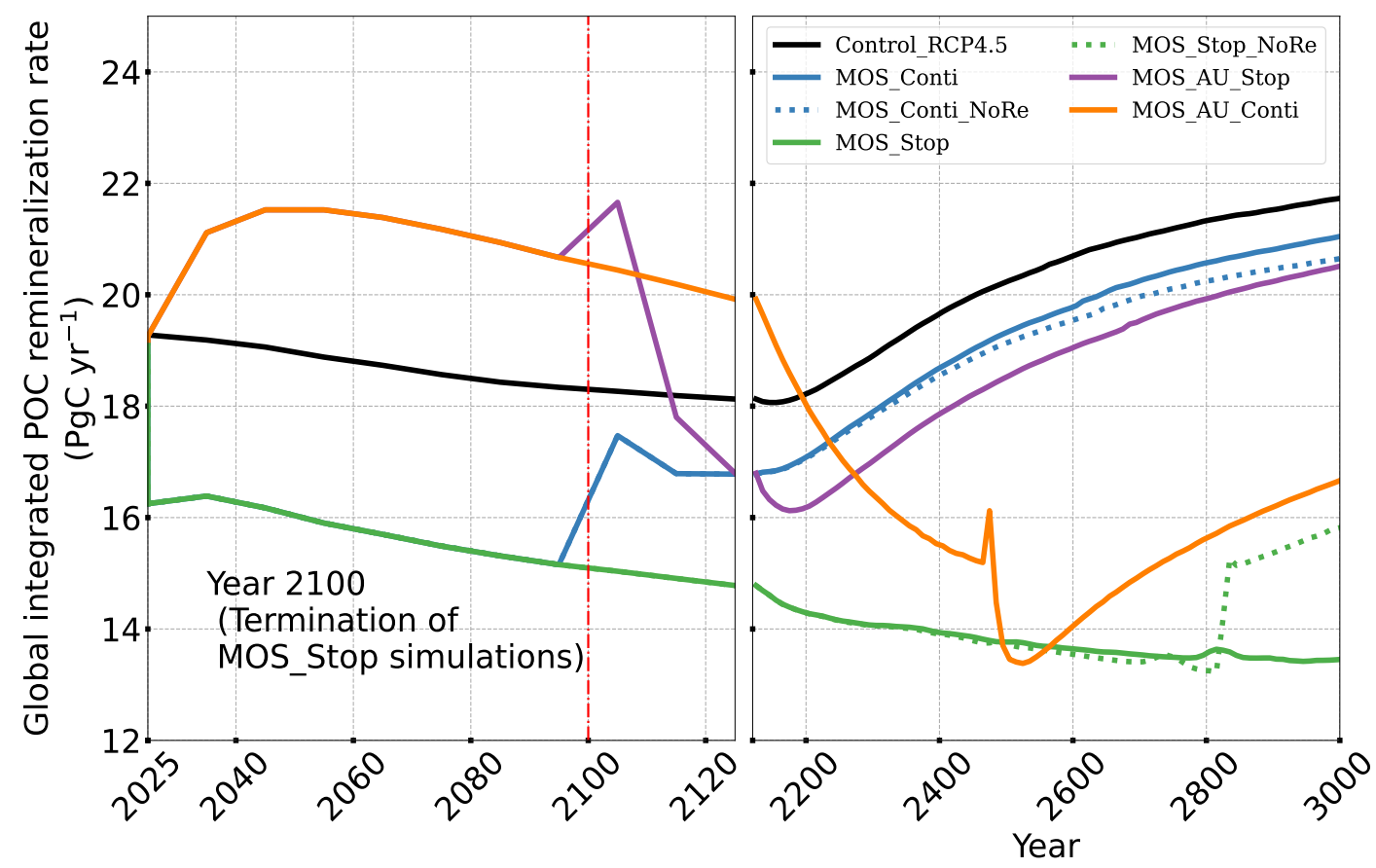

Figure B6. Plot of 0-2km averaged detritus remineralization rate 
https://doi.org/10.5194/esd-2021-104

Preprint. Discussion started: 14 January 2022

(c) Author(s) 2022. CC BY 4.0 License.

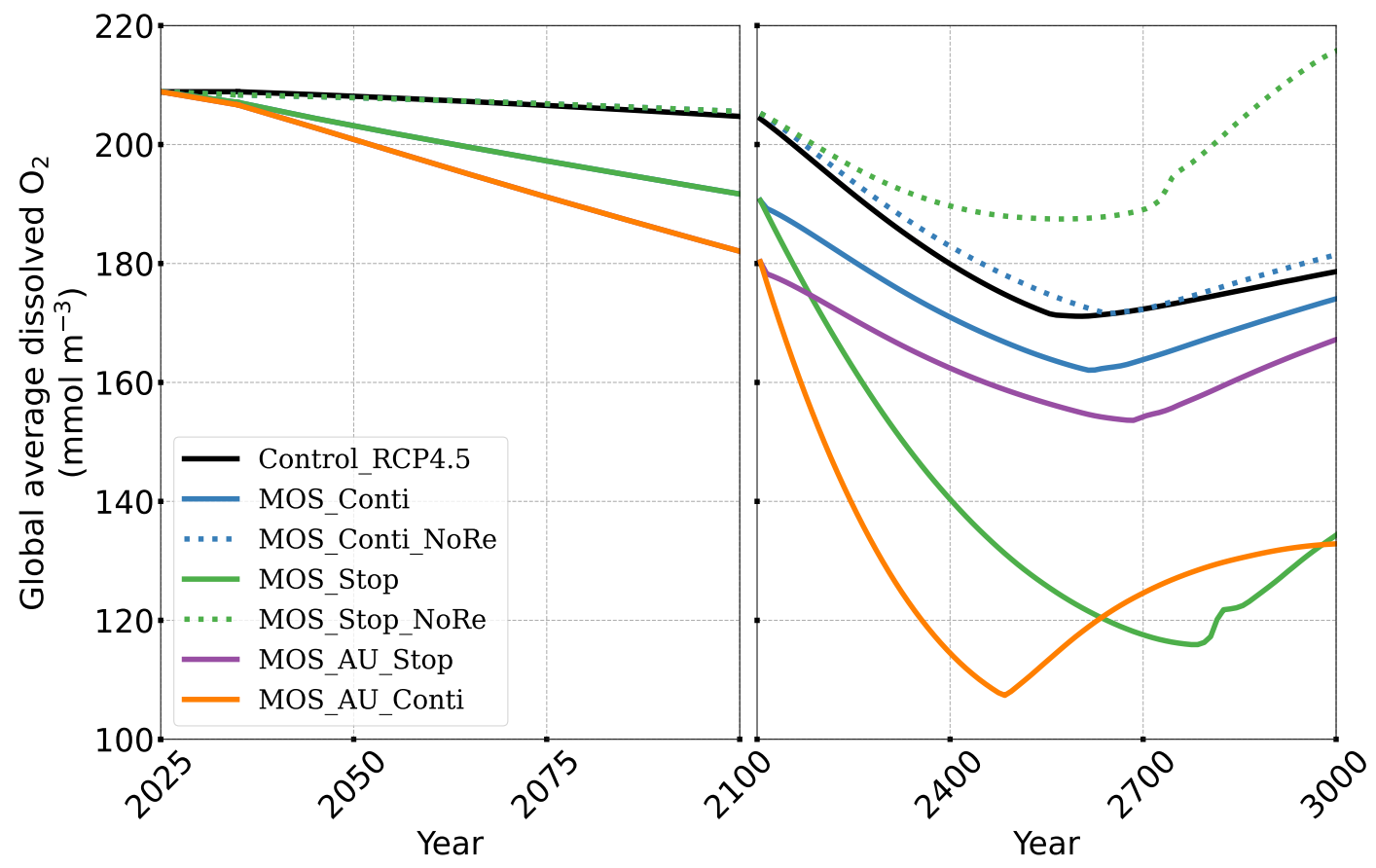

Figure B7. 3-6km averaged dissolved oxygen concentrations 

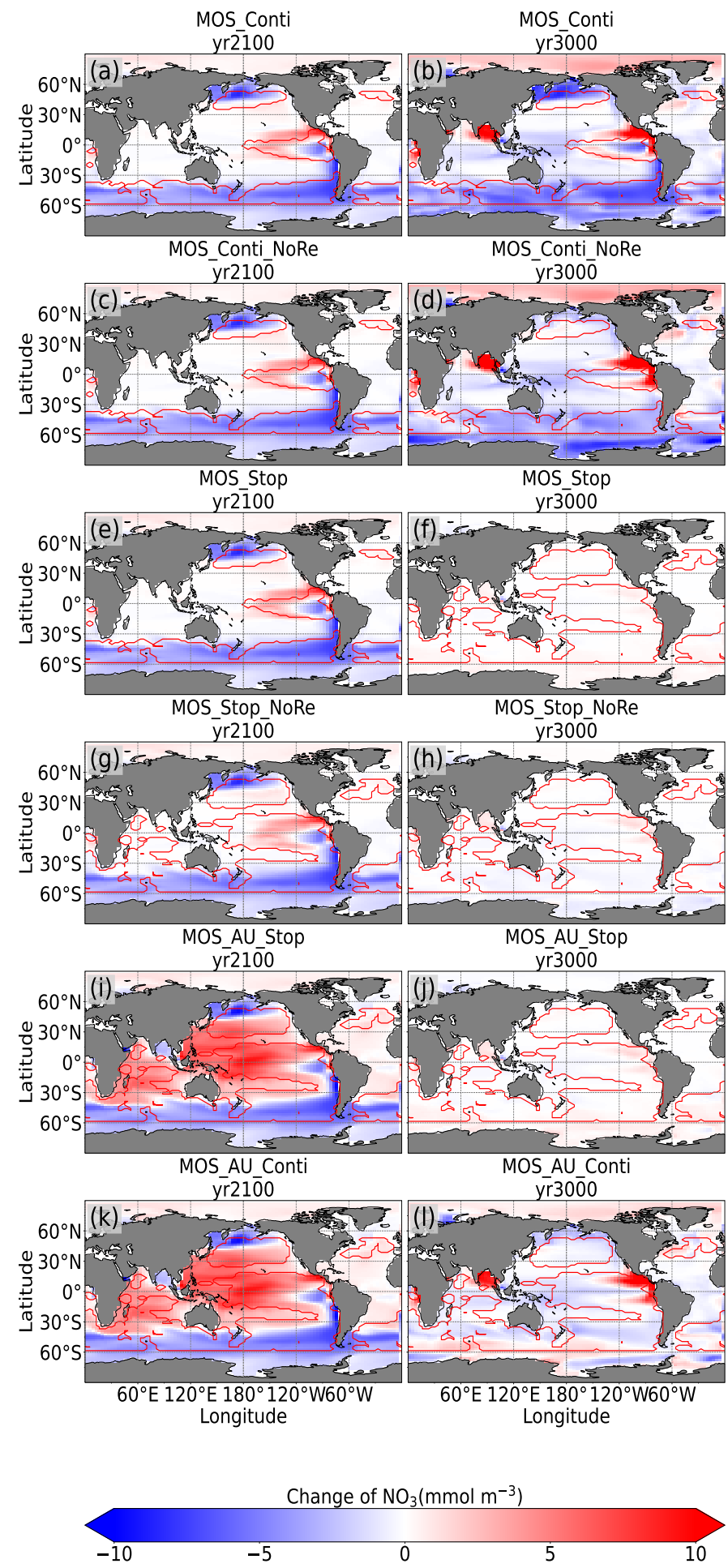

Figure B8. Redistributions of $\mathrm{NO}_{3}$ avg. 0-200m depth relative to RCP4.5 


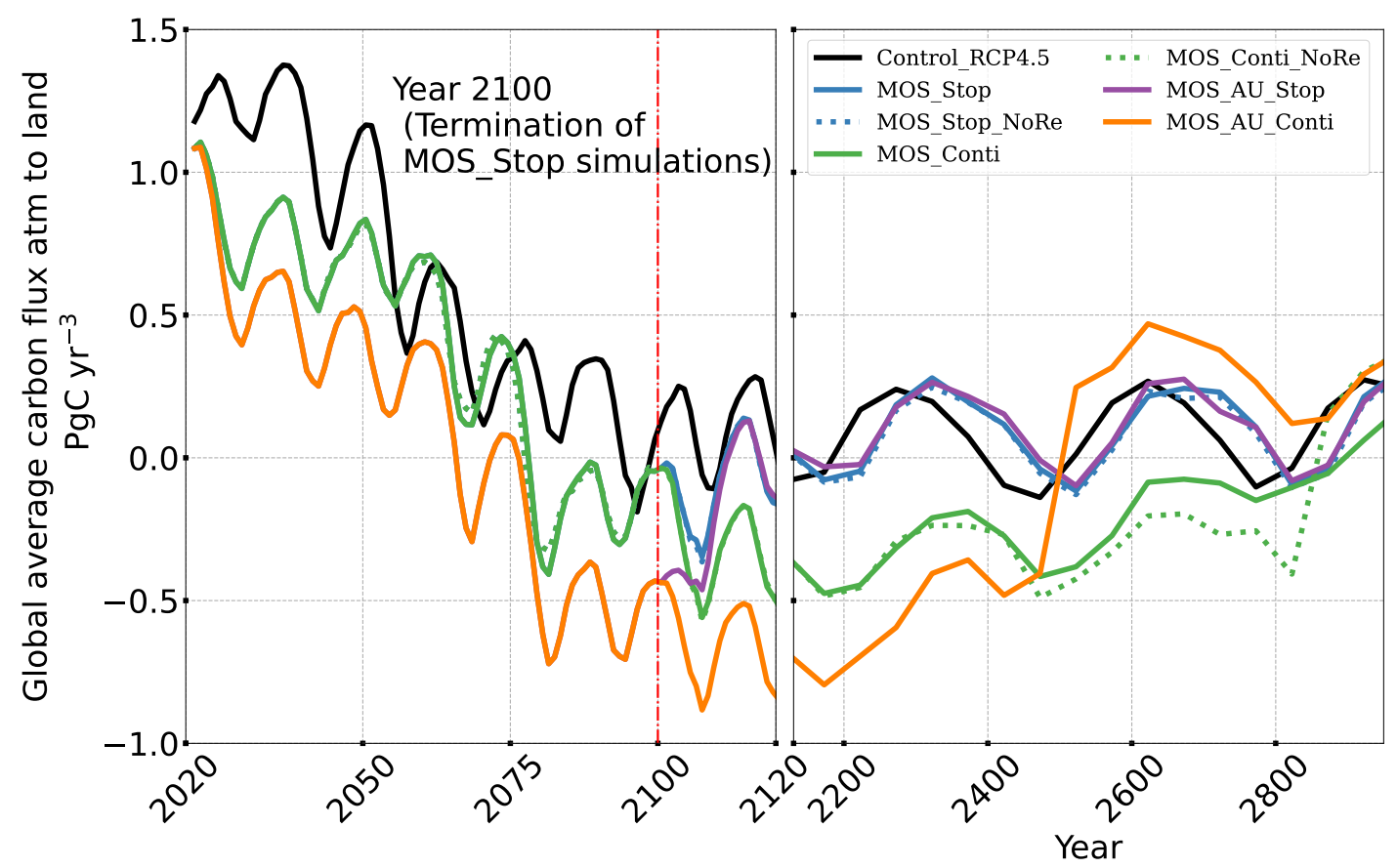

Figure B9. Global averaged carbon flux from atmosphere to land

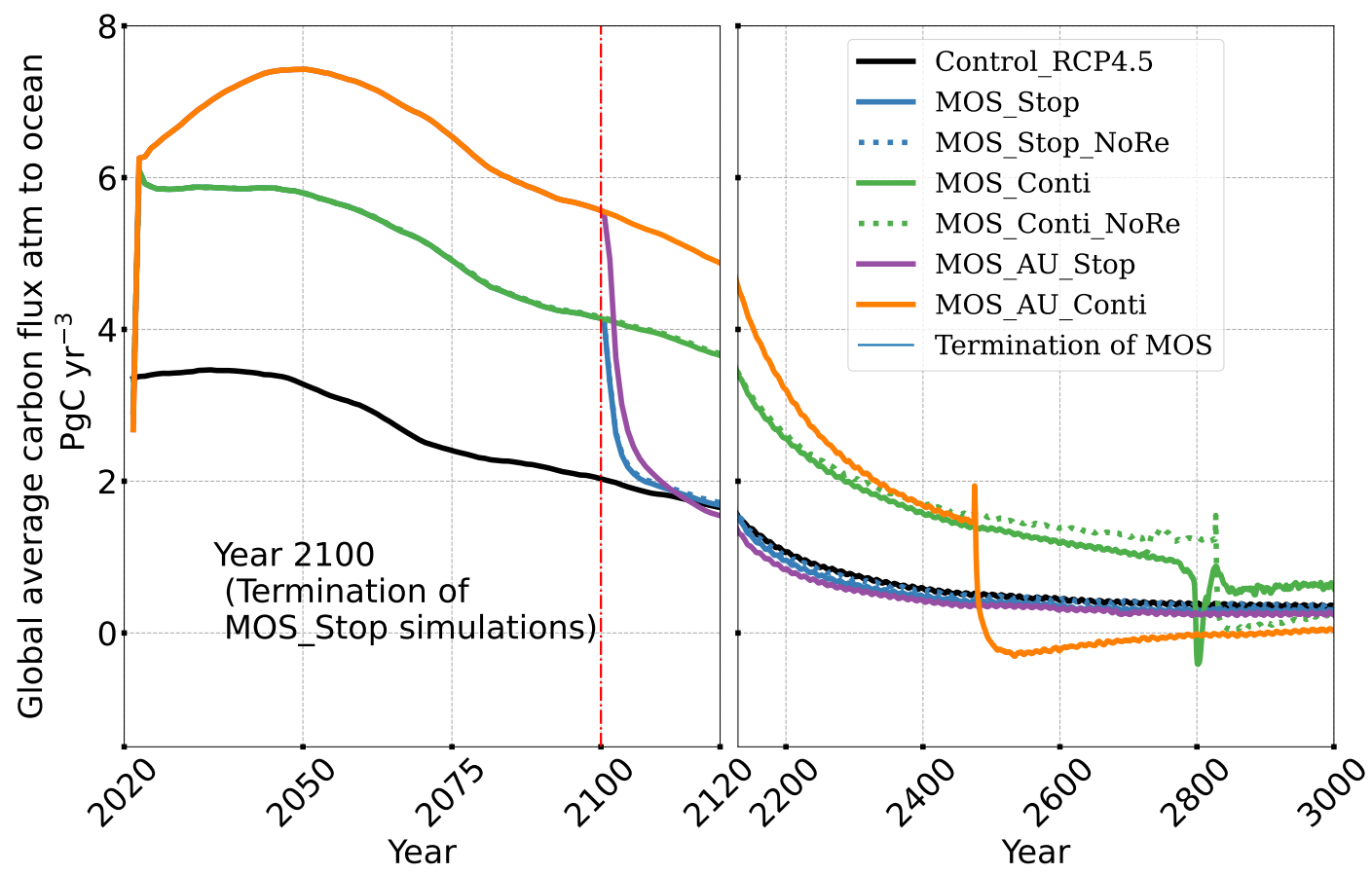

Figure B10. Global averaged carbon flux from atmosphere to ocean 


\section{Appendix C: MOS under RCP8.5 scenario}

Two MOS simulations are performed under RCP8.5 high emission scenario. To analyse the maximum CDR potential of MOS, macroalgal biomass remineralization rate $\left(\mathrm{u}_{\max }\right.$ in Tab.1) is set to zero therein. The sunk macroalgal biomass thus accumulated on the seafloor permanently without interaction with ambient biogeochemistry.

Due to the high emissions in RCP8.5, in the beginning 80 years, even the maximum MOS is not able to significantly drop the atmospheric $\mathrm{CO}_{2}$ concentration $\left(\mathrm{pCO}_{2}\right)$ nor the SAT. By the end of 21st Century, $190.3 \mathrm{PgC}$ of $\mathrm{C}_{a t m}$ is removed from the atmosphere to the oceanic carbon pool. $\mathrm{pCO}_{2}$ is reduced by $89.7 \mathrm{ppm}$ while SAT descended to $17.48^{\circ} \mathrm{C}$ with $-0.29^{\circ} \mathrm{C}$. This mitigation result is far away above the $2^{\circ} \mathrm{C}$ target, let alone the the $1.5^{\circ} \mathrm{C}$ ambition (Tab.C1).

In MOS_8.5_Conti_NoRe with continuous deployment of MOS, in total $2767 \mathrm{PgC}$ of $\mathrm{CO}_{2}$ is sequestered by MOS. An obvious reduction of $\mathrm{pCO}_{2}$ appeared till year 2200, followed by a sharp decrease of $2195 \mathrm{PgC}$ by the end (Tab.C1), resulting in a decreasing of SAT by $2.30^{\circ} \mathrm{C}$. Nevertheless, under RCP8.5 scenario with high anthropogenic GHGs emissions, the mitigation capacity of MOS alone is insufficient to counteract the ascent $\mathrm{pCO}_{2}$ nor global warming relative the results under the RCP4.5 scenario with moderate mitigation.

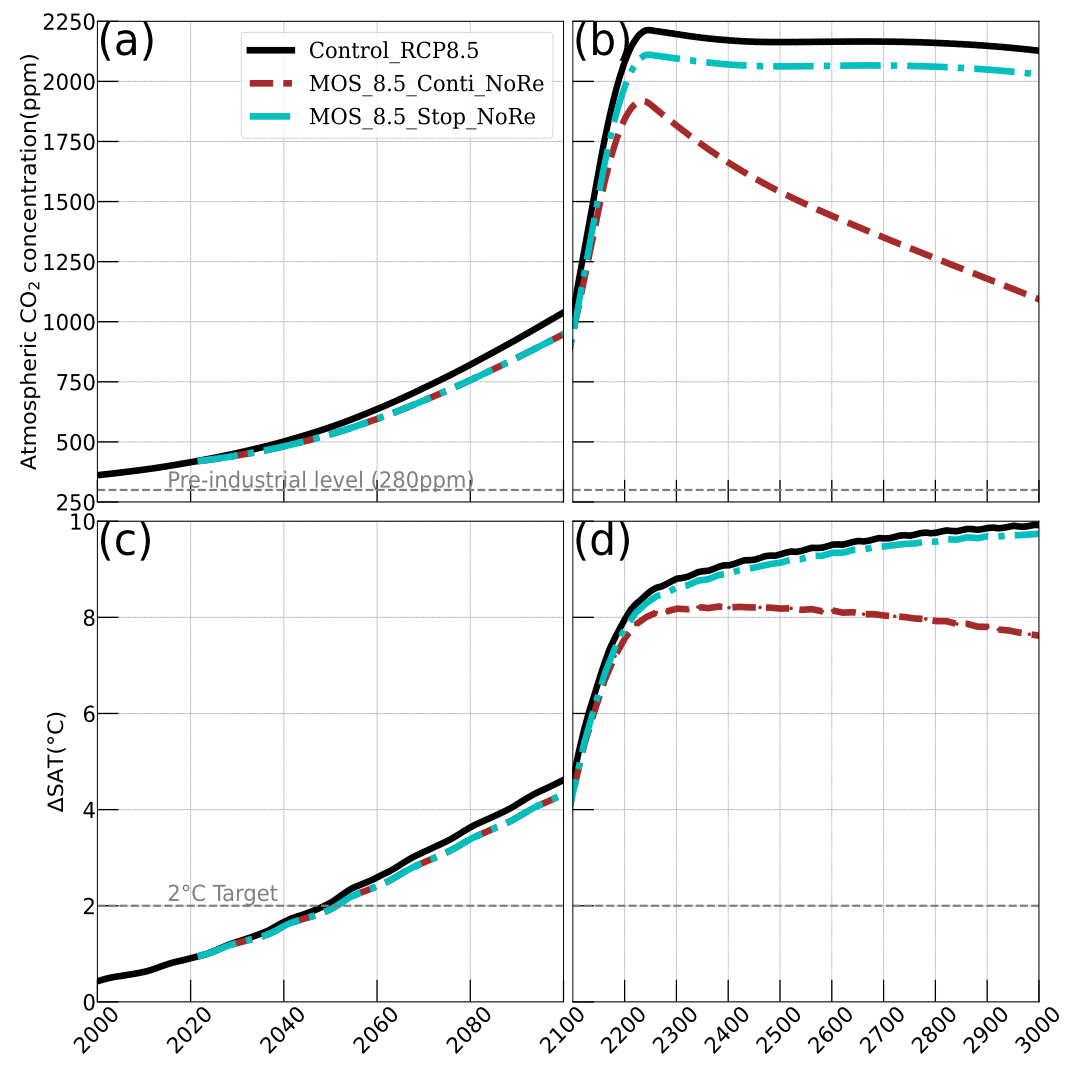

Figure C1. Simulation under RCP8.5 Scenario: a, b:Annual global mean atmospheric $\mathrm{CO}_{2}$ concentration; c, d: Surface averaged temperature subtracted from pre-industrial level $13.18^{\circ} \mathrm{C}(\Delta \mathrm{SAT})$ 
https://doi.org/10.5194/esd-2021-104

Preprint. Discussion started: 14 January 2022

(c) Author(s) 2022. CC BY 4.0 License.

(c) (i)

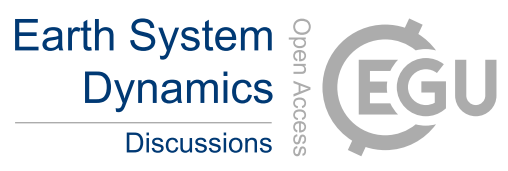

Table C1. Model Simulations under RCP8.5 scenario

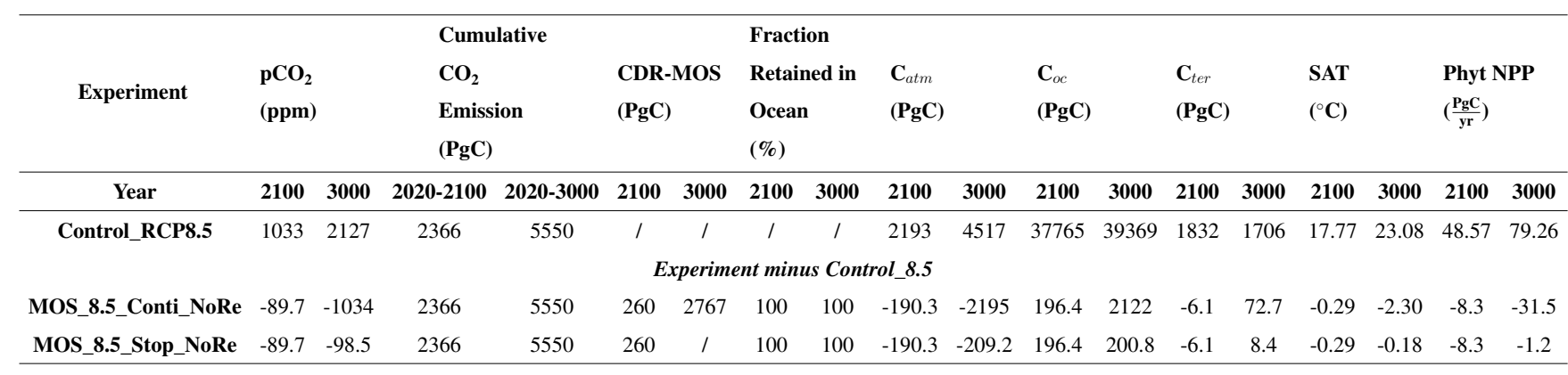




\section{References}

Albright, R., Caldeira, L., Hosfelt, J., Kwiatkowski, L., Maclaren, J. K., Mason, B. M., Nebuchina, Y., Ninokawa, A., Pongratz, J., Ricke, K. L., Rivlin, T., Schneider, K., Sesboüé, M., Shamberger, K., Silverman, J., Wolfe, K., Zhu, K., and Caldeira, K.: Reversal of ocean acidification enhances net coral reef calcification, Nature, 531, 362-365, https://doi.org/10.1038/nature17155, 2016.

Aldridge, J. N. and Trimmer, M.: Modelling the distribution and growth of 'problem' green seaweed in the Medway estuary, UK, Hydrobiologia, 629, 107-122, https://doi.org/10.1007/s10750-009-9760-6, 2009.

Anderson, K. and Peters, G.: The trouble with negative emissions, Science (80-. )., 354, 182-183, https://doi.org/10.1126/science.aah4567, 2016.

APAR-e, U. D. o. E.: Macroalgae Research Inspiring Novel Energy Resources, https://arpa-e.energy.gov/technologies/programs/mariner, 2021.

Atkinson, M. J. and Smith, S. V.: C:N:P ratios of benthic marine plants, Limnol. Oceanogr., 28, 568-574, https://doi.org/10.4319/lo.1983.28.3.0568, 1983.

Bach, L. T., Tamsitt, V., Gower, J., Hurd, C. L., Raven, J. A., and Boyd, P. W.: Testing the climate intervention potential of ocean afforestation using the Great Atlantic Sargassum Belt, Nat. Commun., 12, 2556, https://doi.org/10.1038/s41467-021-22837-2, 2021.

Baird, M. E., Walker, S. J., Wallace, B. B., Webster, I. T., and Parslow, J. S.: The use of mechanistic descriptions of algal growth and zooplankton grazing in an estuarine eutrophication model, Estuar. Coast. Shelf Sci., 56, 685-695, https://doi.org/10.1016/S0272-7714(02)00219-6, 2003.

Baker, J. M., Sturges, W. T., Sugier, J., Sunnenberg, G., Lovett, A. A., Reeves, C. E., Nightingale, P. D., and Penkett, S. A.: Emissions of $\mathrm{CH} 3 \mathrm{Br}$, organochlorines, and organoiodines from temperate macroalgae, Chemosph. - Glob. Chang. Sci., 3, 93-106, https://doi.org/10.1016/S1465-9972(00)00021-0, 2001.

Bange, H. W., Arévalo-Martínez, D. L., de la Paz, M., Farías, L., Kaiser, J., Kock, A., Law, C. S., Rees, A. P., Rehder, G., Tortell, P. D., Upstill-Goddard, R. C., and Wilson, S. T.: A harmonized nitrous oxide (N 2 O) ocean observation network for the 21 st century, Front. Mar. Sci., 6, 1-10, https://doi.org/10.3389/fmars.2019.00157, 2019.

Bird, M. I., Wurster, C. M., de Paula Silva, P. H., Bass, A. M., and de Nys, R.: Algal biochar - production and properties, Bioresour. Technol., 102, 1886-1891, https://doi.org/10.1016/j.biortech.2010.07.106, 2011.

Bitz, C. M. and Lipscomb, W. H.: An energy-conserving thermodynamic model of sea ice, J. Geophys. Res. Ocean., 104, 15 669-15 677, https://doi.org/10.1029/1999jc900100, 1999.

Bowie, G., Mills, W., Porcella, D., Campbell, C., Pagenkopf, J., Rupp, G., Johnson, K., Chan, P., Gherini, S., and Chamberlin, C.: Rates, constants, and kinetics formulations in surface water quality modeling, Epa, 600, 3-85, 1985.

Breeman, A. M.: Relative importance of temperature and other factors in determining geographic boundaries of seaweeds: Experimental and phenological evidence, Helgoländer Meeresuntersuchungen, 42, 199-241, https://doi.org/10.1007/BF02366043, 1988.

655 Broch, O. J. and Slagstad, D.: Modelling seasonal growth and composition of the kelp Saccharina latissima, J. Appl. Phycol., 24, 759-776, https://doi.org/10.1007/s10811-011-9695-y, 2012.

Brush, M. J. and Nixon, S. W.: Modeling the role of macroalgae in a shallow sub-estuary of Narragansett Bay, RI (USA), Ecol. Modell., 221, 1065-1079, https://doi.org/10.1016/j.ecolmodel.2009.11.002, 2010.

Buck, B. H. and Buchholz, C. M.: The offshore-ring: A new system design for the open ocean aquaculture of macroalgae, J. Appl. Phycol., 16, 355-368, https://doi.org/10.1023/B:JAPH.0000047947.96231.ea, 2004. 
Buschmann, A. H., Camus, C., Infante, J., Neori, A., Israel, Á., Hernández-González, M. C., Pereda, S. V., Gomez-Pinchetti, J. L., Golberg, A., Tadmor-Shalev, N., and Critchley, A. T.: Seaweed production: overview of the global state of exploitation, farming and emerging research activity, Eur. J. Phycol., 52, 391-406, https://doi.org/10.1080/09670262.2017.1365175, 2017.

Carpenter, L. J. and Liss, P. S.: On temperate sources of bromoform and other reactive organic bromine gases, J. Geophys. Res. Atmos., 105, 20 539-20 547, https://doi.org/10.1029/2000JD900242, 2000.

Chen, H., Zhou, D., Luo, G., Zhang, S., and Chen, J.: Macroalgae for biofuels production: Progress and perspectives, Renew. Sustain. Energy Rev., 47, 427-437, https://doi.org/10.1016/j.rser.2015.03.086, 2015.

Chung, I. K., Beardall, J., Mehta, S., Sahoo, D., and Stojkovic, S.: Using marine macroalgae for carbon sequestration: A critical appraisal, J. Appl. Phycol., 23, 877-886, https://doi.org/10.1007/s10811-010-9604-9, 2011.

Ciais, P., Sabine, C., Bala, G., Bopp, L., Brovkin, V., Canadell, J., Chhabra, A., DeFries, R., Galloway, J., Heimann, M., Jones, C., Quéré, C. L., Myneni, R., Piao, S., and Thornton, P.: Carbon and other biogeochemical cycles, in: Clim. Chang. 2013 Phys. Sci. Basis Work. Gr. I Contrib. to Fifth Assess. Rep. Intergov. Panel Clim. Chang., edited by Intergovernmental Panel on Climate Change, vol. 9781107057, pp. 465-570, Cambridge University Press, Cambridge, https://doi.org/10.1017/CBO9781107415324.015, 2013.

Conover, J., Green, L. A., and Thornber, C. S.: Biomass decay rates and tissue nutrient loss in bloom and non-bloom-forming macroalgal species, Estuar. Coast. Shelf Sci., 178, 58-64, https://doi.org/10.1016/j.ecss.2016.05.018, 2016.

Daniel, J. S., Solomon, S., and Albritton, D. L.: On the evaluation of halocarbon radiative forcing and global warming potentials, J. Geophys. Res., 100, 1271-1285, https://doi.org/10.1029/94JD02516, 1995.

D'Auriac, M. A., Hancke, K., Gundersen, H., Frigstad, H., and Borgersen, G.: Blue Carbon eDNA - A novel eDNA method to trace macroalgae carbon in marine sedients, Tech. rep., Norwegian Institute for Water Research, 2021.

Dean, J., Kiendler-Scharr, A., Mengis, N., Rudich, Y., Schepanski, K., and Zimmermann, R.: Above us only sky, Commun. Earth Environ., 2, 179, https://doi.org/10.1038/s43247-021-00245-0, 2021.

Duarte, C. M., Wu, J., Xiao, X., Bruhn, A., and Krause-Jensen, D.: Can seaweed farming play a role in climate change mitigation and adaptation?, Front. Mar. Sci., 4, https://doi.org/10.3389/fmars.2017.00100, 2017.

Duarte, P. and Ferreira, J.: A model for the simulation of macroalgal population dynamics and productivity, Ecol. Modell., 98, 199-214, https://doi.org/10.1016/S0304-3800(96)01915-1, 1997.

Duarte, P., Meneses, R., Hawkins, A. J., Zhu, M., Fang, J., and Grant, J.: Mathematical modelling to assess the carrying capacity for multispecies culture within coastal waters, Ecol. Modell., 168, 109-143, https://doi.org/10.1016/S0304-3800(03)00205-9, 2003.

Eby, M., Zickfeld, K., Montenegro, A., Archer, D., Meissner, K. J., and Weaver, A. J.: Lifetime of anthropogenic climate change: Millennial time scales of potential CO2 and surface temperature perturbations, J. Clim., 22, 2501-2511, https://doi.org/10.1175/2008JCLI2554.1, 2009.

Eby, M., Weaver, A. J., Alexander, K., Zickfeld, K., Abe-Ouchi, A., Cimatoribus, A. A., Crespin, E., Drijfhout, S. S., Edwards, N. R., Eliseev, A. V., Feulner, G., Fichefet, T., Forest, C. E., Goosse, H., Holden, P. B., Joos, F., Kawamiya, M., Kicklighter, D., Kienert, H., Matsumoto, K., Mokhov, I. I., Monier, E., Olsen, S. M., Pedersen, J. O., Perrette, M., Philippon-Berthier, G., Ridgwell, A., Schlosser, A., Von Deimling, T. S., Shaffer, G., Smith, R. S., Spahni, R., Sokolov, A. P., Steinacher, M., Tachiiri, K., Tokos, K., Yoshimori, M., Zeng, N., and Zhao, F.: Historical and idealized climate model experiments: An intercomparison of Earth system models of intermediate complexity, Clim. Past, 9, 1111-1140, https://doi.org/10.5194/cp-9-1111-2013, 2013.

Edo, A., Hertwich, E., and Heeren, N.: Emissions Gap Report 2019, UNEP/Earthprint, Nairobi, http://www.unenvironment.org/emissionsgap, 2019. 
https://doi.org/10.5194/esd-2021-104

Preprint. Discussion started: 14 January 2022

(C) Author(s) 2022. CC BY 4.0 License.

Eisaman, M. D., Parajuly, K., Tuganov, A., Eldershaw, C., Chang, N., and Littau, K. A.: CO2 extraction from seawater using bipolar membrane electrodialysis, Energy Environ. Sci., 5, 7346-7352, https://doi.org/10.1039/c2ee03393c, 2012.

Eriksson, B. K. and Bergström, L.: Local distribution patterns of macroalgae in relation to environmental variables in the northern Baltic Proper, Estuar. Coast. Shelf Sci., 62, 109-117, https://doi.org/10.1016/j.ecss.2004.08.009, 2005.

Fanning, A. F. and Weaver, A. J.: An atmospheric energy-moisture balance model: Climatology, interpentadal climate change, and coupling to an ocean general circulation model, J. Geophys. Res. Atmos., 101, 15 111-15 128, https://doi.org/10.1029/96jd01017, 1996.

FAO: The State of World Fisheries and Aquaculture 2018-Meeting the sustainable development goals, 2018.

Fernand, F., Israel, A., Skjermo, J., Wichard, T., Timmermans, K. R., and Golberg, A.: Offshore macroalgae biomass for bioenergy production: Environmental aspects, technological achievements and challenges, Renew. Sustain. Energy Rev., 75, 35-45, https://doi.org/10.1016/j.rser.2016.10.046, 2017.

Fogarty, M. C., Fewings, M. R., Paget, A. C., and Dierssen, H. M.: The Influence of a Sandy Substrate, Seagrass, or Highly Turbid Water on Albedo and Surface Heat Flux, J. Geophys. Res. Ocean., 123, 53-73, https://doi.org/10.1002/2017JC013378, 2018.

Friedlingstein, P., Jones, M. W., O’Sullivan, M., Andrew, R. M., Bakker, D. C. E., Hauck, J., Le Quéré, C., Peters, G. P., Peters, W., Pongratz, J., Sitch, S., Canadell, J. G., Ciais, P., Jackson, R. B., Alin, S. R., Anthoni, P., Bates, N. R., Becker, M., Bellouin, N., Bopp, L., Chau, T. T. T., Chevallier, F., Chini, L. P., Cronin, M., Currie, K. I., Decharme, B., Djeutchouang, L., Dou, X., Evans, W., Feely, R. A., Feng, L., Gasser, T., Gilfillan, D., Gkritzalis, T., Grassi, G., Gregor, L., Gruber, N., Gürses, O., Harris, I., Houghton, R. A., Hurtt, G. C., Iida, Y., Ilyina, T., Luijkx, I. T., Jain, A. K., Jones, S. D., Kato, E., Kennedy, D., Klein Goldewijk, K., Knauer, J., Korsbakken, J. I., Körtzinger, A., Landschützer, P., Lauvset, S. K., Lefèvre, N., Lienert, S., Liu, J., Marland, G., McGuire, P. C., Melton, J. R., Munro, D. R., Nabel, J. E. M. S., Nakaoka, S.-I., Niwa, Y., Ono, T., Pierrot, D., Poulter, B., Rehder, G., Resplandy, L., Robertson, E., Rödenbeck, C., Rosan, T. M., Schwinger, J., Schwingshackl, C., Séférian, R., Sutton, A. J., Sweeney, C., Tanhua, T., Tans, P. P., Tian, H., Tilbrook, B., Tubiello, F., van der Werf, G., Vuichard, N., Wada, C., Wanninkhof, R., Watson, A., Willis, D., Wiltshire, A. J., Yuan, W., Yue, C., Yue, X., Zaehle, S., and Zeng, J.: Global Carbon Budget 2021, Earth System Science Data Discussions, 2021, 1-191, https://doi.org/10.5194/essd-2021-386, 2021.

Froehlich, H. E., Afflerbach, J. C., Frazier, M., and Halpern, B. S.: Blue Growth Potential to Mitigate Climate Change through Seaweed Offsetting, Curr. Biol., 29, 3087-3093.e3, https://doi.org/10.1016/j.cub.2019.07.041, 2019.

Fuss, S., Canadell, J. G., Ciais, P., Jackson, R. B., Jones, C. D., Lyngfelt, A., Peters, G. P., and Van Vuuren, D. P.: Moving toward Net-Zero

Emissions Requires New Alliances for Carbon Dioxide Removal, One Earth, 3, 145-149, https://doi.org/10.1016/j.oneear.2020.08.002, 2020.

Gao, G., Burgess, J. G., Wu, M., Wang, S., and Gao, K.: Using macroalgae as biofuel: Current opportunities and challenges, Bot. Mar., 63, 355-370, https://doi.org/10.1515/bot-2019-0065, 2020.

Gao, K. and McKinley, K. R.: Use of macroalgae for marine biomass production and CO2 remediation: a review, J. Appl. Phycol., 6, 45-60, https://doi.org/10.1007/BF02185904, 1994.

Garcia, H. E., Locarnini, R. A., Boyer, T. P., Antonov, J. I., Zweng, M. M., Baranova, O. K., and Johnson, D. R.: World Ocean Atlas 2009, Volume 4: Nutrients (phosphate, nitrate, and silicate), NOAA World Ocean Atlas, 71, 398, http://www.nodc.noaa.gov/OC5/indprod.html, 2010.

Glaser, J. A.: Climate geoengineering, Clean Technol. Environ. Policy, 12, 91-95, https://doi.org/10.1007/s10098-010-0287-3, 2010. 

C. L., Mathis, J. T., Murata, A., Olsen, A., Perez, F. F., Sabine, C. L., Tanhua, T., and Wanninkhof, R.: The oceanic sink for anthropogenic CO 2 from 1994 to 2007, Science (80-. )., 363, 1193-1199, https://doi.org/10.1126/science.aau5153, 2019.

Hadley, S., Wild-Allen, K., Johnson, C., and Macleod, C.: Modeling macroalgae growth and nutrient dynamics for integrated multi-trophic aquaculture, J. Appl. Phycol., 27, 901-916, https://doi.org/10.1007/s10811-014-0370-y, 2015.

Heinze, C., Meyer, S., Goris, N., Anderson, L., Steinfeldt, R., Chang, N., Le Quéré, C., and Bakker, D. C.: The ocean carbon sink - Impacts, vulnerabilities and challenges, Earth Syst. Dyn., 6, 327-358, https://doi.org/10.5194/esd-6-327-2015, 2015.

IPCC: Summary for Policymakers, in: Global Warming of $1.5^{\circ} \mathrm{C}$. An IPCC Special Report on the impacts of global warming of $1.5^{\circ} \mathrm{C}$ above pre-industrial levels and related global greenhouse gas emission pathways, in the context of strengthening the global response to the threat of climate change, edited by Masson-Delmotte, V., Roberts, P. Z. H.-O. P. D., Skea, J., Shukla, P., Pirani, A., Moufouma-Okia, W., Péan, C., Pidcock, R., Connors, S., Matthews, J., Chen, Y., Zhou, X., Gomis, M., Lonnoy, E., Maycock, T., Tignor, M., and (eds.), T. W., pp. 17-20, World Meteorological Organization, Geneva, Switzerland, www.environmentalgraphiti.org, 2018.

Jiang, Z., Liu, J., Li, S., Chen, Y., Du, P., Zhu, Y., Liao, Y., Chen, Q., Shou, L., Yan, X., Zeng, J., and Chen, J.: Kelp cultivation effectively improves water quality and regulates phytoplankton community in a turbid, highly eutrophic bay, Sci. Total Environ., 707, 135561 , https://doi.org/10.1016/j.scitotenv.2019.135561, 2020.

Keller, D. P., Oschlies, A., and Eby, M.: A new marine ecosystem model for the University of Victoria earth system climate model, Geosci. Model Dev., 5, 1195-1220, https://doi.org/10.5194/gmd-5-1195-2012, 2012.

Keller, D. P., Feng, E. Y., and Oschlies, A.: Potential climate engineering effectiveness and side effects during a high carbon dioxide-emission scenario, Nat. Commun., 5, 3304, https://doi.org/10.1038/ncomms4304, 2014.

Keller, D. P., Lenton, A., Littleton, E. W., Oschlies, A., Scott, V., and Vaughan, N. E.: The Effects of Carbon Dioxide Removal on the Carbon Cycle, Curr. Clim. Chang. Reports, 4, 250-265, https://doi.org/10.1007/s40641-018-0104-3, 2018.

Kim, J. K., Stekoll, M., and Yarish, C.: Opportunities, challenges and future directions of open-water seaweed aquaculture in the United States, Phycologia, 58, 446-461, https://doi.org/10.1080/00318884.2019.1625611, 2019.

Kirk, J. T. O.: Light and Photosynthesis in Aquatic Ecosystems, Cambridge University Press, 2 edn., https://doi.org/10.1017/CBO9780511623370, 1994.

Koch, M., Bowes, G., Ross, C., and Zhang, X. H.: Climate change and ocean acidification effects on seagrasses and marine macroalgae, Glob. Chang. Biol., 19, 103-132, https://doi.org/10.1111/j.1365-2486.2012.02791.x, 2013.

Köhler, P., Abrams, J. F., Völker, C., Hauck, J., and Wolf-Gladrow, D. A.: Geoengineering impact of open ocean dissolution of olivine on atmospheric CO2, surface ocean pH and marine biology, Environ. Res. Lett., 8, https://doi.org/10.1088/1748-9326/8/1/014009, 2013.

Krause-Jensen, D. and Duarte, C. M.: Substantial role of macroalgae in marine carbon sequestration, Nat. Geosci., 9, 737-742, https://doi.org/10.1038/ngeo2790, 2016.

Kvale, K., Prowe, A. E., Chien, C. T., Landolfi, A., and Oschlies, A.: Zooplankton grazing of microplastic can accelerate global loss of ocean oxygen, Nat. Commun., 12, https://doi.org/10.1038/s41467-021-22554-w, 2021.

Kvale, K. F. and Meissner, K. J.: Primary production sensitivity to phytoplankton light attenuation parameter increases with transient forcing, Biogeosciences, 14, 4767-4780, https://doi.org/10.5194/bg-14-4767-2017, 2017.

Latumus, F.: Release of volatile halogenated organic compounds by unialgal cultures of polar macroalgae, Chemosphere, 31, 3387-3395, https://doi.org/10.1016/0045-6535(95)00190-J, 1995. 
Laurens, L. M., Lane, M., and Nelson, R. S.: Sustainable Seaweed Biotechnology Solutions for Carbon Capture, Composition, and Deconstruction, Trends Biotechnol., 38, 1232-1244, https://doi.org/10.1016/j.tibtech.2020.03.015, 2020.

Lawrence, M. G., Schäfer, S., Muri, H., Scott, V., Oschlies, A., Vaughan, N. E., Boucher, O., Schmidt, H., Haywood, J., and Schefhttps://doi.org/10.1038/s41467-018-05938-3, 2018.

Leedham, E. C., Hughes, C., Keng, F. S., Phang, S. M., Malin, G., and Sturges, W. T.: Emission of atmospherically significant halocarbons by naturally occurring and farmed tropical macroalgae, Biogeosciences, 10, 3615-3633, https://doi.org/10.5194/bg-10-3615-2013, 2013.

Lehahn, Y., Ingle, K. N., and Golberg, A.: Global potential of offshore and shallow waters macroalgal biorefineries to provide for food, chemicals and energy: feasibility and sustainability, Algal Res., 17, 150-160, https://doi.org/10.1016/j.algal.2016.03.031, 2016.

Liu, Z. and Huguenard, K.: Hydrodynamic Response of a Floating Aquaculture Farm in a Low Inflow Estuary, J. Geophys. Res. Ocean., 125, 0-3, https://doi.org/10.1029/2019JC015625, 2020.

Luo, M., Gieskes, J., Chen, L., Scholten, J., Pan, B., Lin, G., and Chen, D.: Sources, Degradation, and Transport of Organic Matter in the New Britain Shelf-Trench Continuum, Papua New Guinea, J. Geophys. Res. Biogeosciences, 124, 1680-1695, https://doi.org/10.1029/2018JG004691, 2019.

Macreadie, P. I., Serrano, O., Maher, D. T., Duarte, C. M., and Beardall, J.: Addressing calcium carbonate cycling in blue carbon accounting, Limnol. Oceanogr. Lett., 2, 195-201, https://doi.org/10.1002/lol2.10052, 2017.

Macreadie, P. I., Anton, A., Raven, J. A., Beaumont, N., Connolly, R. M., Friess, D. A., Kelleway, J. J., Kennedy, H., Kuwae, T., Lavery, P. S., Lovelock, C. E., Smale, D. A., Apostolaki, E. T., Atwood, T. B., Baldock, J., Bianchi, T. S., Chmura, G. L., Eyre, B. D., Fourqurean, J. W., Hall-Spencer, J. M., Huxham, M., Hendriks, I. E., Krause-Jensen, D., Laffoley, D., Luisetti, T., Marbà, N., Masque, P., McGlathery, K. J., Megonigal, J. P., Murdiyarso, D., Russell, B. D., Santos, R., Serrano, O., Silliman, B. R., Watanabe, K., and Duarte, C. M.: The future of Blue Carbon science, Nat. Commun., 10, 1-13, https://doi.org/10.1038/s41467-019-11693-w, 2019.

Martin, T., Park, W., and Latif, M.: Multi-centennial variability controlled by Southern Ocean convection in the Kiel Climate Model, Clim. Dyn., 40, 2005-2022, https://doi.org/10.1007/s00382-012-1586-7, 2013.

Martins, I. and Marques, J. C.: A model for the growth of opportunistic macroalgae (Enteromorpha sp.) in tidal estuaries, Estuar. Coast. Shelf Sci., 55, 247-257, https://doi.org/10.1006/ecss.2001.0900, 2002.

Matear, R. J. and Elliott, B.: Enhancement of oceanic uptake of anthropogenic CO2 by macronutrient fertilization, J. Geophys. Res. C Ocean., 109, 1-14, https://doi.org/10.1029/2000JC000321, 2004.

Meinshausen, M., Smith, S. J., Calvin, K., Daniel, J. S., Kainuma, M. L., Lamarque, J., Matsumoto, K., Montzka, S. A., Raper, S. C., Riahi, K., Thomson, A., Velders, G. J., and van Vuuren, D. P.: The RCP greenhouse gas concentrations and their extensions from 1765 to 2300 , Clim. Change, 109, 213-241, https://doi.org/10.1007/s10584-011-0156-z, 2011.

Meissner, K. J., Weaver, A. J., Matthews, H. D., and Cox, P. M.: The role of land surface dynamics in glacial inception: A study with the UVic Earth System Model, Clim. Dyn., 21, 515-537, https://doi.org/10.1007/s00382-003-0352-2, 2003.

Mengis, N., Martin, T., Keller, D. P., and Oschlies, A.: Assessing climate impacts and risks of ocean albedo modification in the Arctic, J.

Geophys. Res. Ocean., 121, 3044-3057, https://doi.org/10.1002/2015JC011433, 2016.

Minx, J. C., Lamb, W. F., Callaghan, M. W., Bornmann, L., and Fuss, S.: Fast growing research on negative emissions, Environ. Res. Lett., 12, https://doi.org/10.1088/1748-9326/aa5ee5, 2017. 
Navarrete, I. A., Kim, D. Y., Wilcox, C., Reed, D. C., Ginsburg, D. W., Dutton, J. M., Heidelberg, J., Raut, Y., and Wilcox, B. H.: Effects of depth-cycling on nutrient uptake and biomass production in the giant kelp Macrocystis pyrifera, Renew. Sustain. Energy Rev., 141, 110747, https://doi.org/10.1016/j.rser.2021.110747, 2021.

Nepf, H. M.: Hydrodynamics of vegetated channels, J. Hydraul. Res., 50, 262-279, https://doi.org/10.1080/00221686.2012.696559, 2012.

N'Yeurt, A. D. R., Chynoweth, D. P., Capron, M. E., Stewart, J. R., and Hasan, M. A.: Negative carbon via ocean afforestation, Process Saf. Environ. Prot., 90, 467-474, https://doi.org/10.1016/j.psep.2012.10.008, 2012.

Orr, J., Najjar, R., Sabine, C., and Joos, F.: Abiotic-howto, Intern. OCMIP Report, LSCE/CEA Saclay, Gifsur-Yvette, Fr., 1999, 1-29, http://www.cgd.ucar.edu/oce/klindsay/OCMIP/HOWTO-Abiotic.pdf, 1999.

Orr, J. C. and Sarmiento, J. L.: Potential of marine macroalgae as a sink for CO2: Constraints from a 3-D general circulation model of the global ocean, Water, Air, Soil Pollut., 64, 405-421, https://doi.org/10.1007/BF00477113, 1992.

Oschlies, A.: A committed fourfold increase in ocean oxygen loss, Nat. Commun., 12, 2307, https://doi.org/10.1038/s41467-021-22584-4, 2021.

Oschlies, A., Pahlow, M., Yool, A., and Matear, R. J.: Climate engineering by artificial ocean upwelling: Channelling the sorcerer's apprentice, Geophys. Res. Lett., 37, 1-5, https://doi.org/10.1029/2009GL041961, 2010.

Oschlies, A., Koeve, W., Landolfi, A., and Kähler, P.: Loss of fixed nitrogen causes net oxygen gain in a warmer future ocean, Nat. Commun., 10, 1-7, https://doi.org/10.1038/s41467-019-10813-w, 2019.

Oyinlola, M. A., Reygondeau, G., Wabnitz, C. C., and Cheung, W. W.: Projecting global mariculture diversity under climate change, Glob. Chang. Biol., 26, 2134-2148, https://doi.org/10.1111/gcb.14974, 2020.

Pacanowski, R.: MOM 2 Version 2.0 (beta) Documentation User's Guide and Reference Mannual, Model Mannual, $0,1996$.

Partanen, A. I., Keller, D. P., Korhonen, H., and Matthews, H. D.: Impacts of sea spray geoengineering on ocean biogeochemistry, Geophys. Res. Lett., 43, 7600-7608, https://doi.org/10.1002/2016GL070111, 2016.

Peteiro, C., Sánchez, N., Dueñas-Liaño, C., and Martínez, B.: Open-sea cultivation by transplanting young fronds of the kelp Saccharina latissima, J. Appl. Phycol., 26, 519-528, https://doi.org/10.1007/s10811-013-0096-2, 2014.

Peters, G. P., Andrew, R. M., Boden, T., Canadell, J. G., Ciais, P., Le Quéré, C., Marland, G., Raupach, M. R., and Wilson, C.: The challenge to keep global warming below 2C, Nat. Clim. Chang., 3, 4-6, https://doi.org/10.1038/nclimate1783, 2013.

Ramaswamy, V., Schwarzkopf, M. D., and Shine, K. P.: Radiative forcing of climate from halocarbon-induced global stratospheric ozone loss, Nature, 355, 810-812, https://doi.org/10.1038/355810a0, 1992.

Raven, J.: Blue carbon: Past, present and future, with emphasis on macroalgae, Biol. Lett., 14, 20180336, https://doi.org/10.1098/rsbl.2018.0336, 2018.

Ravishankara, A. R., Daniel, J. S., and Portmann, R. W.: Nitrous oxide (N2O): The dominant ozone-depleting substance emitted in the 21st century, Science (80-. )., 326, 123-125, https://doi.org/10.1126/science.1176985, 2009.

Reith, F., Keller, D. P., and Oschlies, A.: Revisiting ocean carbon sequestration by direct injection: A global carbon budget perspective, Earth Syst. Dyn., 7, 797-812, https://doi.org/10.5194/esd-7-797-2016, 2016.

Roberts, D. A., Paul, N. A., Dworjanyn, S. A., Bird, M. I., and De Nys, R.: Biochar from commercially cultivated seaweed for soil amelioration, Sci. Rep., 5, 1-6, https://doi.org/10.1038/srep09665, 2015.

Robinson, J., Popova, E. E., Yool, A., Srokosz, M., Lampitt, R. S., and Blundell, J. R.: How deep is deep enough? Ocean iron fertilization and carbon sequestration in the Southern Ocean, Geophys. Res. Lett., 41, 2489-2495, https://doi.org/10.1002/2013GL058799, 2014. 
Rogelj, J., Popp, A., Calvin, K. V., Luderer, G., Emmerling, J., Gernaat, D., Fujimori, S., Strefler, J., Hasegawa, T., Marangoni, G., Krey, V., Kriegler, E., Riahi, K., van Vuuren, D. P., Doelman, J., Drouet, L., Edmonds, J., Fricko, O., Harmsen, M., Havlík, P., Humpenöder, F., Stehfest, E., and Tavoni, M.: Scenarios towards limiting global mean temperature increase below $1.5^{\circ} \mathrm{C}$, Nat. Clim. Chang., 8, 325-332, https://doi.org/10.1038/s41558-018-0091-3, 2018.

Schmittner, A., Oschlies, A., Giraud, X., Eby, M., and Simmons, H. L.: A global model of the marine ecosystem for long-term simulations: Sensitivity to ocean mixing, buoyancy forcing, particle sinking, and dissolved organic matter cycling, Global Biogeochem. Cycles, 19, 1-17, https://doi.org/10.1029/2004GB002283, 2005.

Schmittner, A., Oschlies, A., Matthews, H. D., and Galbraith, E. D.: Future changes in climate, ocean circulation, ecosystems, and biogeochemical cycling simulated for a business-as-usual CO2 emission scenario until year 4000 AD, Global Biogeochem. Cycles, 22, 1-21, https://doi.org/10.1029/2007GB002953, 2008.

Scott, V., Haszeldine, R. S., Tett, S. F., and Oschlies, A.: Fossil fuels in a trillion tonne world, Nat. Clim. Chang., 5, 419-423, https://doi.org/10.1038/nclimate2578, 2015.

Sherman, M. T., Blaylock, R., Lucas, K., Capron, M. E., Stewart, J. R., DiMarco, S. F., Thyng, K., Hetland, R., Kim, M., Sullivan, C., Moscicki, Z., Tsukrov, I., Swift, M. R., Chambers, M. D., James, S. C., Brooks, M., Von Herzen, B., Jones, A., and Piper, D.: SeaweedPaddock: Initial Modeling and Design for a Sargassum Ranch, in: Ocean. 2018 MTS/IEEE Charleston, Ocean 2018, pp. 1-6, IEEE, https://doi.org/10.1109/OCEANS.2018.8604848, 2019.

Sichert, A., Corzett, C. H., Schechter, M. S., Unfried, F., Markert, S., Becher, D., Fernandez-Guerra, A., Liebeke, M., Schweder, T., Polz, M. F., and Hehemann, J. H.: Verrucomicrobia use hundreds of enzymes to digest the algal polysaccharide fucoidan, Nat. Microbiol., 5, 1026-1039, https://doi.org/10.1038/s41564-020-0720-2, 2020.

Smetacek, V., Klaas, C., Strass, V. H., Assmy, P., Montresor, M., Cisewski, B., Savoye, N., Webb, A., D’Ovidio, F., Arrieta, J. M., Bathmann, U., Bellerby, R., Berg, G. M., Croot, P., Gonzalez, S., Henjes, J., Herndl, G. J., Hoffmann, L. J., Leach, H., Losch, M., Mills, M. M., Neill, C., Peeken, I., Röttgers, R., Sachs, O., Sauter, E., Schmidt, M. M., Schwarz, J., Terbrüggen, A., and Wolf-Gladrow, D.: Deep carbon export from a Southern Ocean iron-fertilized diatom bloom, Nature, 487, 313-319, https://doi.org/10.1038/nature11229, 2012.

Talley, L. D.: Closure of the global overturning circulation through the Indian, Pacific, and southern oceans, Oceanography, 26, 80-97, https://doi.org/10.5670/oceanog.2013.07, 2013.

Taylor, L. L., Quirk, J., Thorley, R. M., Kharecha, P. A., Hansen, J., Ridgwell, A., Lomas, M. R., Banwart, S. A., and Beerling, D. J.: Enhanced weathering strategies for stabilizing climate and averting ocean acidification, Nat. Clim. Chang., 6, 402-406, https://doi.org/10.1038/nclimate2882, 2016.

Tegtmeier, S., Krüger, K., Quack, B., Atlas, E. L., Pisso, I., Stohl, A., and Yang, X.: Emission and transport of bromocarbons: From the West Pacific ocean into the stratosphere, Atmos. Chem. Phys., 12, 10 633-10 648, https://doi.org/10.5194/acp-12-10633-2012, 2012.

Tegtmeier, S., Quack, B., Atlas, E., Blake, D. R., Engel, A., Hepach, H., Hossaini, R., Navarro, M. A., Raimund, S., Sala, S., Shi, Q., and Ziska, F.: The contribution of oceanic methyl iodide to stratospheric iodine, Atmos. Chem. Phys. Discuss., 13, 11427-11471, https://doi.org/10.5194/acpd-13-11427-2013, 2013.

Thomas, R. E. and McLelland, S. J.: The impact of macroalgae on mean and turbulent flow fields, J. Hydrodyn., 27, 427-435, https://doi.org/10.1016/S1001-6058(15)60500-5, 2015.

Thomas, S.: Blue carbon: Knowledge gaps, critical issues, and novel approaches, Ecol. Econ., 107, 22-38, https://doi.org/10.1016/j.ecolecon.2014.07.028, 2014. 
Trancoso, A. R., Saraiva, S., Fernandes, L., Pina, P., Leitão, P., and Neves, R.: Modelling macroalgae using a 3D hydrodynamic-ecological model in a shallow, temperate estuary, Ecol. Modell., 187, 232-246, https://doi.org/10.1016/j.ecolmodel.2005.01.054, 2005.

Trevathan-Tackett, S. M., Kelleway, J., Macreadie, P. I., Beardall, J., Ralph, P., and Bellgrove, A.: Comparison of marine macrophytes for

their contributions to blue carbon sequestration, Ecology, 96, 3043-3057, https://doi.org/10.1890/15-0149.1, 2015.

UNFCCC, V.: Adoption of the Paris agreement, United Nations Office at Geneva, Geneva Google Scholar, 2015.

Van Der Molen, J., Ruardij, P., Mooney, K., Kerrison, P., O\&apos;Connor, N., Gorman, E., Timmermans, K., Wright, S., Kelly, M., Hughes, A. D., Capuzzo, E., O’Connor, N. E., Gorman, E., Timmermans, K., Wright, S., Kelly, M., Hughes, A. D., Capuzzo, E., O\&apos;Connor, N., Gorman, E., Timmermans, K., Wright, S., Kelly, M., Hughes, A. D., Capuzzo, E., O’Connor, N. E., Gorman, E., Timmermans, K., Wright, S., Kelly, M., Hughes, A. D., and Capuzzo, E.: Modelling potential production and environmental effects of macroalgae farms in UK and Dutch coastal waters, Biogeosciences Discuss., 15, 1-43, https://doi.org/10.5194/bg-15-1123-2018, 2017.

Weaver, A. J., Eby, M., Wiebe, E. C., Bitz, C. M., Duffy, P. B., Ewen, T. L., Fanning, A. F., Holland, M. M., MacFadyen, A., Matthews, H. D., Meissner, K. J., Saenko, O., Schmittner, A., Wang, H., and Yoshimori, M.: The UVic earth system climate model: Model description, climatology, and applications to past, present and future climates, Atmosphere-Ocean, 39, 361-428, https://doi.org/10.1080/07055900.2001.9649686, 2001.

Weber, T. and Bianchi, D.: Efficient Particle Transfer to Depth in Oxygen Minimum Zones of the Pacific and Indian Oceans, Front. Earth Sci., 8, 1-11, https://doi.org/10.3389/feart.2020.00376, 2020.

Yokoyama, S., Jonouchi, K., and Imou, K.: Energy Production from Marine Biomass : Fuel Cell Power Generation Driven by Methane Produced from Seaweed, Eng. Technol., 22, 320-323, http://www.waset.org/journals/waset/v28.php, 2007.

Zhang, D., Yan, M., Niu, Y., Liu, X., van Zwieten, L., Chen, D., Bian, R., Cheng, K., Li, L., Joseph, S., Zheng, J., Zhang, X., Zheng, J., Crowley, D., Filley, T. R., and Pan, G.: Is current biochar research addressing global soil constraints for sustainable agriculture?, Agric. Ecosyst. Environ., 226, 25-32, https://doi.org/10.1016/j.agee.2016.04.010, 2016.

Ziska, F., Quack, B., Abrahamsson, K., Archer, S. D., Atlas, E., Bell, T., Butler, J. H., Carpenter, L. J., Jones, C. E., Harris, N. R., Hepach, H., Heumann, K. G., Hughes, C., Kuss, J., Krüger, K., Liss, P., Moore, R. M., Orlikowska, A., Raimund, S., Reeves, C. E., Reifenhäuser, W., Robinson, A. D., Schall, C., Tanhua, T., Tegtmeier, S., Turner, S., Wang, L., Wallace, D., Williams, J., Yamamoto, H., Yvon-Lewis, S., and Yokouchi, Y.: Global sea-to-air flux climatology for bromoform, dibromomethane and methyl iodide, Atmos. Chem. Phys., 13, 8915-8934, https://doi.org/10.5194/acp-13-8915-2013, 2013. 